\title{
ANÁLISE DINÂMICA ELASTO-PLÁSTICA DE ESTRUTURAS METÁLICAS SUJEITAS A EXCITAÇÃO ALEATÓRIA DE SISMOS
}

\author{
Dissertação apresentada à Escola Politécnica \\ da Universidade de São Paulo para obtenção \\ do Título de Mestre em Engenharia.
}




\title{
ANÁLISE DINÂMICA ELASTO-PLÁSTICA DE ESTRUTURAS METÁLICAS SUJEITAS A EXCITAÇÃO ALEATÓRIA DE SISMOS
}

\author{
Dissertação apresentada à Escola Politécnica \\ da Universidade de São Paulo para obtenção \\ do Título de Mestre de Engenharia \\ Área de Concentração: Engenharia de \\ Estruturas. \\ Orientador: Prof. Dr. Reyolando Manoel \\ Lopes Rebello da Fonseca Brasil
}


Ao meu pai, Estevão Corbani Neto. 


\section{Corbani, Silvia}

Análise dinâmica elasto-plástica de estruturas metálicas sujeitas a excitação aleatória de sismos I S. Corbani. - São Paulo, 2006.

$64 p$.

Dissertação (Mestrado) - Escola Politécnica da Universidade de São Paulo. Departamento de Engenharia de Estruturas e Fundações.

1.Dinâmica das estruturas 2.Terremotos 3.Rótulas plásticas 4.Efeitos sísmicos nas estruturas 5.Estruturas metálicas I.Universidade de São Paulo. Escola Politécnica. Departamento de Engenharia de Estruturas e Fundações II.t. 


\section{AGRADECIMENTOS}

Ao Prof. Dr. Reyolando M. L. R. F. Brasil, pela paciência e ajuda constante ao longo desse trabalho.

Ao meu pai, Estevão, pelo investimento em minha educação, pelo incentivo e por sempre fazer o melhor por mim. A minha mãe, Vanda, pelos valores ensinados.

As minhas irmãs assim como meus cunhados, por me carregarem às vezes, por me incentivarem em outras e por estarem sempre perto. Ao meu querido sobrinho, Jorginho.

Ao meu namorado André, por me ajudar, por me motivar, por ser exigente e, principalmente, por existir.

Aos amigos Patrícia e Renoir, por várias coisas desde o início deste mestrado e até hoje. Aos amigos Alice, Marisa, Rosana e Sergio. Aos amigos do LMC, Ricardo, Macksuel, Calebe e Lucas.

Aos meus amigos de longa data, Karina, Renata, Karen, Tânia, Vivian, Walkyria, David, Karin, Leila, Gabriela, Marcelo, Sandra, Fabíola e Paula, por sempre me acolherem nos momentos ruins, por dividirem os momentos bons, pelas risadas e por todo resto também.

Aos funcionários e professores da USP, principalmente Cristiano. 


\section{RESUMO}

Ações sísmicas ocorrem com pouca freqüência e intensidade no Brasil, porém ocorrem em países da América Latina situados na costa do Pacífico e em Portugal, despertando o interesse da engenharia brasileira nesse assunto. Neste trabalho, apresenta-se um modelo numérico para análise de estruturas metálicas aporticadas planas com comportamento elasto-plástico sob excitação aleatória induzida por sismos. Para simular as vibrações aleatórias, utiliza-se uma simulação tipo Monte Carlo fundamentada no "Vento Sintético", proposta pelo Prof. Mário Franco. Nessa simulação, combinações de séries de carregamentos harmônicos são geradas com suas amplitudes extraídas de uma Função de Densidade Espectral de Potência (PSDF) das acelerações do solo e com ângulos de fase obtidos por um algoritmo pseudo-aleatório. A PSDF utilizada é um modelo reduzido do modelo Kanai-Tajimi que determina combinações de séries adimensionais, onde seus resultados para o trecho elástico são calibrados com o espectro de resposta elástica sugerido em norma internacional. A integração numérica passo-a-passo no domínio do tempo é feita para cada função de carregamento adotando-se o método de Newmark. O efeito elastoplástico é modelado pelo conceito de rótulas plásticas, assim, a cada passo é verificada a formação da rótula. Se certa seção atingir o momento fletor de plastificação, o valor do momento permanece constante e introduz-se uma rótula nessa seção com rigidez a flexão nula, permitindo rotações finitas livres. Em caso de reversão da direção do momento fletor, a rigidez elástica é integralmente recuperada com a eliminação da rótula do modelo. Ao final desse processo, obtém-se uma grande quantidade de dados de resposta. Faz-se um tratamento estatístico desses resultados de modo a concluir, do ponto de vista da engenharia, a probabilidade de ocorrência dos eventos. Para validar a metodologia proposta, analisou-se um edifício com cinco pavimentos. Os resultados satisfatórios foram obtidos quando comparados com exemplos da literatura, além de apresentarem-se estável com relação a integração no tempo.

Palavras chave: Dinâmica das estruturas. Terremotos. Rótulas plásticas. Efeitos sísmicos nas estruturas. Estruturas metálicas. 


\begin{abstract}
Seismic actions occur with low intensity and often in Brazil, however they occur in Latin-American countries on the Pacific Coast and in Portugal, arousing interest in this subject of the Brazilian engineering. In this work, a numerical model is presented for the analysis on the elastic-plastic behavior of steel planar framed structures under random seismic excitation. For random vibrations, a Monte Carlo type simulation is used. This simulation is based on the "Synthetic Wind", proposed by Prof. Mario Franco. In this simulation, combinations of series of harmonic loads are generated with their amplitude given by certain provided Power Spectrum Density Functions (PSDF) of ground acceleration and pseudorandomly set phase angles. The used PSDF is reduced model of the Kanai-Tajimi model that determine combinations of non-dimensional series whose results by the behavior elastic are adjusted by international codes Elastic Response Spectra. The step-by-step time integration is performed for each load function using the Newmark method. In order to model, the elastoplastic effect is used the plastic hinge concept. Therefore, at each step the hinge formation is verified. If a certain section reaches its full plastic bending moment, this value of moment is maintained and a hinge in that section is introduced in the model with null stiffness, allowing for free finite rotations. If the rotation in a certain hinged section is reversed, elastic behavior is restored by elimination of the hinge from the model. At the end of this process, a large quantity of response data is obtained. A statistic treatment of these results is performed, in the way that is possible conclude, from the engineering point of view, the probability of occurrence of these events. A statistic treatment based sound engineering conclusions is done for the happened probable events. In order to validate the proposed methodology, a five stories building is analyzed. Satisfactory agreement is obtained when compared to results from the literature, and the results are very stable with respect to the time integration.
\end{abstract}

Keywords: Dynamics of structures. Earthquakes. Plastic hinges. Seismic effects on structures. Steel structures. 


\section{LISTA DE FIGURAS}

Figura 1.1 - Registros de movimentos do solo durante terremotos graves (CHOPRA, 1995)..3

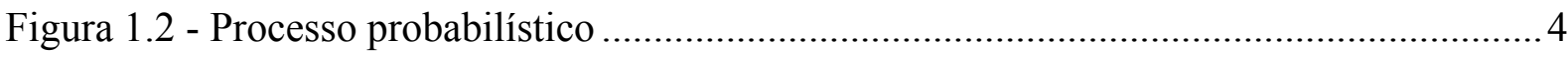

Figura 1.3 - Comparação entre acelerações horizontais médias de cálculo..............................5

Figura 2.1 - Mapa de zoneamento de Portugal (FARINHA et al., 2003) ................................ 11

Figura 2.2 - Acelerograma do terremoto de El Centro, 1940 ................................................ 14

Figura 2.3 - Histórico das respostas de deslocamento da estrutura para o terremoto de El

Centro em 3 sistemas com taxa de amortecimento $\xi 2 \%$ e período natural da estrutura 0,5 ;

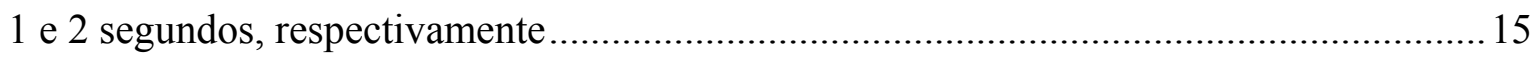

Figura 2.4 - Espectro de resposta do deslocamento para taxa de amortecimento $\xi 2 \%$ do

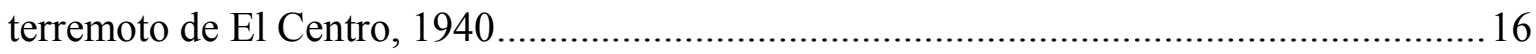

Figura 2.5 - Espectro de aceleração da resposta para taxa de amortecimento $\xi 2 \%$ do

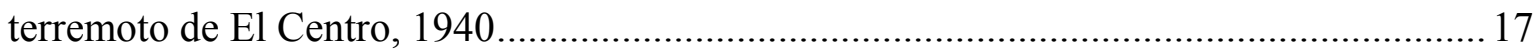

Figura 3.1 - Curva tensão-deformação do aço ..................................................................... 19

Figura 3.2 - Relação tensão-deformação do aço para o modelo elasto-plástico idealizado .... 19

Figura 3.3 - Tensões variáveis para o comportamento do material elasto-plástico ideal ........20

Figura 3.4 - Estado de tensão e deformação de uma seção transversal ................................... 20

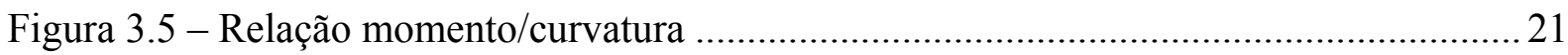

Figura 4.1 - Procedimento para determinação das solicitações devidas à ação de vento e

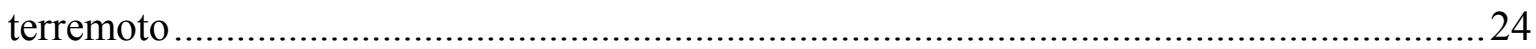

Figura 4.2 - Função de Densidade Espectral de Potência (PSDF) da aceleração do solo

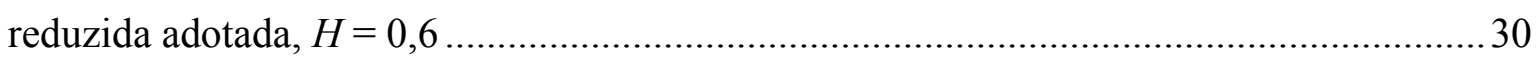

Figura 4.3 - Amplitude dos harmônicos $k$, para 20 harmônicos $\left(\mathrm{T}_{\mathrm{r}}=0,40 \mathrm{~s}\right) \quad \ldots \ldots \ldots \ldots \ldots \ldots \ldots \ldots . . . . . . . . . .31$

Figura 4.4 - Amplitude dos harmônicos $k$, para 11 harmônicos $(\operatorname{Tr}=0,40 \mathrm{~s})$......................... 32

Figura 4.5 - Frequência ressonante de estruturas e terremotos. Uma frequência fundamental típica de prédios com múltiplos andares e frequências dominantes de terremotos (FAGEL e LIU apud GOULD e ABU-SITTA, 1980).

Figura 4.6 - Modelo shear building: sistema estrutural e direção dos deslocamentos

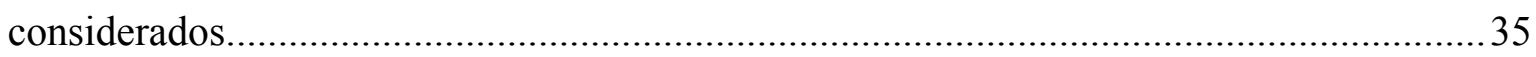

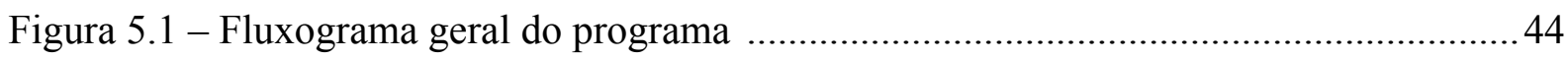


Figura 5.2 - Fluxograma de determinação dos espectros de respostas dos deslocamentos elasto-plásticos, das velocidades e das acelerações ............................................................ 45

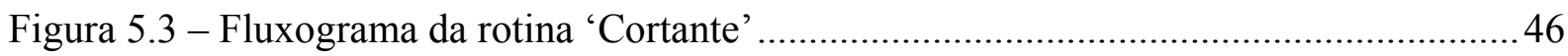

Figura 5.4 - Edifício com 5 pavimentos: características da estrutura ................................... 47

Figura 5.5 - Histórico de respostas dos deslocamentos na direção $u_{l}$, obtido no programa

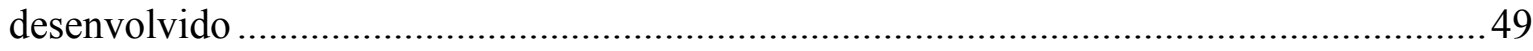

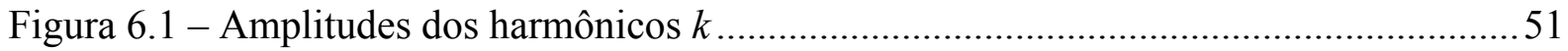

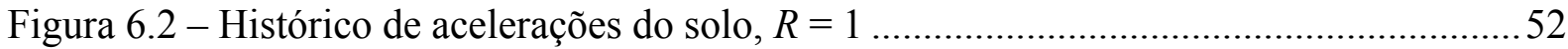

Figura 6.3 - Espectro de resposta elástico, fator de redução 1 ............................................. 53

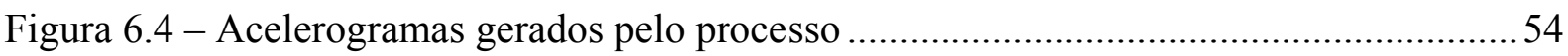

Figura 6.5 - Históricos de respostas para os comportamentos elástico e elasto-plástico,

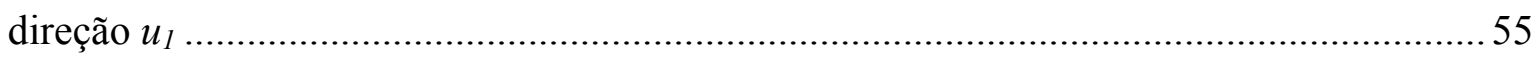

Figura 6.6 - Históricos de respostas para os comportamentos elástico e elasto-plástico,

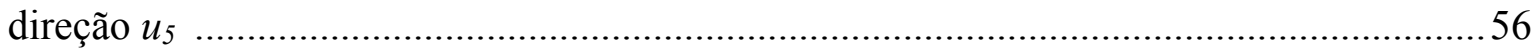

Figura 6.7 - Valores máximos dos deslocamentos de resposta da estrutura..........................57 


\section{LISTA DE TABELAS}

Tabela 4.1 - Tabela para relacionar o período ressonante, termo ressonante e número de funções 33

Tabela 5.1 - Características das colunas em cada pavimento .............................................. 48

Tabela 6.1 - Componentes harmônicos do terremoto .........................................................51

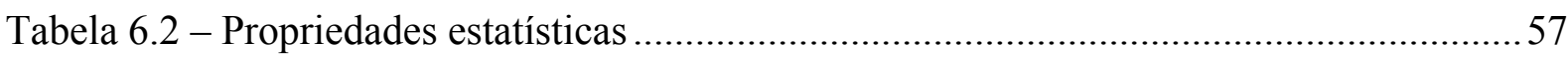




\section{LISTA DE ABREVIATURAS E SIGLAS}

CFE

- COMISIÓN FEDERAL DE ELECTRICIDAD

AIS

- $\quad$ ASOCIACIÓN COLOMBIANA DE INGENIERÍA SÍSMICA

NSR -98

- $\quad$ Normas Colombianas de Diseño y Construcción Sismo Resistente

COVENIN 1756 - COMISIÓN DE NORMAS DE ESTRUCTURAS PARA

EDIFICACIONES DEL MINISTERIO DE DESARROLLO

URBANO Y COMISIÓN VENEZOLANA DE NORMAS

INDUSTRIALES. COVENIN 1756:2001-1. Edificaciones

sismorresistentes

IBCO

- INTERNATIONAL COUNCIL OF BUILDING OFFICIALS

PSDF

- Função de Densidade Espectral de Potência

ABNT

- $\quad$ ASSOCIAÇÃO BRASILEIRA DE NORMAS TÉCNICAS 


\section{LISTA DE SÍMBOLOS}

\section{CAPÍtulo 2}

$\begin{array}{ll}\ddot{u}_{g}(t) & \text { aceleração do solo ao logo do tempo (acelerograma) } \\ m & \text { massa da estrutura } \\ c & \text { amortecimento da estrutura } \\ k & \text { rigidez da estrutura } \\ \ddot{u}(t) & \text { aceleração da estrutura no instante } t \\ \dot{u}(t) & \text { velocidade da estrutura no instante } t \\ u(t) & \text { deslocamento da estrutura no instante } t \\ p(t) & \text { carregamento dinâmico no instante } t \\ \xi & \text { taxa de amortecimento da estrutura (\%) } \\ \bar{\omega} & \text { freqüência natural circular de vibração da estrutura em rad/s } \\ \bar{T} & \text { período da estrutura em } s \\ u_{\text {max }} & \text { deslocamento máximo do espectro de resposta de uma estrutura } \\ S_{u} & \text { espectro de resposta do deslocamento } \\ S_{\dot{u}} & \text { espectro de resposta da velocidade } \\ S_{u} & \text { espectro de resposta da aceleração } \\ f & \text { freqüência em } H z\end{array}$

\section{CAPÍtUlo 3}

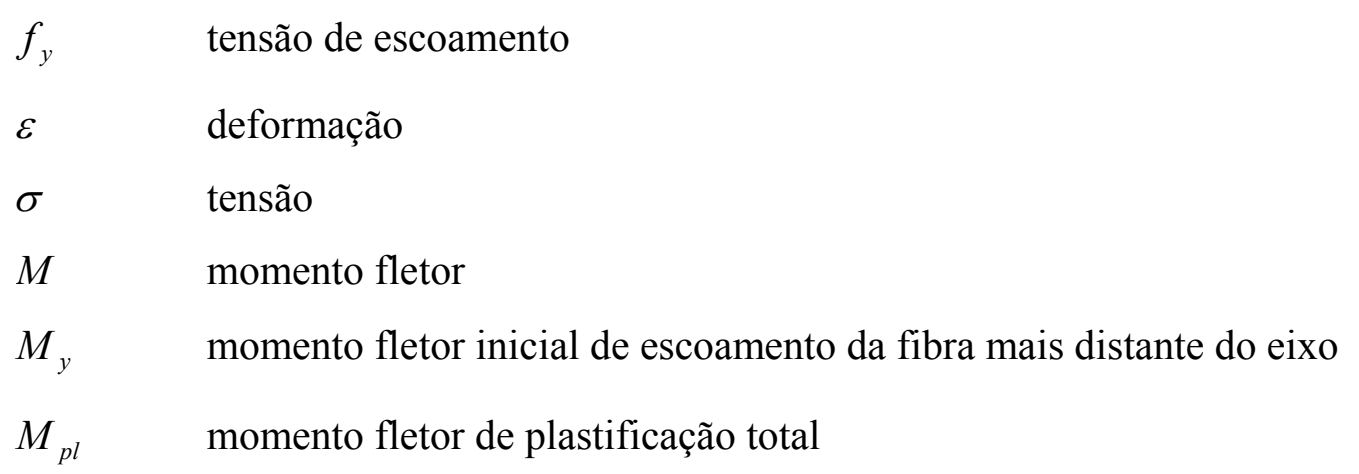




\section{CAPÍtULO 4}

$C(\omega) \quad$ amplitude associada à freqüência $\omega$

$\omega \quad$ freqüência natural circular da excitação de suporte em $\mathrm{rad} / \mathrm{s}$

$\theta(\omega) \quad$ ângulo de fase em $\mathrm{rad}$

$A(\omega)$ e $B(\omega) \quad$ coeficientes de Fourier

m número total de funções harmônicas

$C_{k} \quad$ amplitude associada ao harmônico $k$

$\omega_{r} \quad$ freqüência natural da excitação ressonante com a freqüência da estrutura

$r_{k} \quad$ fator que gera as freqüências múltiplas ou submúltiplas da freqüência ressonante

$\theta_{k} \quad$ ângulo de fase associado ao harmônico $k$.

$S_{i_{g}}(\omega)$ função densidade espectral de potência da aceleração do solo $\left[\frac{m}{s^{2}}\right]^{2} s$

$d \omega \quad$ intervalo elementar de freqüência

$\omega_{1} \quad$ freqüência natural do primeiro modo de vibração da estrutura

$\omega_{2} \quad$ freqüência natural do segundo modo de vibração da estrutura

$r$ termo ressonante (subscrito) ou a relação não-dimensional de freqüências, $\omega / \omega_{g}$.

$d W \quad$ potência elementar

$R_{i i g}(\tau) \quad$ função de autocorrelação da aceleração do solo

$\tau \quad$ incremento de tempo

$A_{k} \quad$ coeficientes das partes reais da Transformada de Fourier complexa, via o algoritmo Transformada discreta de Fourier associada ao harmônico $k$

$B_{k} \quad$ coeficientes das partes imaginárias da Transformada de Fourier complexa, via o algoritmo Transformada discreta de Fourier associada ao harmônico $k$

$N \quad$ quantidade total de valores ou número total de pavimentos

$R_{r} \quad$ função autocorrelação computada

$S_{k} \quad$ valor absoluto (ou módulo) de cada coeficiente da Transformada complexa discreta 


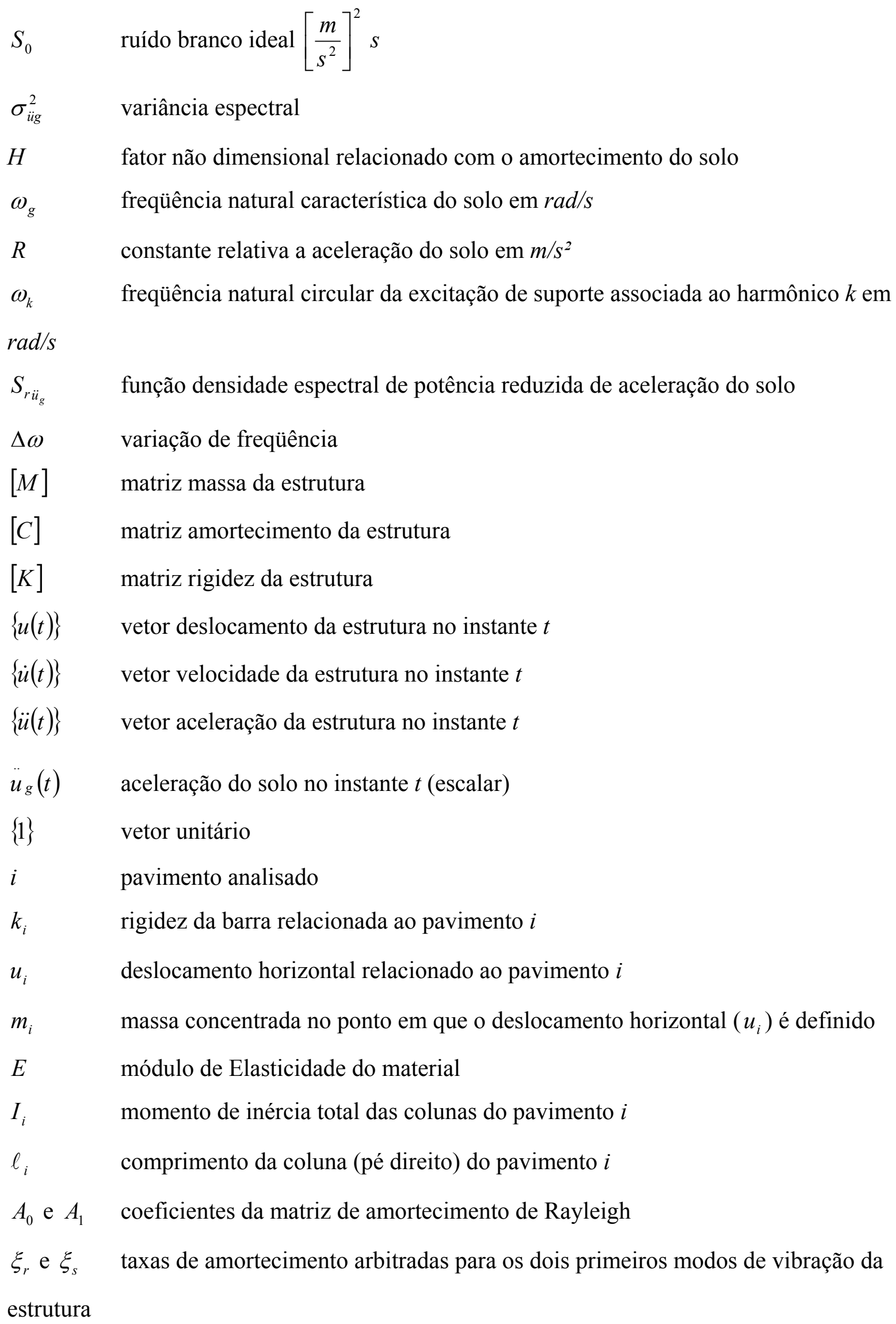


$\omega_{r}$ e $\omega_{s} \quad$ freqüências naturais circulares de vibração da estrutura para os dois primeiros modos

$n \quad$ o passo de integração (subscrito)

$\left\{F_{e}\right\}_{n} \quad$ vetor força restauradora relativo ao passo $n$

$\left\{F_{a}\right\}_{n} \quad$ vetor força de amortecimento relativo ao passo $n$

$\{P\}_{n} \quad$ vetor carregamento da estrutura relativo ao passo $n$

$h \quad$ passo de tempo da integração

$\{u\}_{n} \quad$ vetor deslocamento da estrutura relativo ao passo $n$ ( ou no instante $t$ )

$\{\dot{u}\}_{n} \quad$ vetor velocidade da estrutura relativo ao passo $n$ (ou no instante $t$ )

$\{\ddot{u}\}_{n} \quad$ vetor aceleração da estrutura relativo ao passo $n$ (ou no instante $t$ )

$\left\lfloor K_{\text {efet }}\right\rfloor \quad$ matriz rigidez efetiva de Newmark

$[K]_{n} \quad$ matriz rigidez relativa ao passo $n$

$\left\{\Delta P_{\text {efet }}\right\} \quad$ incremento do carregamento efetivo

$\{\Delta u\}_{n} \quad$ incremento dos deslocamentos relativo ao passo $n$

$\{\Delta \dot{u}\}_{n} \quad$ incremento da velocidade relativo ao passo $n$

$u_{c \max } \quad$ valor característico máximo do deslocamento

$\sigma \quad$ desvio padrão do universo analisado

$\mu \quad$ valor médio dos valores máximos

\section{CAPÍTULO 5}

$Q$ força cortante restauradora local equivalente

$M_{\text {SUP }} \quad$ momento fletor superior

$M_{I N F} \quad$ momento fletor inferior

$I_{0 i} \quad$ momento de inércia da coluna do pavimento $i$

Z módulo de resistência plástico da coluna do pavimento $i$

$Q_{p l} \quad$ força cortante máxima na barra

NDT número total de passos de integração

$Q_{f} \quad$ força cortante do passo $n$ referente ao pavimento $i$ 
$Q \quad$ força cortante do passo $(n-1)$ referente ao pavimento $i$

$k_{c} \quad$ rigidez da coluna para o passo $n$ referente ao pavimento $i$

$D_{\text {elta }} \quad$ diferença entre a variação do deslocamento $(\Delta u)$ do pavimento $i$ e $(i+1)$

determinada no passo $(n-1)$.

\section{CAPÍTULO 6}

$\ddot{u}_{\text {máx }} \quad$ resposta máxima elástica da aceleração

Ad ordenadas do espectro de resposta elástico indicadas em COVENIN 1756 (2001)

$\alpha \quad$ fator de importância

$T_{0}, T^{*}, \beta, \mathrm{p} \quad$ parâmetros sugeridos em COVENIN 1756 (2001)

$\varphi \quad$ fator de correção do coeficiente de aceleração

$A_{0} \quad$ coeficiente de aceleração horizontal de acordo com a zona sísmica

j acelerograma analisada 


\section{SUMÁRIO}

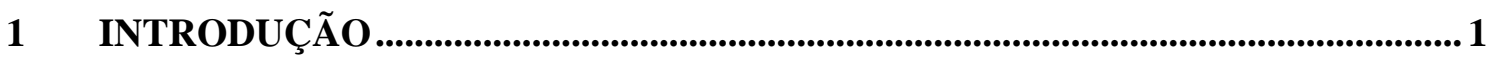

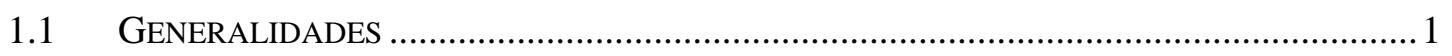

1.2 TEMA E MOTIVAÇÃO ……………………………………………………….

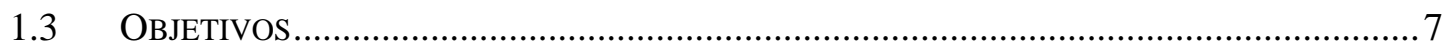

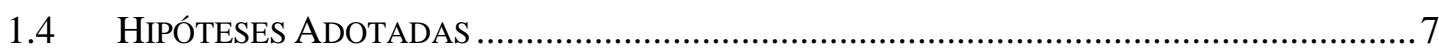

1.5 LiMITAÇõES DA PESQUISA ...................................................................................

1.6 PLANO DA DISSERTAÇÃO.................................................................................

2 DETERMINAÇÃO USUAL DA AÇÃO DE SISMOS EM REGIME ELÁSTICO10

2.1 RECOMENDAÇÕES EM NORMAS .............................................................................. 10

2.2 ESPECTRO DE RESPOSTA ELÁSTICO …………………………………………...... 13

3 COMPORTAMENTO ELASTO-PLÁSTICO DO AÇO ESTRUTURAL................18

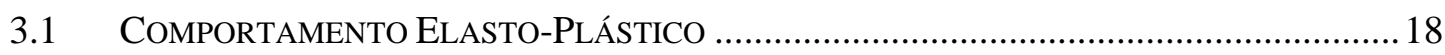

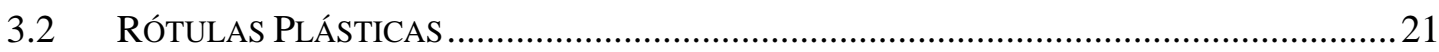

4 ANÁLISE DINÂMICA ALEATÓRIA DE ESTRUTURAS SOB EFEITO DE

SISMOS ...................................................................................................................................... 23

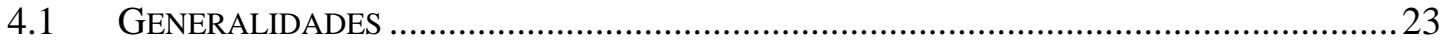

4.1.1 O Método do Vento Sintético ……………………………………………......23

4.1.2 Aplicação da Análise de Fourier ....................................................................... 25

4.1.3 Função de Autocorrelação e Função de Densidade Espectral de Potência ......27

4.1.4 Modelos semi-empíricos para sismos......................................................... 28

4.2 FORMULAÇÃO DAS EQUAÇÕES DO MOVIMENTO............................................................

4.2.1 Matriz de Massa ......................................................................................... 35

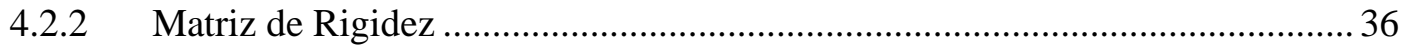

4.2.3 Matriz de Amortecimento ............................................................................... 37

4.3 INTEGRAÇÃO DIRETA PASSO-A-PASSO NO TEMPO: NEWMARK ……………………......... 38

4.4 IMPLEMENTAÇÃO DO MÉTODO ………………………………………………........ 40 
5 DESENVOLVIMENTO DE UM PROGRAMA COMPUTACIONAL ...................42

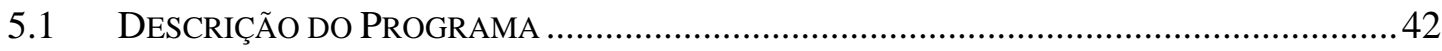

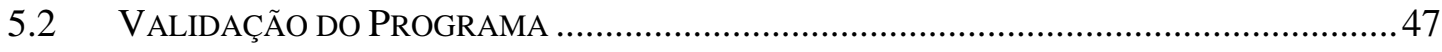

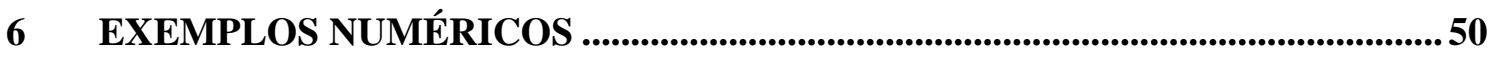

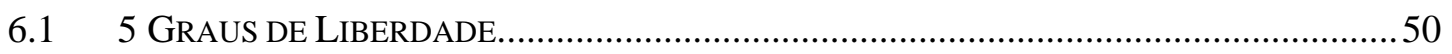

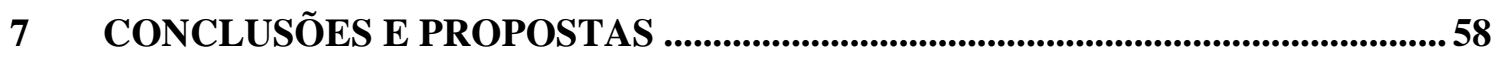

REFERÊNCIAS 


\section{INTRODUÇÃO}

No estado atual de conhecimento da Geofísica, de acordo com Buchholdt (1999), admite-se que a crosta terrestre divide-se em placas tectônicas, que são extensas porções de rocha limitadas por regiões de atrito e/ou regiões de deslizamento. Como descrito em McGuire e Winter (1968), nas regiões de contato entre elas, podem acontecer interações mais ou menos violentas que seriam responsáveis pela geração de ondas mecânicas conhecidas por sismos ou terremotos. Exemplos dessas regiões sismicamente ativas são as margens do oceano Pacífico, regiões da Ásia, e em torno do mar Mediterrâneo.

Assim, no Brasil, não há registros significativos de ações sísmicas, conseqüentemente, não é comum a consideração desse tipo de ação em estruturas. Entretanto, em estruturas especiais, tais como barragens e usinas nucleares, já se considera essa ação. Para esses casos, o procedimento usual é seguir as recomendações de normas estrangeiras.Recentemente está disponível para discussão uma proposta de procedimento brasileiro para esse fim.

Conforme COMISIÓN FEDERAL DE ELECTRICIDAD (CFE, 1993), as principais preocupações, quando ocorre um terremoto, são preservar a vida humana e minimizar os danos estruturais. Nessas condições são estabelecidos os procedimentos para se dimensionar as estruturas resistentes a sismos.

\subsection{GENERALIDADES}

Procedimentos adequados para projetar estruturas resistentes a ações sísmicas já estão bem detalhados na literatura, mas ainda merecem grande atenção dos pesquisadores modernos. As maiores dificuldades para essa área de pesquisa, apontadas em McGuire e Winter (1968), são:

- conhecimento insuficiente da freqüência de ocorrência e da intensidade dos terremotos esperados para uma dada área;

- conhecimento insuficiente de características detalhadas do movimento;

- complexidade de técnicas analíticas; 
- questões relacionadas a determinação da resposta real e da resistência dos elementos estruturais.

Neste item, apresentam-se generalidades de cada tópico acima a fim de estabelecer as bases do presente estudo.

A intensidade dos sismos é fornecida nos Códigos (Normas) de cada país na forma de zonas sísmicas determinadas sobre o mapa desse país. Divide-se o território em zonas tais que a principal diferença entre cada região seja a freqüência de ocorrência desse fenômeno. Essa consideração é discutível, pois será que é uma boa simulação dividir um país em zonas sísmicas obtidas pela raridade desse evento? Em McGuire e Winter (1968), comenta-se sobre um terremoto moderado em Agadir, Marroco, onde aproximadamente 5.000 pessoas foram mortas, basicamente porque seus prédios não tinham resistência lateral.

Desta forma, é difícil definir um melhor critério para esse fator, visto que as forças ao longo do tempo geradas por ações sísmicas são forças inerciais, dadas matematicamente pelo produto das massas da estrutura excitada pelo histórico de aceleração do solo (acelerograma). Assim, as forças envolvidas em sismos dependem, em um primeiro instante, do movimento do solo e das massas externas.

Além da intensidade esperada, a sua variação no tempo é ainda uma incógnita. Conforme Clough (1975), uma boa solução para determinar o movimento em um sismo é uma simulação aleatória.

Ainda reforçando essa idéia, Chopra (1995) cita vários registros de acelerogramas de terremotos reais, tais como El Centro (1940), Parkfield (1966), São Francisco (1957), Chile (1985), Koyna (1967) entre outros. Com base nesses registros, é possível exemplificar a grande variabilidade de amplitudes, de tempo de duração e a forma que varia sua aceleração ao longo do tempo em cada terremoto, como ilustrado na Figura 1.1. 


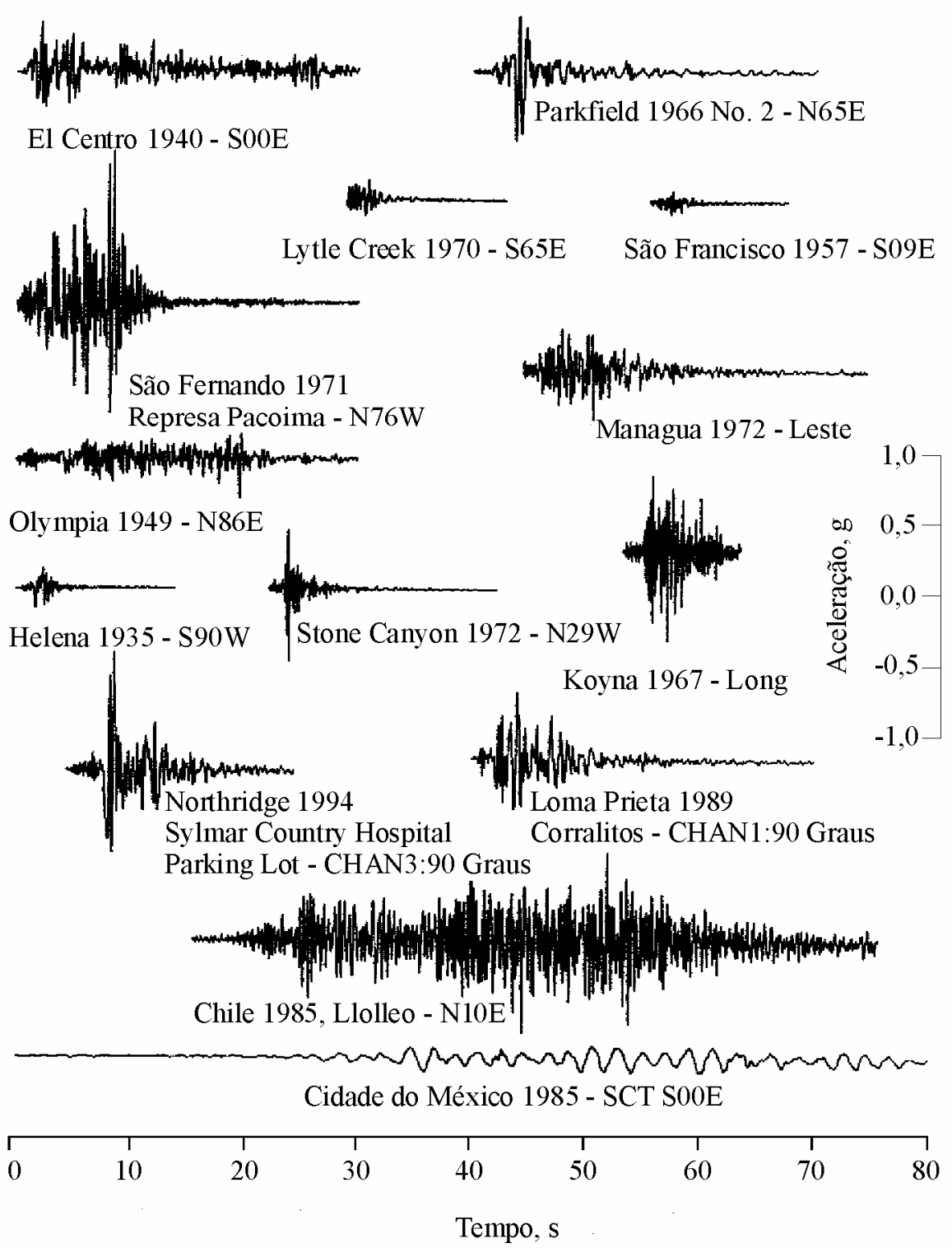

Figura 1.1 - Registros de movimentos do solo durante terremotos graves (CHOPRA, 1995).

Em função dessas incertezas, são propostas técnicas analíticas para simular adequadamente o fenômeno. As técnicas propostas para gerar acelerogramas são em geral complexas, como pode ser verificado em Buchholdt (1999), Clough (1975), Gould e AbuSitta (1980) e Rofooei; Mobarake e Ahmadi (2001).

Na Figura 1.2 é esquematizado o processo probabilístico aplicado para sismo, semelhante ao sugerido para vento em Davenport apud Blessmann (1998). Nesta figura, os históricos e os espectros obtidos são relacionados. 


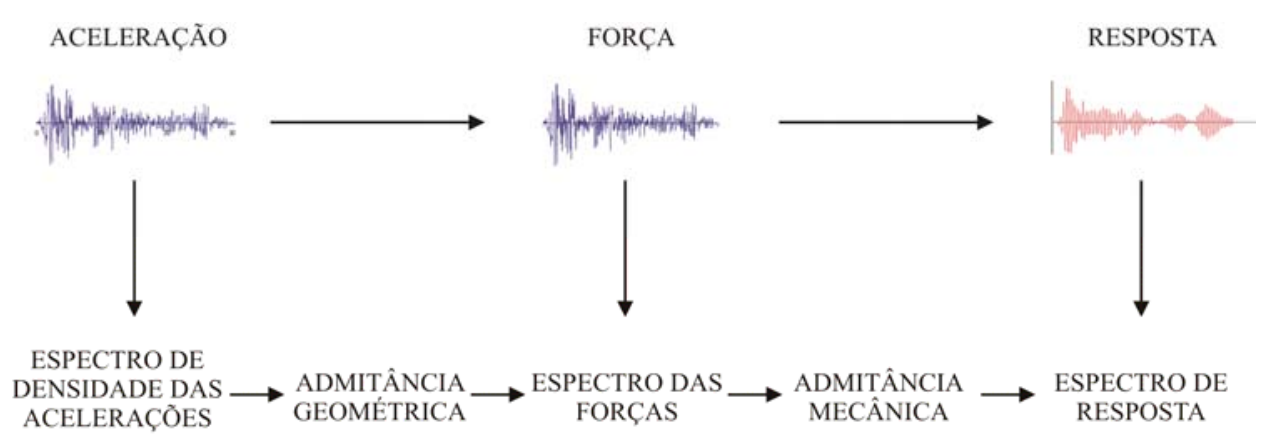

Figura 1.2 - Processo probabilístico.

Como se explica em Blessmann (1998), a principal aplicação do espectro de potência é para determinar a composição, em freqüência, de um processo aleatório, dessa forma, definindo uma possível maneira de se determinar um acelerograma. Essa metodologia é mais utilizada em ventos. Para o caso de sismos, utiliza-se geralmente o espectro de resposta como, por exemplo, sugerido em ASOCIACIÓN COLOMBIANA DE INGENIERÍA SÍSMICA (AIS) Normas Colombianas de Diseño y Construcción Sismo Resistente (NSR-98, 1997) e em Levy e Wilkinson (1975), que representa o espectro das respostas máximas obtidas para um sistema elástico simplificado. Conseqüentemente, esse modelo já considera o comportamento estrutural, pois é obtido a partir do histórico de respostas da estrutura, ao contrário do espectro de potência descrito anteriormente, pois ainda é necessário definir o comportamento da estrutura a fim de se estabelecer um método para definir a resposta.

Para os dois processos, deve-se considerar o material envolvido para determinar uma resposta próxima a resposta real. Essa questão é discutida em normas, por exemplo, em COMISIÓN DE NORMAS DE ESTRUCTURAS PARA EDIFICACIONES DEL MINISTERIO DE DESARROLLO URBANO Y COMISIÓN VENEZOLANA DE NORMAS INDUSTRIALES - Edificaciones sismorresistentes (COVENIN 1756, 2001) e em Farinha et al. (2003), onde se sugere freqüentemente soluções para o sistema com comportamento elástico, mas se admite um coeficiente, relacionado à ductilidade do material utilizado, que corrija os valores decorrentes desse espectro de resposta.

Já para se determinar a resposta devida a um acelerograma, há procedimentos para análise elástica e análise não-linear em Clough (1975). 


\subsection{TEMA E MOTIVAÇÃO}

Todos os anos, centenas de pequenos tremores ocorrem em nosso país. Segundo Silveira (2002), há registros de tremores de magnitude média em diversas áreas nacionais.

Como também se explica em Santos e Lima (2005), há uma baixa sismicidade em nosso país, contudo nem sempre essa ação deve ser desprezada. Na figura 1.3 (SANTOS e LIMA, op. cit.), tem-se uma comparação entre as acelerações na estrutura devida à ação do vento e à ação de sismos, de acordo com os números de andares do edifício. Observa-se que para edifícios de poucos andares a ação de sismo tem maior importância, justificando-se assim a necessidade em considerá-la no dimensionamento de edificações no Brasil.

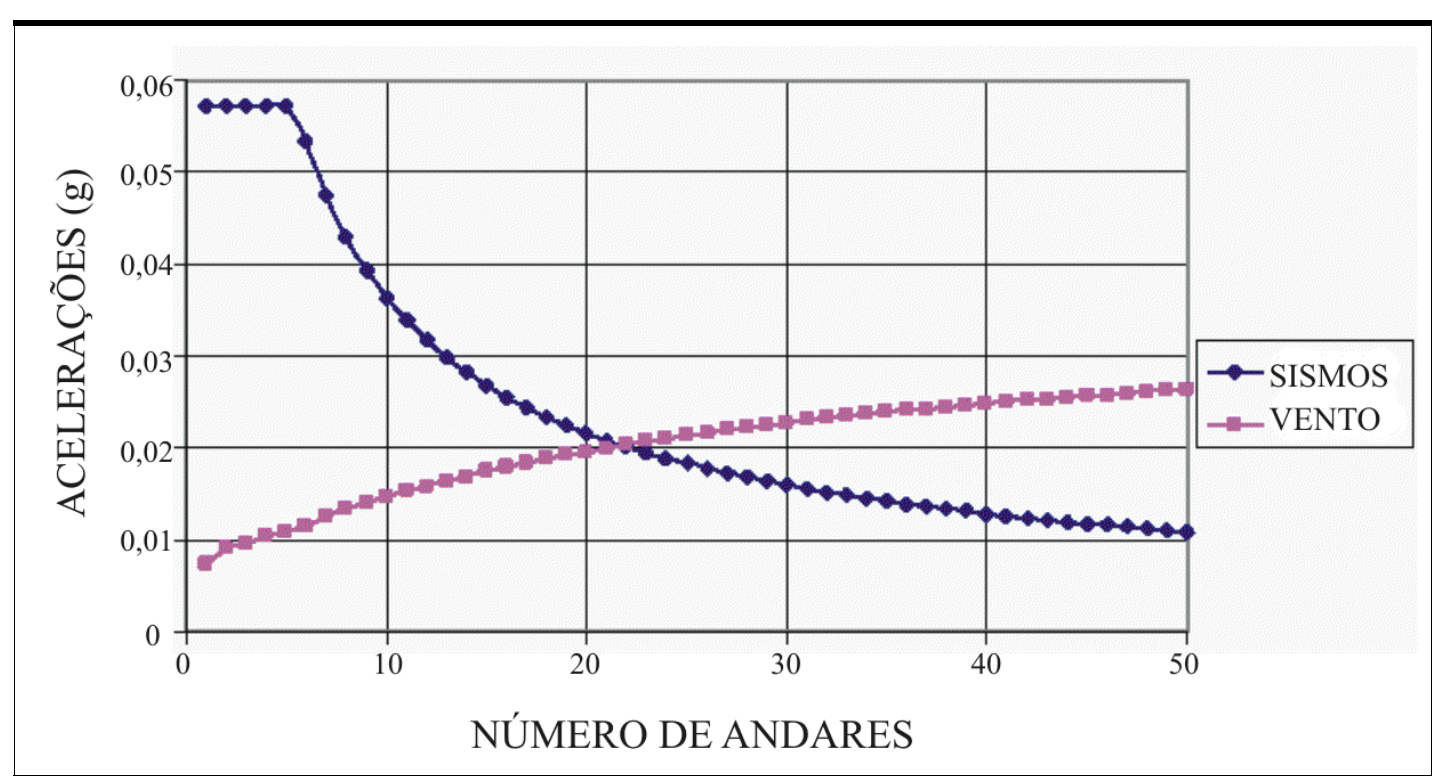

Figura 1.3 - Comparação entre acelerações horizontais médias de cálculo

Dessa forma, uma norma nacional está em andamento, Projeto 02:122.15-001 (em fase de elaboração $)^{1}$, tornando o dimensionamento a sismos um assunto de interesse nacional. Além do mais, a globalização faz com que os engenheiros, cada vez mais, tenham necessidade de competência em áreas de interesse mundial.

\footnotetext{
${ }^{1}$ ASSOCIAÇÃO BRASILEIRA DE NORMAS TÉCNICAS (ABNT). Projeto 02:122.15001: Projeto de estruturas resistentes a sismos - Procedimento. Rio de Janeiro, 2006. 20 p.
} 
Na análise de estruturas resistentes a sismos, percebe-se que ainda não há uma metodologia consagrada em Normas para o problema dinâmico com comportamento elastoplástico. Conforme Chopra (1995), esse assunto tem atraído muitos pesquisadores.

Assim, neste trabalho, propõe-se uma metodologia para a análise dinâmica de estruturas com o comportamento elasto-plástico do material sob excitação aleatória de sismos.

Adota-se um modelo estocástico, visto que, conforme comentado em Clough (1975), a natureza complexa da formação de ondas sísmicas faz com que seja conveniente essa consideração para gerar um acelerograma artificial.

Ainda em Clough (op. cit.), ondas sísmicas são iniciadas e seguidas por uma redução irregular de falhas por reflexões, refrações e atenuações numerosas e aleatórias ao longo do solo por onde passam. Então, aponta-se a excitação de suporte causada por ações sísmicas como uma das mais importantes aplicações de análise dinâmica estocástica na obtenção da resposta de estruturas.

Outro fator importante explorado é encontrado em Balendra (1993), em que se aborda a baixa probabilidade de ocorrência de uma ação sísmica na vida útil de uma estrutura. Dessa maneira, justifica-se a análise dinâmica dessa ação e a consideração de um comportamento elasto-plástico do material, pois, como também explica Balendra (op. cit.), analisar uma estrutura em regime plástico é uma boa solução em terremotos graves uma vez que é inviável economicamente que permaneça em regime elástico.

Neste trabalho, uma técnica tipo Monte Carlo, o “Vento Sintético”, proposta por Franco (1993), Franco e Isyumov (1997) e Franco (2003) para análise de carregamentos aleatórios de vento, serve de inspiração para o caso dos sismos na geração de um grande número de séries temporais de possíveis respostas de estruturas a sismos.

No caso da ação de vento, o método consiste em gerar pressões aleatórias a partir de Funções Espectrais de Potência de Velocidades do vento, que são bem conhecidas na Engenharia de Vento e podem ser encontrados facilmente em normas. Analogamente, em uma simulação de simos deve-se gerar acelerogramas aleatórios e utilizar funções equivalentes. Infelizmente, Funções Espectrais de Potência de Acelerações do solo não são tão fáceis de se encontrar.

De acordo com Buchholdt (1999), Clough (op. cit.) e Gould e Abu-Sitta (1980), para gerar acelerogramas artificiais deve-se utilizar uma Função de Densidade Espectral de Potência de aceleração. E, neste trabalho, sugere-se que se faça uma compatibilização desse espectro de densidade da aceleração do solo com o espectro de resposta sugerido em normas para modelos elásticos. 
Determinado o acelerograma, pode-se aplicar o carregamento na estrutura para o comportamento elasto-plástico definido como, por exemplo, em McGuire e Winter (1968) e em Neal (1956). Como no método do "Vento Sintético“, devem-se gerar vários acelerogramas com ângulos de fase sorteados e determinar a resposta máxima para cada acelerograma. Ao fim desse processo, faz-se um tratamento estatístico dessa amostragem de respostas, para permitir determinar probabilidades de ocorrência de eventos.

\subsection{OBJETIVOS}

Uma nova proposta para se gerar acelerogramas é sugerida. Com base em uma simulação de Monte Carlo, determina-se o acelerograma crítico para uma estrutura tipo shear building com o comportamento elasto-plástico. Para alcançar esse objetivo, fez-se necessário:

- desenvolver uma metodologia para gerar uma amostragem de acelerogramas; este trabalho baseou-se no processo "Vento Sintético".

- implementar um programa na linguagem de programação MATLAB (CHAPMAN, 2003) para se determinar a resposta máxima de uma estrutura com comportamento elasto-plástico a partir de um histórico de acelerações.

\subsection{HIPÓTESES ADOTADAS}

O modelo de edificações adotado neste trabalho é o shear building. Assim:

- admite-se apenas deslocamento horizontal nos nó;

- as massas são concentrada nos nós onde se definem os deslocamentos;

- despreza-se a massa das colunas;

- admite-se rigidez infinita nas lajes, aproximando a um engastamento perfeito;

- as ações são aplicadas apenas no plano do pórtico;

- a curva tensão-deformação é considerada elasto-plástica ideal. 


\subsection{LIMITAÇÕES DA PESQUISA}

A possibilidade que ocorra instabilidade elástica de qualquer elemento durante a análise é excluída.

O algoritmo implementado para simulação de sismos implica em históricos de carregamento periódicos.

\subsection{PLANO DA DISSERTAÇÃO}

Este trabalho foi escrito em sete capítulos. No capítulo 2, apresenta-se uma introdução sobre a metodologia utilizada para se considerar a ação de sismos. Assim, com base em CFE (1993), COVENIN 1756 (2001), Farinha et al. (2003), INTERNATIONAL COUNCIL OF BUILDING OFFICIALS (IBCO, 1988) e em NSR-98 (1997), faz-se uma síntese sobre as recomendações para se determinar a magnitude dessa ação e o método de análise para a estrutura.

Explica-se também a determinação de um espectro de resposta elástica para um terremoto real. Na exemplificação do processo, adota-se o terremoto de El Centro, 1940 de acordo com os registros dados em Chopra (1995).

No capítulo 3, descreve-se o comportamento elasto-plástico do material, onde se discute o comportamento dúctil do aço. Estabelece-se a curva tensão-deformação adotada.

No capítulo 4, encontram-se descritos os elementos necessários para a determinação da resposta do modelo estrutural adotado. Isto é, apresenta-se a metodologia adotada para simular o carregamento dinâmico e a formulação das matrizes de massa, de amortecimento e de rigidez da estrutura. Na seqüência, detalha-se o modelo numérico utilizado para se determinar o histórico de resposta para essa estrutura. O processo utilizado neste trabalho é o método de integração direta passo-a-passo no tempo. Por fim, fez-se a sistematização do procedimento utilizado nesta dissertação.

No capítulo 5, apresenta-se o programa desenvolvido para esta dissertação. Este programa foi desenvolvido para um material elasto-plástico ideal, como explicado no capítulo 3 e fez-se a integração numérica de Newmark (CLOUGH, 1975). 
No capítulo 6, exemplifica-se a aplicação do processo para um modelo de shear building com 5 graus de liberdades extraído de Chopra (1995).

Finalmente, as conclusões do trabalho são apresentadas no capítulo 7, onde se discutem as vantagens, as desvantagens e as propostas para futuros trabalhos. 


\section{DETERMINAÇÃO USUAL DA AÇÃO DE SISMOS EM REGIME ELÁSTICO}

As grandes incertezas nas características dos movimentos sísmicos tornam impossível o exato estabelecimento de critérios de projeto visando, assim, minimizar os efeitos desse tipo de ação sobre estruturas.

Neste capítulo, serão apresentadas algumas recomendações de procedimentos para estimativa da ação de sismos sobre estruturas. Em particular, na seqüência, trata-se da utilização de Espectros de Resposta no dimensionamento de estruturas de comportamento elástico pelo método dinâmico.

\subsection{RECOMENDAÇÕES EM NORMAS}

Os procedimentos indicados em diversas Normas internacionais para se dimensionar uma estrutura resistente a sismo preocupam-se em determinar a segurança requerida, conduzindo-se a uma análise econômica de diferentes alternativas de projeto. Desta forma, estabelecem-se o custo inicial, o custo e conseqüência de uma falha eventual e a relação entre ambos. Uma vez determinados, analisa-se a melhor solução.

Para exemplo, são aqui utilizadas CFE (1993), COVENIN 1756 (2001), as recomendações legais de Portugal e do Eurocode encontradas em Farinha et al. (2003), IBCO (1988) e NSR-98 (1997). Recomendações semelhantes aparecem em todos esses códigos para se determinar a resposta a sismos de uma estrutura, onde se ressalta o destino da obra, a ductilidade do material, o risco sísmico da região e o perfil do solo.

Então, de acordo com o destino da obra utiliza-se uma tabela, sugerida nas referências acima, denominada de classificação de importância da construção. Assim, dividem-se as construções em grupos que consideram as construções que devem permanecer em perfeitas condições durante e depois de um terremoto e as que podem sofrer algum dano.

Analisam-se, também, as características próprias de ductilidade da estrutura, visto que a capacidade para dissipar energia mediante a deformações inelásticas interfere consideravelmente na resposta da estrutura. Também se considera o sistema estrutural 
adotado. A partir dessas considerações, estabelece-se o coeficiente de ductilidade do material. Uma outra proposta é a adotada no ENV 1998 Eurocódigo 8 - Projecto de estruturas em regiões sísmicas, como explica Farinha et al. (2003), em que se indica uma correção da resposta da estrutura quando o material for dúctil e de acordo com o sistema estrutural utilizado, se dispondo de contraventamento adequado ou não.

Outro fator importante é a influência sobre as ações a determinar da região onde se executará a estrutura. Assim, sugere-se uma intensidade de pico de aceleração do sismo denominada de risco sísmico do local. O risco sísmico varia do grau 0 ao grau 7 , que indica desde a ausência até as regiões de grande freqüência desse fenômeno.

Encontra-se em CFE (1993), COVENIN 1756 (2001), Farinha et al. (op. cit.), IBCO (1988) e em NSR-98 (1997), mapas de zoneamento dos diversos países, sugerindo, com base no risco sísmico da região, o coeficiente de aceleração ou coeficiente de sismicidade. Na Figura 2.1, apresenta-se, como exemplo, o mapa de Portugal (FARINHA et al., op. cit.). As zonas sísmicas A, B, C e D representam, respectivamente, onde há maior influência a sismicidade.

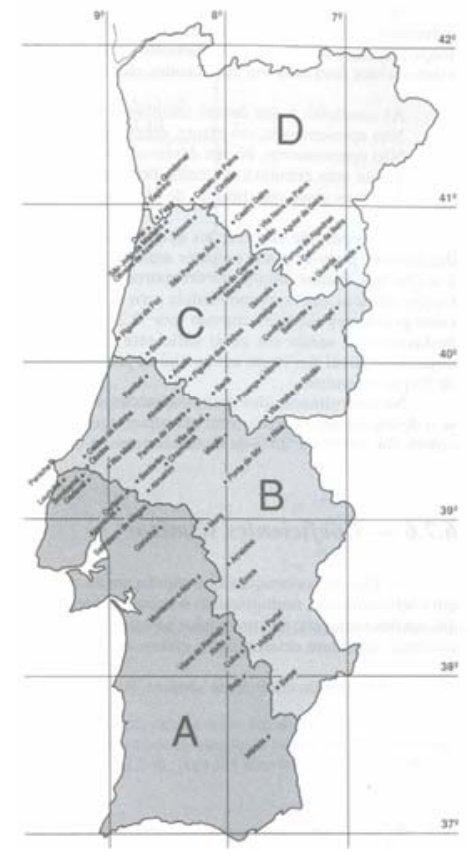

Figura 2.1 - Mapa de zoneamento de Portugal (FARINHA et al., 2003).

Além disso, o tipo de solo por onde essa ação se propaga também influencia na intensidade dos carregamentos finais que agem sobre a estrutura. Dessa forma, é necessário levar em conta o perfil do solo local. 
Finalmente, deve-se determinar o método adequado para se analisar a estrutura. Visando-se isso, vários níveis de análise são propostos, dependendo de uma série de fatores relacionados com o tipo, magnitude e importância das obras: método simplificado, método estático, método dinâmico e o método dinâmico com integração passo-a-passo.

Tomando, apenas como exemplo, CFE (1993), indica-se o método simplificado de análise estática para construções com distribuições proporcionais entre massa e rigidez, altura inferior a 13 metros e razão entre altura da construção e menor lado da construção inferior a 1,5 metros.

Satisfeitas essas condições, verifica-se unicamente se a soma das forças cortantes resistentes das paredes, projetadas na direção em que se considera a aceleração, é superior a força cortante atuante total. Se for, esse piso dispensa qualquer verificação, caso contrário, sugere-se verificar pelo método estático.

O método estático, proposto em CFE (op. cit.), COVENIN 1756 (2001), Farinha et al. (2003), IBCO (1988) e em NSR-98 (1997), considera o carregamento proporcional ao peso próprio da estrutura. Esse carregamento constante com o tempo é projetado na direção da aceleração e deve-se corrigir sua intensidade final pelos parâmetros descritos anteriormente. Em COVENIN 1756 (op. cit.), por exemplo, indica-se esse método para construções médias (prédios até 10 andares ou até 30 metros).

No caso de estruturas que excedam as dimensões máximas sugeridas, deve-se adotar o método dinâmico para sua análise. E pode ser aplicado para o comportamento elástico ou um comportamento que possibilite a plastificação do material utilizado. Nesse método, o carregamento varia ao longo do tempo.

Para o caso de uma análise dinâmica, CFE (op. cit.), COVENIN 1756 (op. cit.) e em NSR-98 (op. cit.), por exemplo, sugerem um espectro de resposta de projeto indicado apenas para o comportamento linear da estrutura. São indicadas expressões para trechos desse espectro com valores normalizados e esse valor é corrigido de acordo com as características de importância da construção, a ductilidade do material, o perfil do solo e o risco de sismicidade da região.

Aconselha-se também utilizar acelerogramas diferentes para simular essa ação, verificando a confiabilidade da resposta para a estrutura analisada. Esses acelerogramas seriam registros anteriores de sismos nesse local.

Em COVENIN 1756 (op. cit.), comenta-se sobre um procedimento para dimensionar as estruturas com comportamento elasto-plástico tanto para uma análise estática como dinâmica. Para o processo dinâmico, sugere-se, a partir da determinação experimental 
do acelerograma do solo, a integração passo a passo. Deve-se usar 4 acelerogramas diferentes do local, a fim de se estabelecer a resposta máxima.

Ainda em COVENIN 1756 (2001), recomenda-se que por meio de um desses acelerogramas deva-se aproximar, conservadoramente, do espectro de projeto para um valor unitário de redução da resposta devido à ductilidade do material na faixa dos períodos próprios da estrutura.

\subsection{ESPECTRO DE RESPOSTA ELÁSTICO}

O espectro de resposta elástico, recomendado em diversas normas, é utilizado freqüentemente para se determinar as solicitações em uma estrutura sob a ação de sismos. Pode-se obtê-lo a partir de qualquer acelerograma de terremoto $\ddot{u}_{g}(t)$ ou por expressões sugeridas em normas de sismos.

Para o caso de um acelerograma conhecido, admite-se um sistema massaamortecedor-mola para um grau de liberdade como, por exemplo, descrito em Clough (1975). A equação dinâmica de movimento é:

$$
m \ddot{u}(t)+c \dot{u}(t)+k u(t)=p(t)
$$

onde, $m$ representa a massa da estrutura, $c$, o amortecimento e $k$, a rigidez da estrutura. $\ddot{u}(t), \dot{u}(t), u(t)$ e $p(t)$ estão relacionados ao instante de tempo $t$, e indicam, respectivamente, a aceleração, a velocidade, o deslocamento e o carregamento dinâmico que excita a estrutura.

Dividindo-se a eq. (2.1) por $m$, obtém-se:

$$
\ddot{u}(t)+2 \xi \bar{\omega} \dot{u}(t)+\bar{\omega}^{2} u(t)=\frac{p(t)}{m}
$$

onde, $\xi$ é a taxa de amortecimento da estrutura, em \%, determinada pela razão entre o amortecimento $c$ e a taxa de amortecimento crítico $C_{c} \cdot \bar{\omega}$ indica a freqüência natural da estrutura em $\mathrm{rad} / \mathrm{s}$.

Para excitação de suporte da estrutura, o carregamento dinâmico $p(t)$ dá-se pelo produto entre a massa $m$ e a aceleração do solo ao longo do tempo $\ddot{u}_{g}(t)$ com sentido oposto a essa aceleração. Assim:

$$
p(t)=-m \ddot{u}_{g}(t) \text {. }
$$


Resultando em:

$$
\ddot{u}(t)+2 \xi \bar{\omega} \dot{u}(t)+\bar{\omega}^{2} u(t)=-\ddot{u}_{g}(t)
$$

$\mathrm{e} \quad \bar{\omega}=\frac{2 \pi}{\bar{T}}$

onde, o período da estrutura é $\bar{T}$, em $s$.

A seguir, aplica-se um registro do histórico de acelerações do solo para qualquer registro de terremoto. Exemplifica-se, na Figura 2.2, o acelerograma (histórico de acelerações do solo) do terremoto de El Centro (1940) extraídas de Chopra (1995).

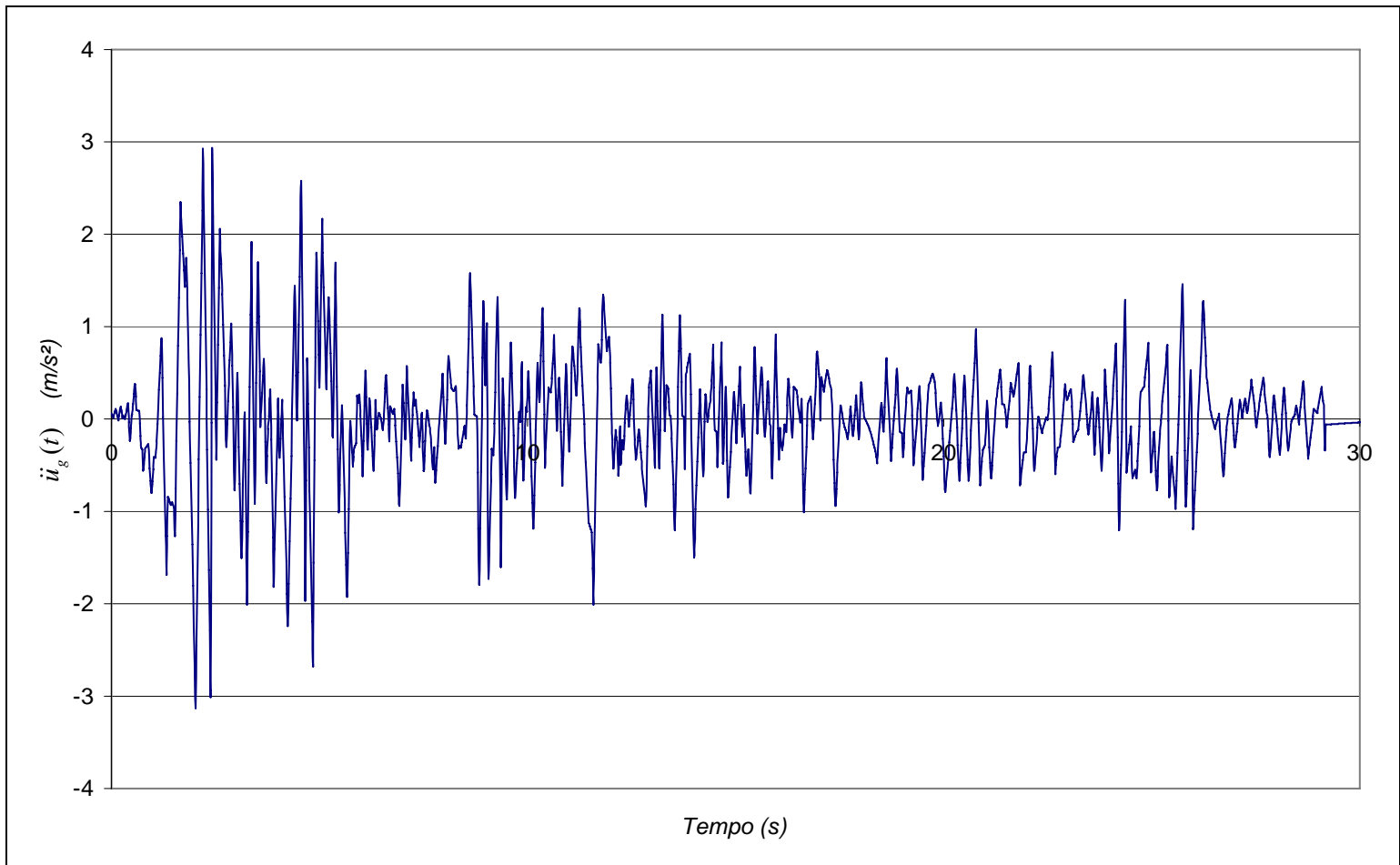

Figura 2.2 - Acelerograma do terremoto de El Centro, 1940.

O período da estrutura é variado em pequenos passos para uma taxa fixa de amortecimento assumida para esse sistema, obtendo-se um histórico de respostas de deslocamentos para cada período. Assim, é possível determinar a resposta máxima de cada histórico. Na Figura 2.3 é ilustrado, conforme Chopra (1995), esse procedimento. 

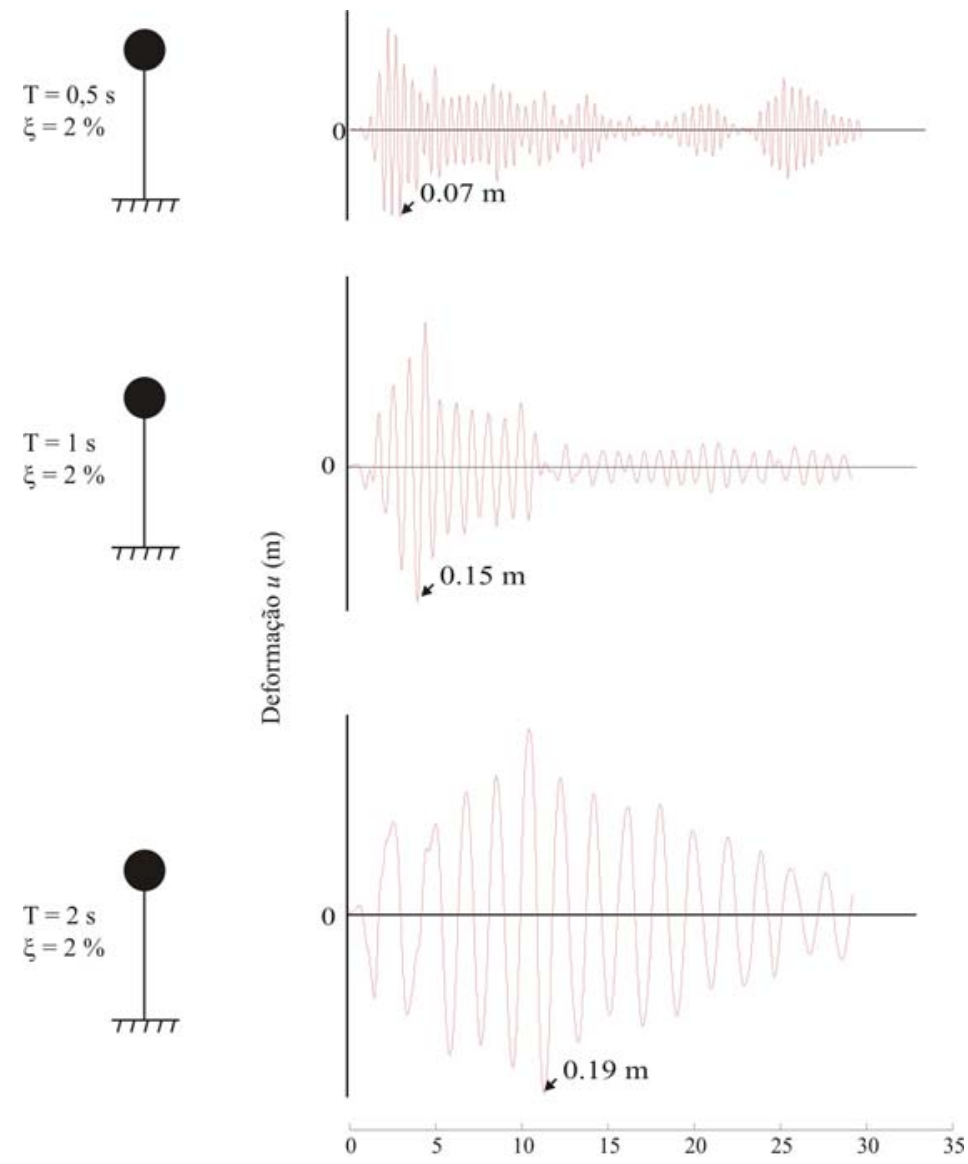

Tempo (s)

Figura 2.3 - Histórico das respostas de deslocamento da estrutura para o terremoto de El Centro em 3 sistemas com taxa de amortecimento $\xi 2 \%$ e período natural da estrutura 0,$5 ; 1$ e 2 segundos, respectivamente.

Portanto, pode-se obter um gráfico relacionando o período e a resposta máxima do sistema para uma taxa constante de amortecimento da estrutura, como é apresentado na Figura 2.4. Esse gráfico é denominado de espectro de resposta do deslocamento. 


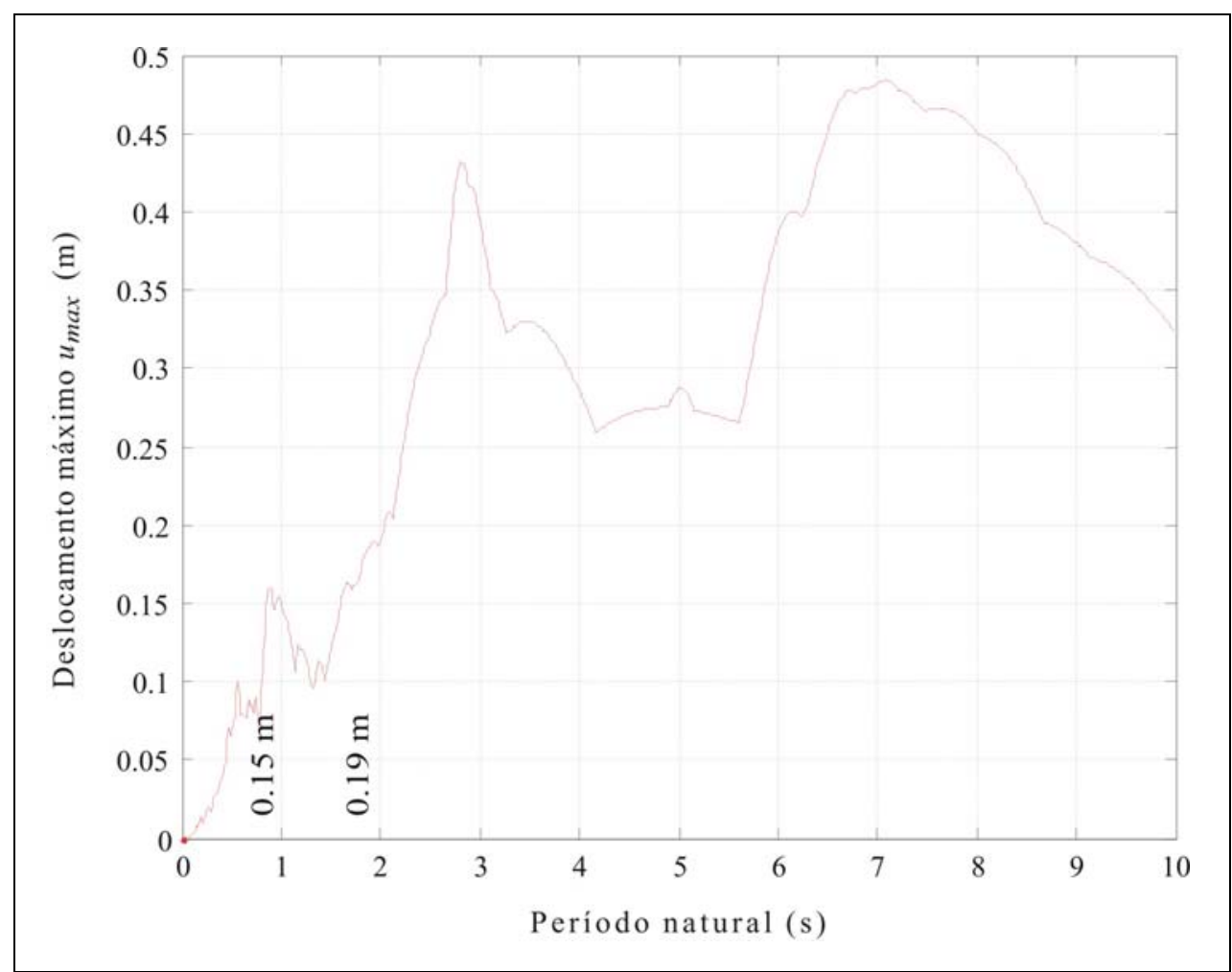

Figura 2.4 - Espectro de resposta do deslocamento para taxa de amortecimento $\xi 2 \%$ do terremoto de El Centro, 1940.

Conforme descrito em Buchholdt (1999), dado o deslocamento máximo $u_{\max }$, pode-se obter a aceleração máxima, pois:

$$
u_{\max }=S_{u}=\bar{\omega} S_{\dot{u}}=\bar{\omega}^{2} S_{\ddot{u}}
$$

onde, $S_{u}$ representa o espectro de resposta do deslocamento, $S_{\dot{u}}$, o espectro de resposta da velocidade e, finalmente, $S_{\ddot{u}}$, o espectro de resposta da aceleração.

O espectro de resposta elástico ou espectro de projeto é o gráfico da aceleração máxima do sistema ao longo da variação da freqüência $f$, em $\mathrm{Hz}$, ou da variação do período da estrutura $\bar{T}$, em $s$, visto que $f=\frac{1}{\bar{T}}$. O espectro de resposta provém de medidas significativas da intensidade do terremoto, pois indica os picos de acelerações. 


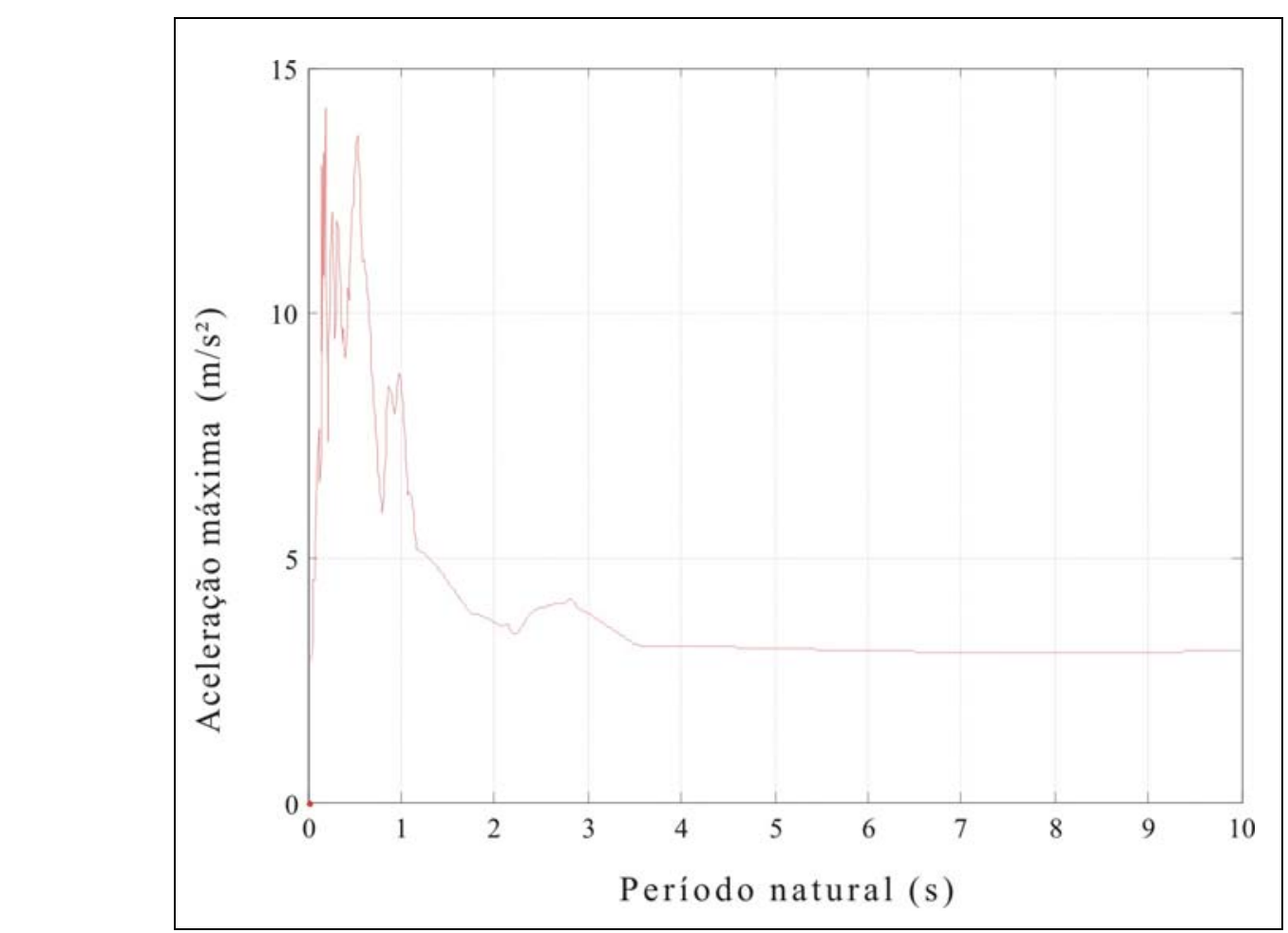

Figura 2.5 - Espectro de aceleração da resposta para taxa de amortecimento $\xi 2 \%$ do terremoto de El Centro, 1940.

Na Figura 2.5 é apresentado o gráfico do espectro de resposta da aceleração para o terremoto El Centro (1940). Nesse espectro é ilustrado como uma estrutura real com determinado período de vibração e amortecimento responderia a esse movimento do solo para um comportamento elástico (acelerograma). Conforme citado em Clough (1975), a limitação nessa aplicação é que a resposta é assumida elástica linear.

Assim, o espectro de resposta não pode definir a dimensão de danos esperados em um terremoto real, visto que estes envolvem deformações plásticas. Apenas pode-se obter a intensidade do movimento do solo.

Os espectros de projeto, também chamados de espectros de resposta elástica são sugeridos em normas para a análise dinâmica com o comportamento elástico de uma estrutura: por exemplo, CFE (1993), COVENIN 1756 (2001), Farinha et al. (2003), IBCO (1988) e NSR-98 (1997). 


\section{COMPORTAMENTO ELASTO-PLÁSTICO DO AÇO ESTRUTURAL}

O comportamento elasto-plástico do material sob a ação de sismos foi adotado neste trabalho, pois, segundo Clough (1975), as deformações plásticas da estrutura são um fator predominante para dissipação da energia desenvolvida nesse fenômeno. Aponta-se também que essa consideração é feita em códigos e normas internacionais de sismos, que empiricamente consideram esse efeito.

Primeiramente, na seção 3.1 descreve-se o comportamento elasto-plástico do material e na seção 3.2 é apresentada a hipótese de rótulas plásticas utilizada para simular esse comportamento.

\subsection{COMPORTAMENTO ELASTO-PLÁSTICO}

De acordo com Balendra (1993), o aço é um dos mais importantes materiais para uso em estruturas. Suas propriedades são a alta resistência e a ductilidade, que é a capacidade de se deformar substancialmente antes da ruptura.

Essa habilidade do aço estrutural se deformar plasticamente é ilustrada na Figura 3.1, apresentada em Chen e Sohal (1995). Observa-se que após atingir o limite elástico, ocorrem alongamentos quinze vezes maiores que a deformação $\varepsilon$ limite elástica. De um modo geral, o colapso da estrutura só ocorre após o escoamento de várias seções, para carregamentos superiores aos que causam o primeiro desses eventos. Assim, essas estruturas têm uma resistência de reserva devido ao reajuste do comportamento estrutural e conseqüente redistribuição dos esforços internos. 


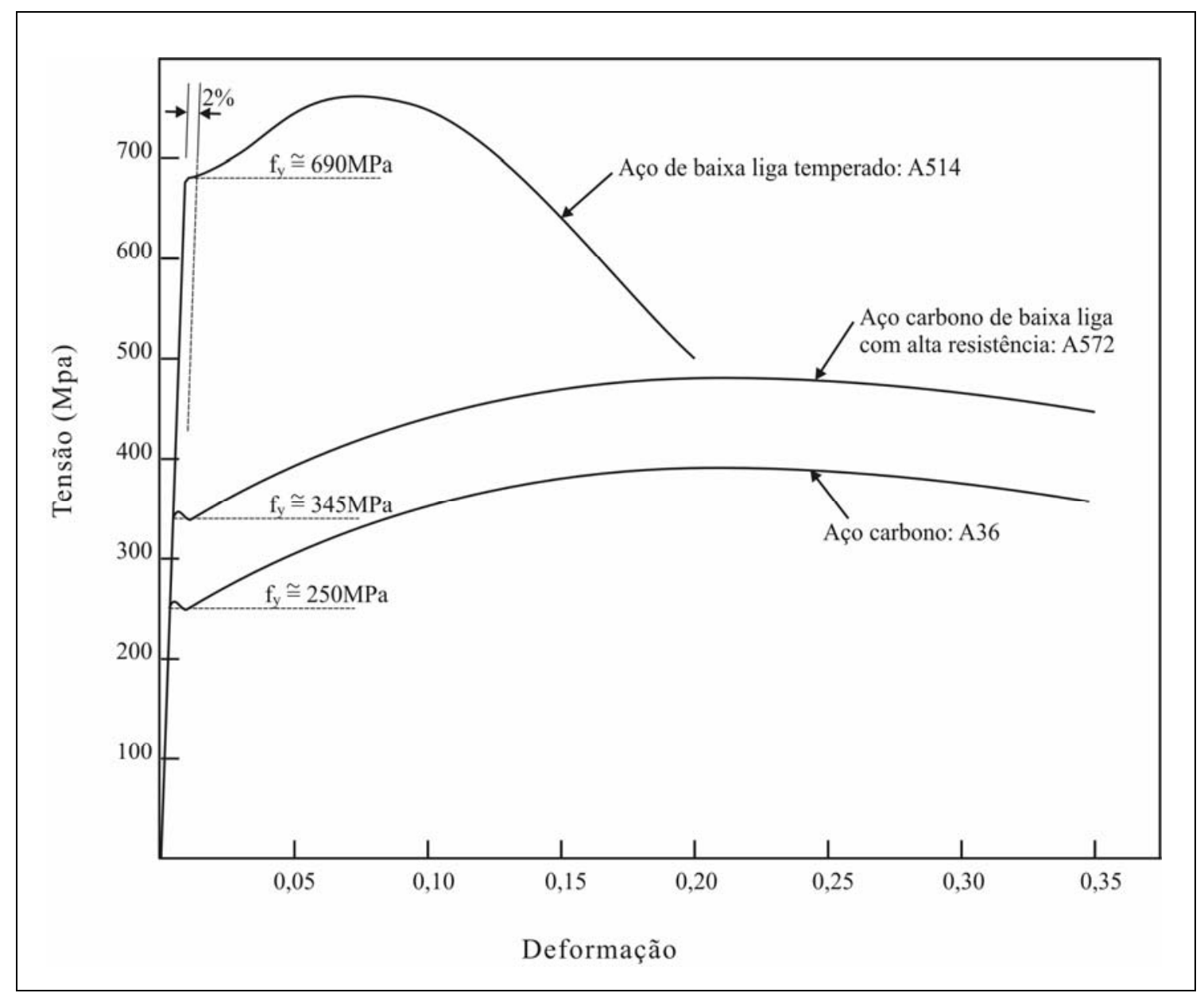

Figura 3.1 - Curva tensão-deformação do aço

Por simplicidade, a curva tensão-deformação do aço pode ser idealizada por duas retas como mostra a Figura 3.2. Até atingir a tensão de escoamento $f_{y}$, o material é elástico. Depois da tensão de escoamento ser alcançada, podem ocorrer acréscimos de deformações enquanto a tensão $\sigma$ permanece constante. Esse é o modelo físico do comportamento elastoplástico perfeito de um material.

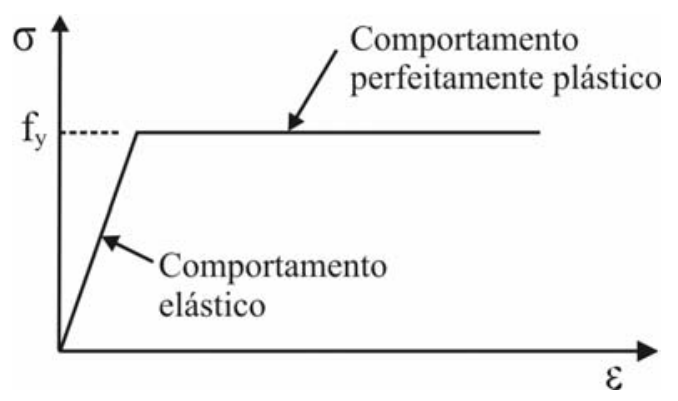

Figura 3.2 - Relação tensão-deformação do aço para o modelo elasto-plástico idealizado 
Outra característica importante é que, após se atingir a tensão de escoamento do material, a ocorrência de um decréscimo de solicitações faz retornar o comportamento elástico, permanecendo, todavia, uma deformação residual. Indica-se esse comportamento na Figura 3.3.

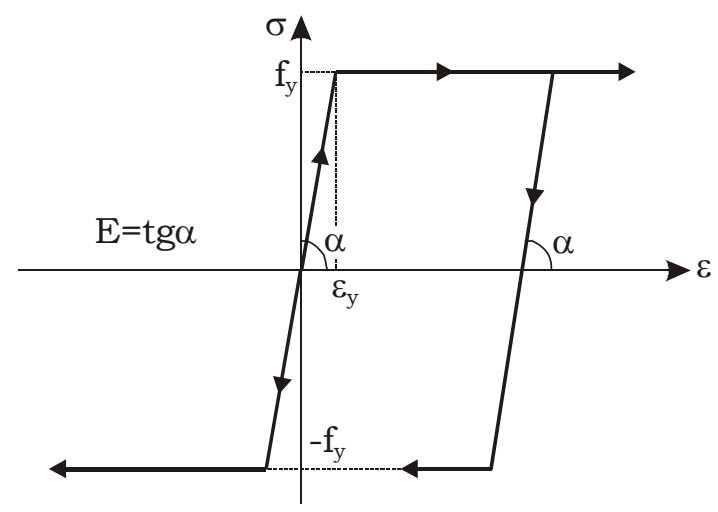

Figura 3.3 - Tensões variáveis para o comportamento do material elasto-plástico ideal.

No caso da solicitação de flexão de um perfil metálico, pode-se visualizar na Figura 3.4 as tensões que surgem nas fibras da seção transversal à medida que cresce o momento fletor. Nesse processo, indica-se inicialmente o comportamento elástico. Segue-se o acréscimo de momento, resultando no acréscimo de tensões. Assim, atinge-se, nas fibras extremas, a tensão de escoamento dessa peça. Conforme se adiciona mais momento, expandese essa tensão para as fibras mais internas. No momento limite de plastificação $M_{p l}$, todas as fibras estarão com tensão igual à tensão de escoamento.
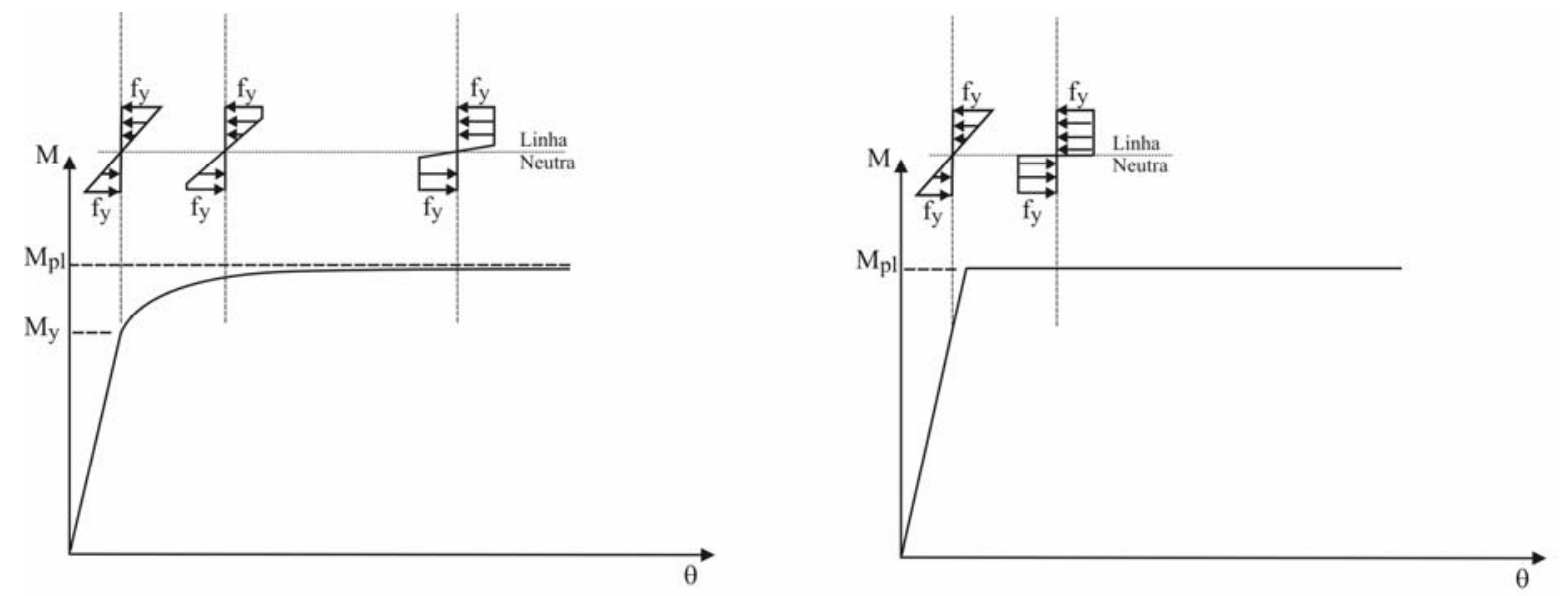

Figura 3.4 - Estado de tensão e deformação de uma seção tranversal. 


\subsection{RÓTULAS PLÁSTICAS}

Como descrito por Neal (1956), quando certa seção transversal da estrutura atinge a plastificação total devido à flexão, essa passa a se comportar como uma rótula. Pode-se adicionar mais rotação, sem a alteração do momento inicial, que se torna constante, pois essa seção não consegue mais absorver energia. Esse tipo de rótula é chamado de rótula plástica.

O momento fletor aplicado na rótula é o momento de plastificação da seção. Uma hipótese da teoria de rótulas plásticas é que esse momento mantenha-se constante e igual para toda a fase de plastificação, possibilitando a ocorrência de rotações com qualquer magnitude.

Quando uma rótula é formada, seu sentido de rotação coincide com o sentido do momento de plastificação da seção. Se o sentido da rotação é invertida, o comportamento elástico retorna à seção.

De acordo com Baker e Heyman (1969), o valor do momento de plastificação pode ser calculado como uma função da tensão de escoamento e a forma e dimensão da seção transversal.

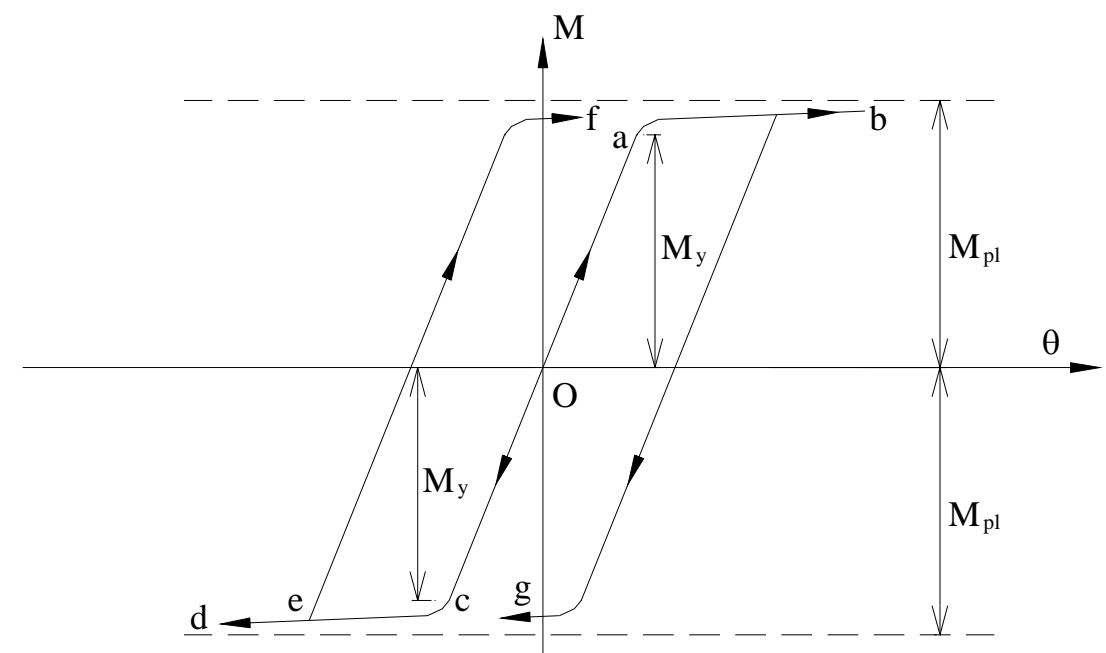

Figura 3.5 - Relação momento/ curvatura

A Figura 3.5. mostra o comportamento de um material elasto-plástico. Conforme descrito por Lazanha (2003), a posição O representa uma barra descarregada. Se for aplicado 
um momento fletor positivo, a curvatura cresce linearmente, percorrendo o trecho Oa. Esse trecho é um intervalo elástico.

Caso o momento fletor atinja o valor de $M_{y}$ (inicial de escoamento da fibra mais distante do eixo), a curvatura crescerá rapidamente, tendendo ao infinito ao se aproximar de um valor limite do momento. Esse valor é chamado momento de plastificação total, $M_{p l}$. A tensão produzida por esse momento é igual à tensão de escoamento do material, dessa forma o trecho ab é um trecho de comportamento plástico.

De modo semelhante se comporta a barra quando aplicado um momento fletor negativo, todavia o trecho agora em questão seria o Oc, partindo de um elemento descarregado, esse também seria um trecho elástico e o trecho plástico seria cd.

Outro caso a descrever é a aplicação de um momento crescente após a aplicação de um momento negativo que tenha ultrapassado o valor de $M_{y}$. A curva Oce representa o carregamento inicial. Quando o momento passa a crescer a partir do ponto e, a curva começa a se comportar na direção ef, paralela ao trecho ab, com uma deformação plástica permanente associada. O mesmo comportamento ocorreria para um momento inicial positivo maior que $M_{y}$ seguido por um momento decrescente. 


\section{ANÁLISE DINÂMICA ALEATÓRIA DE ESTRUTURAS SOB EFEITO DE SISMOS}

O modelo de cálculo para uma análise dinâmica aleatória de estruturas com comportamento elástico é bem conhecido e normalizado nos diversos códigos nacionais. Já para estruturas com não-linearidade física e/ou geométrica, a consideração de ações aleatórias ainda é um assunto em aberto. Nos próximos itens será descrita a metodologia que se adota neste trabalho.

\subsection{GENERALIDADES}

O grande desafio deste trabalho é obter um acelerograma artificial que simule adequadamente um terremoto real para aplicação a uma estrutura com comportamento não linear.

\subsubsection{O MÉTODO DO VENTO SINTÉTICO}

A semelhança existente entre a metodologia para se simular ações devidas ao vento e devidas a sismos favorece a migração de técnicas utilizadas em um caso para outro. No entanto, algumas adaptações devem ser feitas. Neste capitulo, far-se-á uma breve apresentação do método "Vento Sintético", proposto por Franco (1993) para análise dinâmica das estruturas de comportamento linear sob carregamento aleatório do vento e suas adaptações para ser aplicado em carregamentos sísmicos. 
$\mathrm{Na}$ Figura 4.1, apresenta-se as seqüências típicas de análise de estruturas sob a ação de vento e a ação de terremoto. Tem-se como base tabela em Gould e Abu-Sitta (1980).

\section{PROJETO PARA RESPOSTA DEVIDO A VENTO}

Condições Meteorológicas (Velocidade do vento, direção, turbulência)

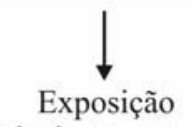

(Rugosidade do terreno, topografia, obstruções locais)

HISTÓRICO DO TEMPO DA VELOCIDADE DO VENTO $(\mathrm{z}, \mathrm{V}(\mathrm{t}))$

Estrutura: propriedades aerodinâmicas (geometria: altura, largura e profundidade)

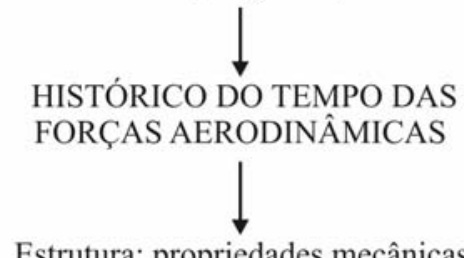

Estrutura: propriedades mecânicas

(Rigidez, massa, amortecimento)

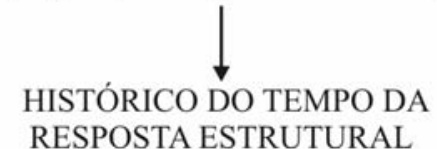

Tensão, deslocamento, aceleração e pressão

CRITÉRIO DE PROJETO

\section{PROJETO PARA RESPOSTA DEVIDO AO TERREMOTO}

Zona (sismicidade, energia liberada, freqüência de ocorrência)

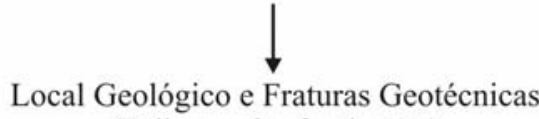

(Falhas, solo, fundações)

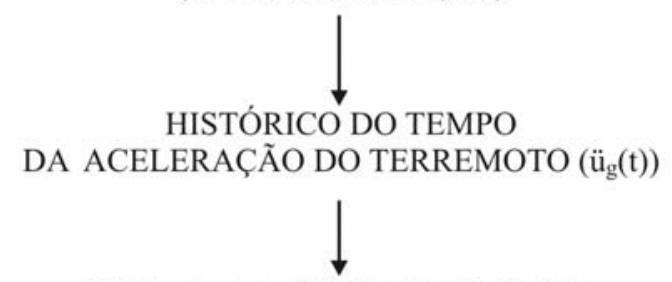

Estrutura: propriedades aerodinâmicas (geometria: altura, largura e profundidade)

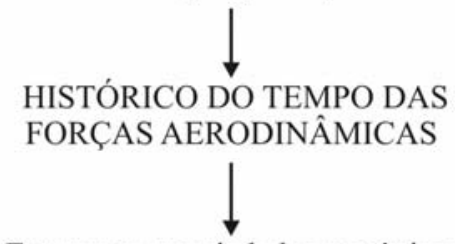

Estrutura: propriedades mecânicas (Rigidez, massa, amortecimento)
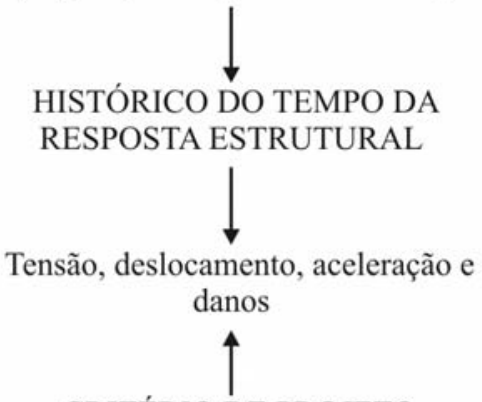

Figura 4.1 - Procedimento para determinação das solicitações devidas à ação de vento e terremoto.

No procedimento original, divide-se a ação do vento em dada direção numa parcela flutuante e uma parcela média. De acordo com o método proposto, a parcela média é aplicada estaticamente à estrutura e a parcela flutuante é dividida em séries de componentes harmônicas com ângulos de fase aleatórios. 
Para a parcela flutuante, utilizam-se 11 componentes harmônicas com uma delas em ressonância com a freqüência fundamental da estrutura. As freqüências das outras componentes são definidas como múltiplos ou submúltiplos dessa freqüência ressonante pelo fator 2. Numa versão melhorada, faz-se esse fator igual à razão entre as freqüências naturais do primeiro e do segundo modos, estabelecendo-se assim funções ressonantes com esses modos fundamentais da estrutura. A amplitude de cada uma das componentes harmônicas é obtida a partir da Função de Densidade Espectral de Potência da velocidade do vento. Pode-se consultar as aplicações desse processo em Carril Júnior (2000), Lazanha (2003) e Leite (1999).

Em uma adaptação para terremotos, de acordo com o capítulo 2, o carregamento estocástico equivalente a essa ação é proporcional às acelerações do solo. Outro fator muito importante que deve ser estudado é a faixa de freqüência importante para essa ação, e a duração do fenômeno. Nesse último aspecto, Gould e Abu-Sitta (1980) sugerem uma duração de tempo entre 15 e 50 segundos.

\subsubsection{APLICAÇÃO DA ANÁLISE DE FOURIER}

Seguindo um procedimento semelhante ao de Franco (1993), a função aceleração do solo $\ddot{u}_{g}(t)$ pode ser representada como uma integral de Fourier:

$$
\ddot{u}_{g}(t)=\int_{-\infty}^{\infty} C(\omega) \cos [\omega t-\theta(\omega)] d \omega
$$

onde, $C(\omega)$ representa a amplitude associada à freqüência natural circular da excitação de suporte $\omega$, em rad/s. A variável $t$ indica o tempo, em $s$, e $\theta(\omega)$ é o ângulo de fase associado a freqüência, em rad.

Com,

$$
\begin{aligned}
& C(\omega)=\sqrt{A^{2}(\omega)+B^{2}(\omega),} \\
& \theta(\omega)=\tan ^{-1} \frac{B(\omega)}{A(\omega)},
\end{aligned}
$$

onde $A(\omega)$ e $B(\omega)$ são os coeficientes de Fourier, definidos como, 


$$
\begin{aligned}
& A(\omega)=\int_{-\infty}^{\infty} \ddot{u}_{g}(t) \cos (\omega t) d t \\
& B(\omega)=\int_{-\infty}^{\infty} \ddot{u}_{g}(t) \operatorname{sen}(\omega t) d t
\end{aligned}
$$

Em vez de usar um número infinito de funções, $\ddot{u}_{g}(t)$ pode ser aproximado por uma superposição de um número finito $m$ de funções harmônicas. Convenientemente, trabalha-se dentro de uma faixa de freqüências do espectro adotado que realmente contenha as contribuições importantes da excitação e da estrutura.

Então,

$$
\ddot{u}_{g}(t)=\sum_{k=1}^{m} C_{k} \cos \left(\frac{\omega_{r}}{r_{k}} t-\theta_{k}\right)
$$

onde, $C_{k}$ é a amplitude associada ao harmônico $k, \omega_{r}$ é a freqüência natural da excitação ressonante com a freqüência da estrutura, $\theta_{k}$ representa o ângulo de fase associado ao harmônico $k$ e $r_{k}$, o fator que gera as freqüências múltiplas ou submúltiplas da freqüência ressonante através do fator 2 associado ao harmônico $k$. Numa versão melhorada, deve-se determinar a razão entre o primeiro modo de vibração e o segundo, gerando-se assim funções harmônicas com freqüências ressonantes com esses modos da estrutura.

A amplitude $C_{k}$ é dada por:

$$
C_{k}=\sqrt{2 \int_{(k)} S_{\ddot{u} g}(\omega) d \omega}
$$

e, $r_{k}$ para a versão original é:

$$
r_{k}=2^{k-r}
$$

e para a versão melhorada:

$$
r_{k}=\ln \sqrt{\frac{\omega_{1}}{\omega_{2}}}
$$

onde, $\omega_{1}$ representa a freqüência natural do primeiro modo de vibração da estrutura e $\omega_{2}$, freqüência natural do segundo modo de vibração da estrutura.

Os valores $C_{k}$ são calculados com integração da Função Densidade Espectral de Potência (PSDF) na faixa de freqüência do harmônico $k(d \omega)$.

Os ângulos de fase se mantêm indeterminados e as componentes harmônicas são superpostas com combinações aleatórias desses ângulos. 
O proposto por Franco (1993), para o caso do vento, são onze funções harmônicas, tal que uma delas esteja com a freqüência ressonante com a do primeiro modo de vibração da estrutura ( $r$. Entretanto, para o caso de terremotos, ainda deve-se estudar um número adequado de funções harmônicas.

\subsubsection{FUNÇÃO DE AUTOCORRELAÇÃo E FUNÇÃo DE DENSIDADE ESPECTRAL DE POTÊNCIA}

A Função de Densidade Espectral de Potência (PSDF), de acordo com Blessman (1998), indica a distribuição da energia contida num fenômeno em diversas freqüências. Admitindo-se que o sinal fornecido por sismos constitua de uma função não-periódica complexa, pelo teorema de Fourier essa função pode ser encarada como uma superposição de funções harmônicas simples, como descrito em Newland (1975).

Pode-se calcular a potência elementar $d W$, associada ao intervalo elementar de freqüência $d \omega$, com a expressão:

$$
d W=S_{\ddot{i} g}(\omega) d \omega .
$$

A função $S_{u i g}(\omega)$ é conhecida como Função Densidade Espectral de Potência da aceleração e é, conforme a conhecida relação de Wiener-Khintchine, apresentada em Blessman (op. cit.) e em Newland (op. cit.), relacionada com a Transformada de Fourier da função de autocorrelação do processo.

$$
S_{\text {ïg }}(\omega)=\frac{1}{2 \pi} \int_{-\infty}^{+\infty} R_{\ddot{i u g}}(\tau) e^{-i \omega \tau} d \tau
$$

onde $R_{\text {üg }}(\tau)$ é a função de autocorrelação da aceleração do solo. Conforme Blessman (op. cit.) explica, a função de autocorrelação descreve a dependência geral entre o valor do fenômeno em um instante de tempo $t$ e em outro instante, $t+\tau$, na forma:

$$
R_{\ddot{u} g}(\tau)=\int_{-\infty}^{+\infty} \ddot{u}_{g}(t) \ddot{u}_{g}(t+\tau) d t .
$$

Várias funções empíricas são propostas para aproximar o espectro requerido como uma função da freqüência $\omega$. Na prática, a integral indicada em eq. (4.12) é muito difícil de ser obtida em forma fechada, assim obtém-se numericamente os coeficientes das partes reais e 
imaginárias dessa Transformada de Fourier complexa, via o algoritmo Transformada discreta de Fourier (DFT), respectivamente:

$$
\begin{array}{r}
A_{k}=\frac{1}{N} \sum_{r=0}^{N-1} R_{r}\left(\cos \frac{2 \pi k}{N} r\right) \\
B_{k}=\frac{1}{N} \sum_{r=0}^{N-1} R_{r}\left(\operatorname{sen} \frac{2 \pi k}{N} r\right),
\end{array}
$$

onde, $R_{r}$ é cada um dos $N$ valores discretos da função autocorrelação computada. $\mathrm{O}$ valor absoluto (ou módulo) de cada coeficiente da Transformada complexa discreta é:

$$
S_{k}=2 \sqrt{A_{k}^{2}+B_{k}^{2}}
$$

\subsubsection{MODELOS SEMI-EMPÍRICOS PARA SISMOS}

Os espectros de acelerações dependem da natureza do movimento do terremoto e podem ser bastante diferentes de um caso para outro. Assim, as dificuldades para a escolha de um espectro padrão são óbvias.

Os Espectros de Resposta (elástica), apresentados no Capítulo 2 só podem ser aplicados para estruturas de comportamento linear. Conforme já abordado, obtém-se a aceleração de resposta a um terremoto modelo (o de El Centro, por exemplo) de um sistema linear massa-mola-amortecedor cuja freqüência natural varia ao longo da faixa de freqüências de excitação de interesse.

No caso de sistemas não-lineares é necessário utilizar um processo de integração numérica passo-a-passo no tempo. O carregamento a considerar é obtido pelo produto das massas suspensas e aceleração da base. Históricos no tempo dessa aceleração devem ser sintetizados a partir de espectros de potência de projeto.

PSDF ou espectros de potência para sismos são construídos plotando em ordenadas valores de $\ddot{u}_{g}^{2} / \omega$ (aceleração do solo ao quadrado por freqüência circular) e $\omega$ (freqüência circular, em rad/s) nas abscissas. Tais espectros tendem a ter muitos picos e requerem ajustes para fins de projeto. Eles são, em geral, resultantes de médias de vários terremotos normalizados para a mesma aceleração de pico e sofrem um processo de ajuste de curvas. 
A idealização mais simples de uma PSDF de sismos é o ruído branco ideal

$$
S_{\text {ïg }}(\omega)=S_{0}, \quad 0<\omega<\infty .
$$

Essa descrição é, entretanto, pouco razoável, por corresponder a potência infinita. Uma forma mais realista, que será utilizada neste trabalho, é o modelo de ruído branco filtrado da formulação que se segue, atribuída a Kanai (1957) e a Tajimi (1960), conhecido como modelo de Kanai-Tajimi.

Nesse modelo, o movimento do solo é visto como a resposta em aceleração absoluta de um sistema de um grau de liberdade sujeito a uma aceleração de base de um espectro tipo ruído branco ideal. Supõe-se que esse oscilador modele os extratos de solo sobre a rocha. A formulação para o modelo Kanai-Tajimi é encontrada em Buchholdt (1999) e em Gould e Abu-Sitta (1980), com algumas variações de parâmetros.

Propõe-se em Gould e Abu-Sitta (op. cit.), conforme Tajimi (op. cit.):

$$
\frac{\bar{\omega} S_{\text {ïg }}(\omega)}{\sigma_{\text {iig }}^{2}}=\frac{4}{\pi} \frac{H}{1+4 H^{2}} \frac{r\left[1+4 H^{2} r^{2}\right]}{\left(1-r^{2}\right)^{2}+4 H^{2} r^{2}}
$$

onde, $S_{i_{g}}(\omega)$ representa a função densidade espectral de potência da aceleração do solo, em $\left[\frac{\mathrm{m}}{\mathrm{s}^{2}}\right]^{2} \mathrm{~s}, \bar{\omega}$ é freqüência natural circular de vibração da estrutura (em $\left.\mathrm{rad} / \mathrm{s}\right)$ e $\sigma_{i g}^{2}$, a variância espectral. $H$ é um fator não dimensional relacionado com o amortecimento do solo, em geral entre 0,6 e 0,7 , e $r$, a relação não-dimensional de freqüências, $\omega / \omega_{g} \cdot \omega_{g}$ indica a freqüência natural característica do solo (em $\mathrm{rad} / \mathrm{s})$, entre $4 \pi$ e $6 \pi$ para solos firmes,

Em Buchholdt (op. cit.), conforme Kanai (op. cit.), tem-se a expressão:

$$
S_{\text {üg }}(\omega)=S_{0} \frac{\left[1+4 H^{2} r^{2}\right]}{\left(1-r^{2}\right)^{2}+4 H^{2} r^{2}}
$$

novamente, $S_{0}$ é utilizado como ruído branco ideal $\left[\frac{m}{s^{2}}\right]^{2} s$.

O modelo Kanai-Tajimi é utilizado em muitos trabalhos que procuram estimar acelerogramas artificiais de terremoto. Em Clough (1975) há uma sugestão para gerar acelerogramas compatíveis com o espectro de resposta, onde o modelo também é aplicado, contudo há alterações em sua expressão.

Essa expressão dada por Buchholdt (op. cit.) aparece em Joint Committee on Structural Safety (2001), porém a expressão para o ruído branco ideal já apresenta diferenças. Em Rofooei; Mobarake e Ahmadi (2001), comenta-se sobre as dificuldades na estimativa da 
intensidade de $\mathrm{S}_{0}$ e explica-se que na prática esse parâmetro precisa de registros locais de terremotos anteriores e perfil geológico do solo.

A proposta neste trabalho é, com base na formulação descrita acima, utilizar o seguinte espectro reduzido:

$$
S_{r \ddot{z}_{g}}(\omega)=\frac{\omega S_{i_{g}}(\omega)}{R^{2}}=\frac{H r}{1+4 H^{2}} \frac{1+4 H^{2} r^{2}}{\left(1-r^{2}\right)^{2}+4 H^{2} r^{2}}
$$

$R$ é uma constante, com dimensões de aceleração, dada pelo ajuste do acelerograma obtido pelo processo aos espectros de resposta elásticos preconizados em normas. Faz-se esse ajuste para o trecho elástico das estruturas modeladas, obtendo-se resultados compatíveis, de forma semelhante ao procedimento sugerido em COVENIN 1756 (2001), explicado no Capítulo 2.

$\mathrm{Na}$ Figura 4.2, ilustra-se a curva determinada por PSDF reduzida para um fator não dimensional relacionado com o amortecimento do solo $(H)$ igual a 0,6 .

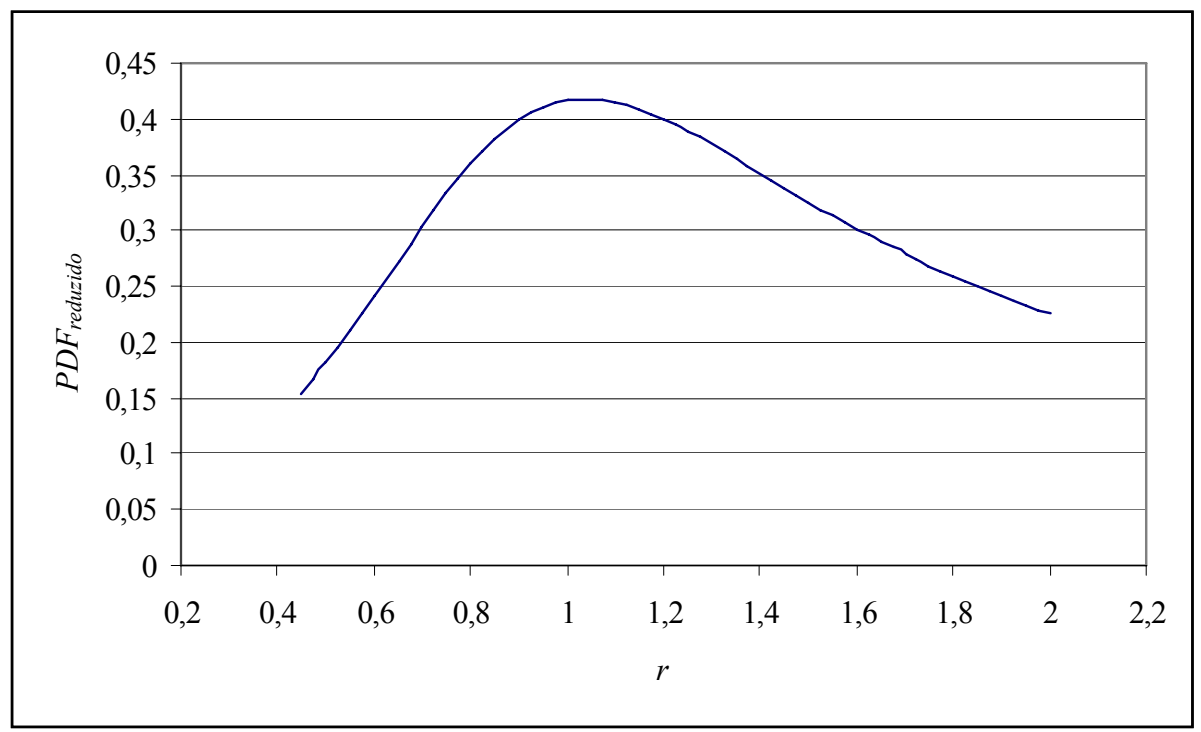

Figura 4.2 - Função de Densidade Espectral de Potência (PSDF) da aceleração do solo reduzida adotada, $H=$ 0,6 .

Adota-se a escala logarítmica para as freqüências $\omega$, assim como no processo "Vento Sintético", resultando:

$$
S_{r \ddot{u}_{g}}(\omega) d(\ln \omega)=\frac{\omega S_{\ddot{u}_{g}}(\omega)}{R^{2}} \frac{1}{\omega} d \omega=\frac{d W}{R^{2}} .
$$


A proposta neste trabalho é modelar matematicamente a excitação de suporte como uma superposição de $m$ componentes harmônicas:

$$
\ddot{u}_{g}(t)=R \sum_{k=1}^{m} C_{k} \cos \left(\omega_{k} t-\theta_{k}\right)
$$

As amplitudes adimensionais são retiradas da PSDF na forma:

$$
C_{k}=\sqrt{2 S_{r \ddot{u}_{g}}\left(\omega_{k}\right) \Delta \omega}
$$

e os ângulos de fase $\theta_{k}$ escolhidos de forma aleatória entre 0 e $2 \pi$.

Depois de estabelecido a PSDF para terremoto, pode-se realizar um estudo do número de funções harmônicas razoável para simular esse fenômeno. Dessa forma, estima-se um número qualquer de funções harmônicas com um termo ressonante, por exemplo, 20 funções harmônicas com o décimo termo em ressonância, para uma estrutura com período de 0,40 segundo. Assume um modelo massa-amortecedor-mola para um grau de liberdade, assim, os demais harmônicos possuem freqüências múltiplas ou submúltiplas da freqüência ressonante através do fator 2 .

Nessas condições, é possível determinar a amplitude do carregamento para cada harmônico $k$, conforme é ilustrado na Figura 4.3.

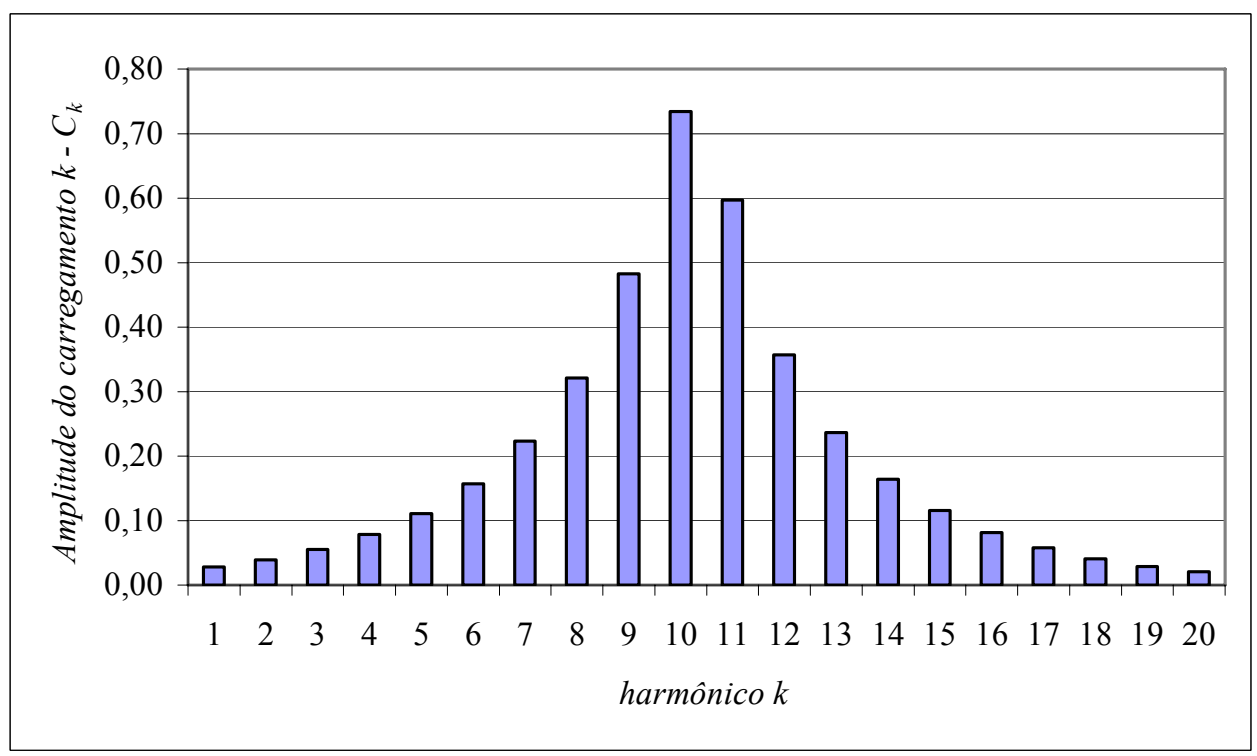

Figura 4.3 - Amplitude dos harmônicos $k$, para 20 harmônicos $\left(T_{r}=0,40 \mathrm{~s}\right)$. 
Uma pequena amplitude é apresentada para os harmônicos 1, 2, 3 e 4, assim como para os harmônicos 16,17,18, 19 e 20, conseqüentemente, a amplitude da resposta decorrente dessas funções harmônicas não expressa uma intensidade significante em comparação as demais e é possível desprezar esses harmônicos, como é apresentado na Figura 4.4.

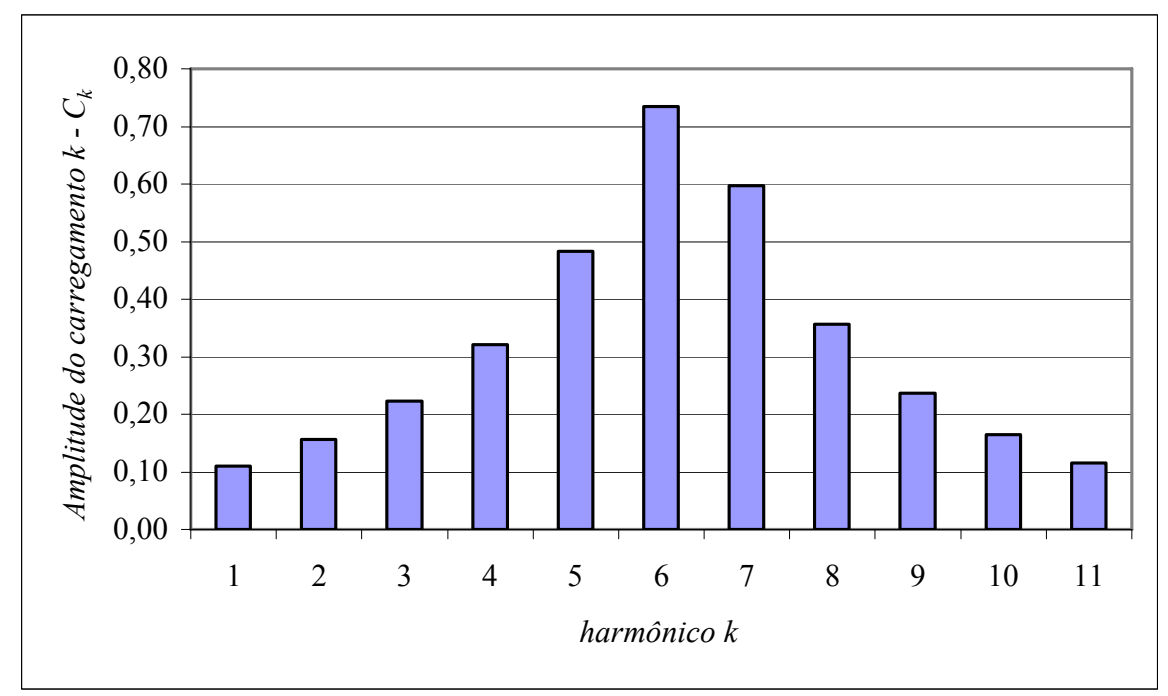

Figura 4.4 - Amplitude dos harmônicos $k$, para 11 harmônicos $\left(\mathrm{T}_{\mathrm{r}}=0,40 \mathrm{~s}\right)$.

Então, uma boa representação para um acelerograma artificial para uma estrutura com período de 0,4 segundo são pelo menos 11 funções harmônicas com a sexta função com freqüência ressonante com a da estrutura.

Analogamente, deve-se realizar esse estudo para outros valores de períodos fundamentais de estruturas. Para esse fim, com base em Gould e Abu-Sitta (1980), utiliza-se uma faixa de período entre $0,2(5 \mathrm{~Hz})$ a 1 segundo $(1 \mathrm{~Hz})$, pois a faixa de freqüência dos terremotos registrados está entre 1 e $5 \mathrm{~Hz}$, como é ilustrado na Figura 4.5 (FAGEL e LIU apud GOULD e ABU-SITTA, op. cit.). 


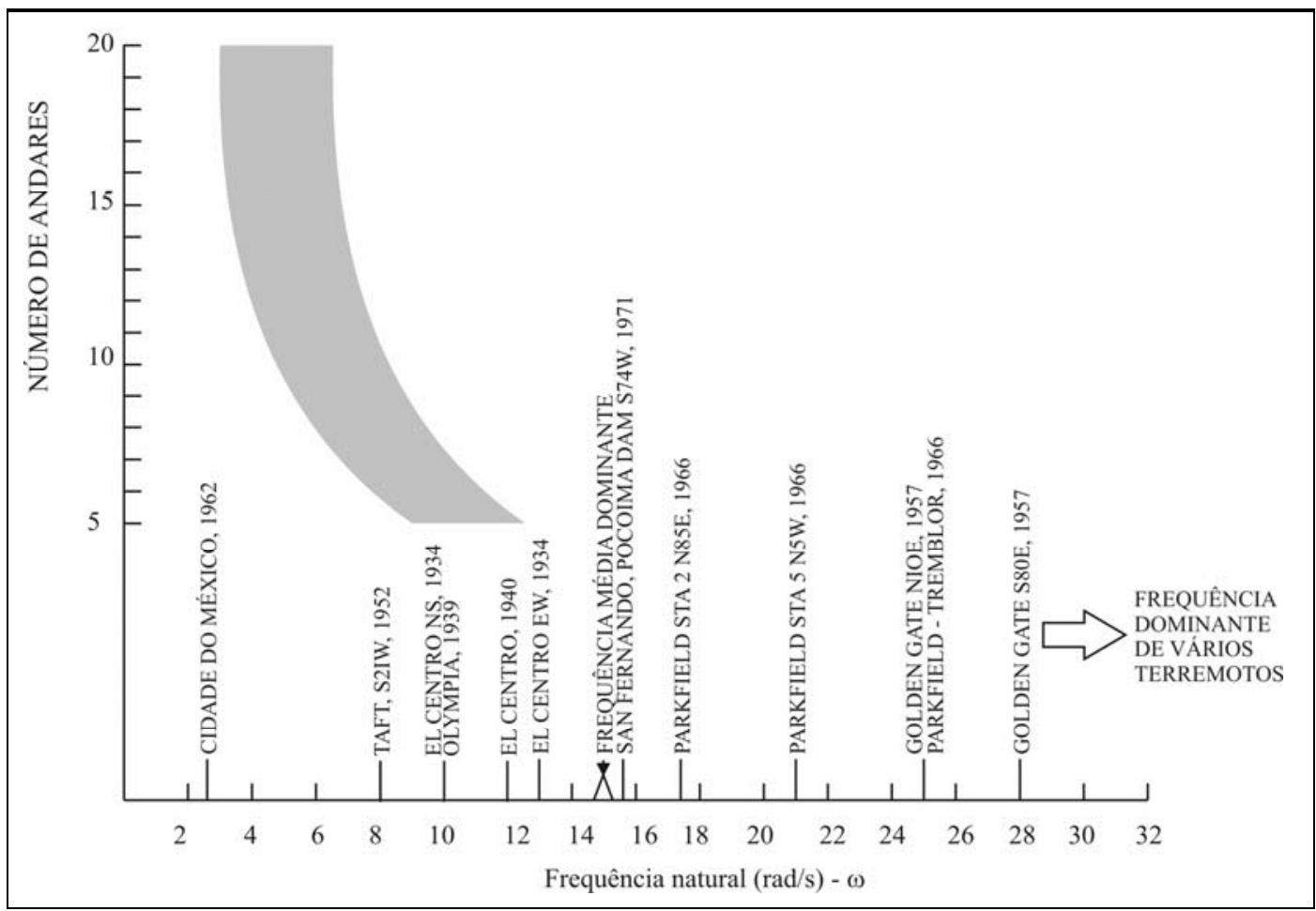

Figura 4.5 - Freqüência ressonante de estruturas e terremotos. Uma freqüência fundamental típica de prédios com múltiplos andares e freqüências dominantes de terremotos (FAGEL e LIU apud GOULD e ABU-SITTA, 1980).

De posse desses dados, para períodos entre 0,2 e 1 segundo, determina-se o número de funções harmônicas mínimo e a melhor posição do termo ressonante. Os resultados finais são apresentados na Tabela 4.1, a fim de se estabelecer um padrão de número de funções interessantes para gerar o acelerograma e o termo mais adequado de freqüência ressonante a freqüência da estrutura.

Tabela 4.1 - Tabela para relacionar período ressonante, termo ressonante e número de funções.

\begin{tabular}{|c|c|c|c|}
\hline$T_{r}(\mathrm{~s})$ & $r$ & $m$ & $f_{r}(\mathrm{~Hz})$ \\
\hline \hline 0,2 & 5 & 11 & 5,00 \\
\hline 0,3 & 6 & 11 & 3,33 \\
\hline 0,4 & 6 & 11 & 2,50 \\
\hline 0,5 & 6 & 11 & 2,00 \\
\hline 0,6 & 7 & 11 & 1,67 \\
\hline 0,7 & 7 & 11 & 1,43 \\
\hline 0,8 & 7 & 11 & 1,25 \\
\hline 0,9 & 7 & 11 & 1,11 \\
\hline 1,0 & 7 & 11 & 1,00 \\
\hline
\end{tabular}


Resumidamente, para uma boa simulação do acelerograma de um terremoto, deve-se utilizar o mesmo número de funções harmônicas sugeridas no processo do "Vento Sintético", entretanto, a função harmônica com a freqüência ressonante parece ser a sexta ou a sétima.

\subsection{FORMULAÇÃO DAS EQUAÇÕES DO MOVIMENTO}

As ações geradas durante um terremoto não são propriamente forças aplicadas diretamente na estrutura, mas sim forças de inércias que resultam dos movimentos da mesma, de acordo com Chopra (1995) e Clough (1975). Dessa forma, a aceleração do solo aparece do lado direito da equação diferencial que governa a resposta de uma estrutura à terremotos.

Na representação para vários graus de liberdade, tem-se:

$$
[M]\{\ddot{u}(t)\}+[C]\{\dot{u}(t)\}+[K]\{u(t)\}=-\ddot{u} g(t)[M]\{1\}
$$

onde, a matriz massa, a matriz amortecimento e a matriz rigidez da estrutura são, respectivamente, $[M],[C]$ e $[K] . \mathrm{E}\{u(t)\}$ representa o vetor deslocamento da estrutura, $\{\dot{u}(t)\}$ é o vetor velocidade da estrutura e $\{\ddot{u}(t)\}$, o vetor aceleração da estrutura, tal que todos

os vetores estão associados ao instante de tempo $t . \ddot{u}_{g}(t)$ é a aceleração do solo e para o instante $t$ é dada por um número escalar. $\{1\}$ representa o vetor unitário.

Na Figura 4.6 pode-se visualizar o modelo shear building que será adotado neste trabalho para análise de edifícios metálicos com múltiplos andares. Observa-se a numeração adotada e as características necessárias da estrutura para a formulação desse problema. 


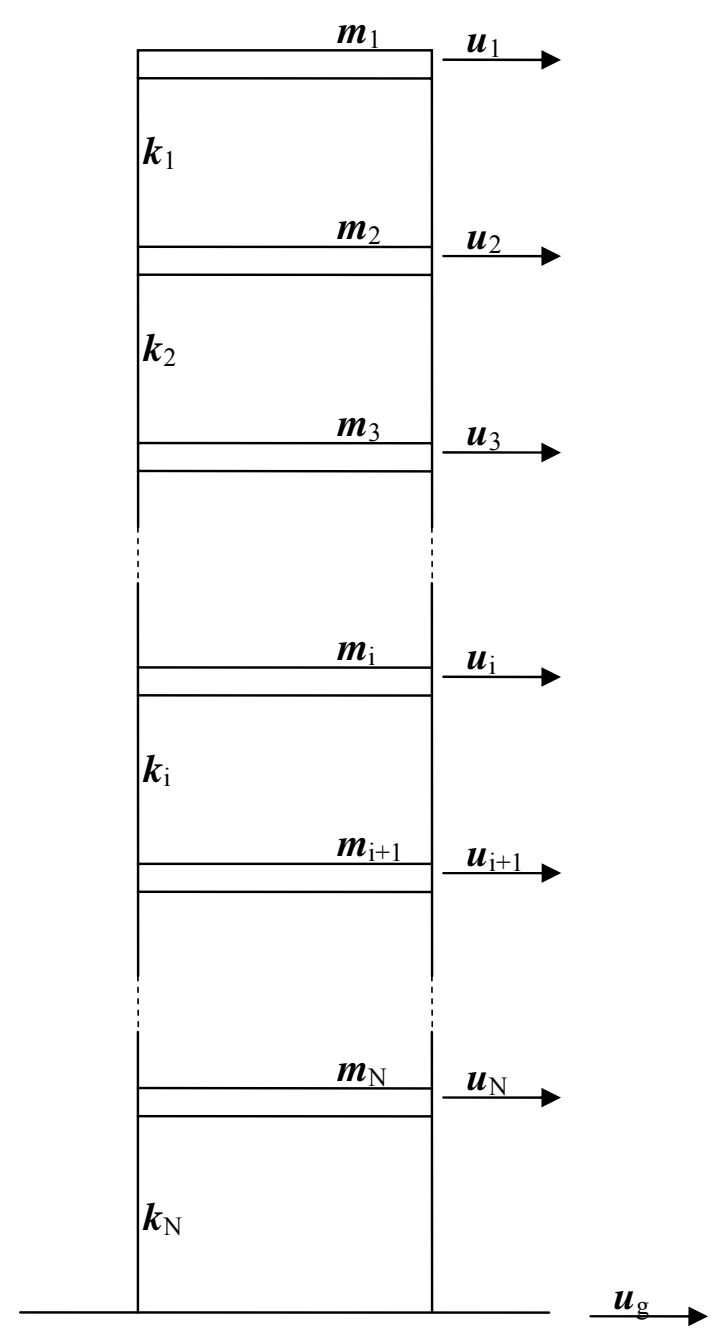

Figura 4.6 - Modelo shear building: sistema estrutural e direção dos deslocamentos considerados.

\subsubsection{MATRIZ DE MASSA}

Será adotado um modelo de lumped mass para definir a matriz de massa, conforme apresentado em Clough (1975). Para esse modelo admite-se que a massa total se concentra nos pontos em que os deslocamentos transversais são definidos. Dessa forma a matriz $[M]$ será diagonal, na forma: 


$$
[M]=\left[\begin{array}{ccccccc}
m_{1} & 0 & 0 & \ldots & 0 & \ldots & 0 \\
0 & m_{2} & 0 & \ldots & 0 & \ldots & 0 \\
0 & 0 & m_{3} & \ldots & 0 & \ldots & 0 \\
\ldots & \ldots & \ldots & \ldots & \ldots & \ldots & \ldots \\
0 & 0 & 0 & \ldots & m_{i} & \ldots & 0 \\
\ldots & \ldots & \ldots & \ldots & \ldots & \ldots & \ldots \\
0 & 0 & 0 & \ldots & 0 & \ldots & m_{N}
\end{array}\right]
$$

\subsubsection{MATRIZ DE RIGIDEZ}

O modelo adotado nas colunas é também descrito em Clough (1975) em que se admite uma rigidez alta nas lajes, assim o apoio das colunas nas lajes será equivalente a um engastamento. Para um comportamento elástico, pode-se dizer que a rigidez $\left(k_{i}\right)$, que representa a rigidez para o trecho total das colunas entre duas lajes, é dada pela expressão:

$$
k_{i}=\frac{12 E I_{i}}{\ell_{i}^{3}}
$$

onde, $E$ representa o módulo de Elasticidade do material, que para caso do material aço, segundo a ABNT - NBR 8800 (1988), o valor sugerido é 205000MPa. $I_{i}$ é a somatória dos momentos de inércia dos perfis metálicos das colunas para cada pavimento e, finalmente, $\ell_{i}$ indica o comprimento da coluna, determinado pela distância entre a laje inferior e a laje superior (pé direito), também de acordo com cada pavimento.

Quando se forma uma rótula plástica em um nó $i$, conforme descrito no capítulo 2, a rigidez é assumida como nula $\left(k_{i}=0\right)$.

Genericamente, a matriz rigidez, que representará todo o edifício, terá a seguinte forma: 


$$
[K]=\left[\begin{array}{ccccccccc}
k_{1} & -k_{1} & 0 & 0 & 0 & 0 & \ldots & 0 & 0 \\
-k_{1} & k_{1}+k_{2} & -k_{2} & 0 & 0 & 0 & \ldots & 0 & 0 \\
0 & -k_{2} & k_{2}+k_{3} & -k_{3} & 0 & 0 & \ldots & 0 & 0 \\
\ldots & \ldots & \ldots & \ldots & \ldots & \ldots & \ldots & \ldots & \ldots \\
\ldots & \ldots & \ldots & \ldots & \ldots & \ldots & \ldots & \ldots & \ldots \\
0 & 0 & 0 & \ldots & -k_{i-1} & k_{i-1}+k_{i} & -k_{i} & \ldots & 0 \\
\ldots & \ldots & \ldots & \ldots & \ldots & \ldots & \ldots & \ldots & \ldots \\
\ldots & \ldots & \ldots & \ldots & \ldots & \ldots & \ldots & \ldots & \ldots \\
0 & 0 & 0 & 0 & 0 & 0 & \ldots & -k_{N-1} & k_{N-1}+k_{N}
\end{array}\right] .
$$

\subsubsection{MATRIZ DE AMORTECIMENTO}

Para se determinar a matriz de amortecimento, será adotado o método proposto por Rayleigh, apresentado em Clough (1975). A estimativa das taxas de amortecimento relativas a um certo número de modos escolhidos, em geral os dois primeiros modos naturais de vibração da estrutura, será necessária. Para o caso de dois modos, serão, respectivamente, $\xi_{\mathrm{r}}$ e $\xi_{\mathrm{s}}$, como também proposto no trabalho de Lazanha (2003).

Estimadas essas taxas de amortecimento, a matriz de amortecimento de Rayleigh pode ser escrita como:

$$
[C]=A_{0}[M]+A_{1}[K]
$$

onde $A_{0}$ e $A_{l}$ são obtidos resolvendo-se o sistema:

$$
\frac{1}{2}\left[\begin{array}{cc}
\frac{1}{\omega_{r}} & \omega_{r} \\
\frac{1}{\omega_{s}} & \omega_{s}
\end{array}\right]\left[\begin{array}{l}
A_{0} \\
A_{1}
\end{array}\right]=\left[\begin{array}{l}
\xi_{r} \\
\xi_{s}
\end{array}\right]
$$

os valores $\omega_{r}$ e $\omega_{s}$ são as freqüências naturais circulares de vibração da estrutura para os dois modos para os quais foram arbitradas as taxas de amortecimento. 


\subsection{INTEGRAÇÃO DIRETA PASSO-A-PASSO NO TEMPO: NEWMARK}

Definida uma série de carregamento, como já foi dito, com $m$ componentes harmônicas e ângulos de fases aleatórios, a resposta estrutural é aqui obtida pelo Método de integração incremental de Newmark, como descrito em, por exemplo, Brasil (1991) e em Clough (1975). Utilizou-se aqui uma adaptação do Algoritmo de Aceleração Média de Newmark para integração numérica das equações diferenciais do movimento. Como neste caso tem-se um material não-linear, em cada passo de tempo verifica-se a possibilidade de formação de uma nova rótula plástica ou retorno ao comportamento elástico, caso já existam rótulas. Essas duas possibilidades levam à imediata correção da matriz rigidez da estrutura.

Para o início do procedimento, é necessário conhecer os valores iniciais dos deslocamentos e velocidades. Quanto às características do material da estrutura, considera-se o módulo de elasticidade constante até se atingir o momento de plastificação de certa seção. Nesse ponto, a rigidez vai a zero pela formação de uma rótula plástica, com rotação livre. Se a rotação é revertida, retorna a rigidez elástica e o deslocamento plástico é acumulado (deslocamentos residuais).

Apresenta-se, a seguir, o algoritmo numérico, para o modelo shear building (subscrito $n$ indica o passo de integração):

$$
\{u\}_{n}=\{u\}_{n-1}+\{\Delta u\}_{n-1}
$$

onde, $\{u\}$ é o vetor deslocamento da estrutura e $\{\Delta u\}_{n-1}$, o incremento dos deslocamentos relativo ao passo $n-1$.

De forma semelhante, o vetor velocidade da estrutura para o passo $n$ é:

$$
\{\dot{u}\}_{n}=\{\dot{u}\}_{n-1}+\{\Delta \dot{u}\}_{n-1}
$$

onde, $\{\Delta \dot{u}\}_{n-1}$ representa o incremento da velocidade relativo ao passo $n-1$.

O vetor força restauradora é:

$$
\left\{F_{e}\right\}_{n}=\left\{F_{e}\right\}_{n-1}+[K]_{n-1}\{\Delta u\}_{n-1}
$$

onde $K$ representa a matriz rigidez associada, conforme a seção 4.2.2.

Para o modelo shear building, a força cortante máxima computada para cada lance de pilar é comparada com a força cortante de plastificação de cada seção (determinada em função do momento de plastificação). Quando maior, a força restauradora é mantida com o valor correspondente ao momento de plastificação e a rigidez se anula. Caso contrário, a 
rigidez é mantida com o valor elástico original e a força elástica varia de acordo com os deslocamentos.

O vetor força de amortecimento é dado como:

$$
\left\{F_{a}\right\}_{n}=[C]\{\dot{u}\}_{n}
$$

onde $C$ é a matriz de amortecimento apresentada na seção 4.2.3.

Aceleração é determinada por:

$$
\{\ddot{u}\}_{n}=[M]^{-1}\left(\{P\}_{n}-\left\{F_{a}\right\}_{n}-\left\{F_{e}\right\}_{n}\right)
$$

e a rigidez efetiva de Newmark é:

$$
\left[K_{\text {efet }}\right]=[K]_{n}+\frac{3}{h}[C]+\frac{6}{h^{2}}[M]
$$

onde $h$ é passo de tempo da integração.

Nota-se que a matriz de rigidez $(K)$ pode ter o valor do elemento genérico $k_{i}$ nulo (rótula plástica) ou o valor inicial $\frac{12 E I}{\ell^{3}}$ (comportamento elástico). Conforme apresentado na seção 4.2.2.

$\mathrm{O}$ incremento do carregamento efetivo é:

$$
\left\{\Delta P_{\text {efet }}\right\}=\{P\}_{n+1}-\{P\}_{n}+[M]\left(\frac{6}{h}\{\dot{u}\}_{n}+3\{\ddot{u}\}_{n}\right)+[C]\left(3\{\dot{u}\}_{n}+\frac{h}{2}\{\ddot{u}\}_{n}\right)
$$

onde $\{P\}_{n}=-\ddot{u}_{g}(t)[M]\{1\}$ é a ação da aceleração nas massas suspensas. O instante $t$ é dado pelo produto entre $(n-1)$ e $h$.

O incremento dos deslocamentos é:

$$
\{\Delta u\}_{n}=\left[K_{\text {efet }}\right]^{-1}\left\{\Delta P_{\text {efet }}\right\} \text {. }
$$

E o incremento da velocidade é dado por:

$$
\{\Delta \dot{u}\}_{n}=\frac{3}{h}\{\Delta u\}_{n}-3\{\dot{u}\}_{n}-\frac{h}{2}\{\ddot{u}\}_{n} \text {. }
$$

A seguir, o processo é repetido até o tempo final da análise.

Quando os deslocamentos máximos para cada grau de liberdade são obtidos para o número de séries de carregamento adotado, uma análise estatística é executada considerando uma distribuição normal.

A distribuição normal é utilizada, pois o número de combinações de funções harmônicas é suficientemente grande tal que essa distribuição seja normal (Teorema do Limite Central, apresentado em HOEL; PORT e STONE, 1978). Conforme Hoel; Port e Stone (op. cit.), decidir sobre a ordem de grandeza para que seja válida a aproximação para 
essa distribuição é difícil. Comenta-se que diversos estudos executados em aplicações práticas típicas indicam que um número superior a 25 amostras é suficientemente grande para que seja válida a distribuição normal.

O valor característico máximo do deslocamento para o quantil de $5 \%$ é:

$$
u_{c \max }=1,65 \sigma+\mu
$$

onde $\sigma$ é o desvio padrão do universo analisado e $\mu$ é o valor médio dos valores máximos.

\subsection{IMPLEMENTAÇÃO DO MÉTODO}

O método implementado neste trabalho consiste:

- Dada uma estrutura, determina-se a freqüência natural para o primeiro modo de vibração.

- Determina-se 11 funções harmônicas com o sexto ou sétimo termo com freqüência ressonante a freqüência a estrutura:

- calcula-se a amplitude para cada função harmônica a partir do espectro de aceleração de Kanai-Tajimi,

- a freqüência do sexto ou sétimo termo harmônico é ressonante a freqüência fundamental da estrutura e as demais são submúltiplas de $\mathrm{r}_{\mathrm{k}}$,

- determina-se aleatoriamente os ângulos de fase.

- Até esta fase, o acelerograma ainda é adimensional.

- Faz-se uma análise elástica dessa estrutura para essa combinação adimensional do acelerograma e obtém-se a resposta máxima. Compara-se essa resposta com a resposta obtida pelo espectro de projeto sugerido em normas, estabelecendo-se a constante $R$.

- Pelo método de integração numérica passo-a-passo de Newmark (programa desenvolvido neste mestrado), determina-se a resposta máxima da estrutura para o comportamento elasto-plástico.

- Faz-se uma simulação de monte Carlo, onde é gerada uma amostragem de acelerogramas. Faz-se essa amostragem sorteando-se novamente os ângulos de fase para cada amostra. Resultando-se em uma amostragem de respostas máximas, onde se faz um tratamento estatístico. 
- Como no processo "Vento Sintético", o acelerograma que resultar em uma resposta próxima a resposta característica obtida é adotado para dimensionar a estrutura. Dáse o nome a esse acelerograma de acelerograma crítico. 


\title{
5 DESENVOLVIMENTO DE UM PROGRAMA COMPUTACIONAL
}

\author{
Neste trabalho, desenvolveu-se um programa na linguagem MATLAB
} (CHAPMAN, 2003) para se determinar a resposta em uma estrutura com comportamento elasto-plástico ideal conforme descrito no capítulo 3. Esse programa foi implementado com base no processo de integração numérica de Newmark levando em conta o comportamento não-linear do material, que verifica a formação da rótula e/ou retorno ao comportamento elástico do material a cada incremento de tempo $h$.

\subsection{DESCRIÇÃO DO PROGRAMA}

No programa desenvolvido foi priorizada uma entrada de dados a partir das características da estrutura visando apenas determinar, independentemente do programa, o vetor aceleração do solo. Assim, a montagem da matriz de massa e da matriz de rigidez dependem primeiramente do número de pavimentos, pois com base nesse dado determinam-se os graus de liberdades da estrutura.

A matriz de massa é criada a partir de dados fornecidos pelo usuário para cada nó da estrutura, conforme é abordado na seção 4.2.1, de forma que possa assumir valores diferentes em cada nó. Facilmente pode-se determinar essa matriz.

Já para se determinar a matriz de rigidez, são necessários dados sobre o módulo de elasticidade, a tensão de escoamento, o momento de inércia e o módulo de resistência plástico do perfil metálico utilizado na coluna, e altura da coluna metálica. Esses dados são também fornecidos pelo usuário, onde os três últimos correspondem às características de cada pavimento e não são necessariamente iguais.

Inicialmente, o programa faz a montagem da matriz rigidez elástica da estrutura, contudo, essa matriz é remontada a cada incremento de tempo, pois deve-se verificar a formação da rótula plástica a fim de considerar o comportamento não linear da estrutura. O parâmetro utilizado para determinar o comportamento atuante é a força cortante restauradora local equivalente atingida em cada passo $n$. 
Essa força cortante restauradora local equivalente $Q$ é determinada para cada coluna e é computada a partir dos momentos fletores em suas extremidades, onde:

$$
Q=\frac{M_{S U P}+M_{I N F}}{\ell_{i}}
$$

onde, $M_{\text {SUP }}$ representa o momento fletor superior e $M_{I N F}$, o momento fletor inferior.

Para o caso elástico, com 2 colunas, tem-se:

$$
M_{S U P}=M_{I N F}=2 \frac{12 E I_{0 i}}{\ell_{i}^{3}} u_{i}
$$

onde, $I_{0 i}$ é o momento de inércia de apenas uma coluna do pavimento $i$ e $u_{i}$ indica o deslocamento horizontal nessa direção.

O valor máximo para o momento fletor superior e o momento fletor inferior, de acordo com o modelo elasto-plástico ideal, é em valor absoluto igual ao momento de plastificação $M_{p l}$, dado pela expressão:

$$
M_{p l}=f_{y} Z_{i}
$$

assim, $Z_{i}$ representa o módulo de resistência plástico da coluna do pavimento $i$.

Consequentemente, a força cortante máxima $Q_{p l}$ para barra será:

$$
Q_{p l}=\frac{2 f_{y} Z_{i}}{\ell_{i}}
$$

Quando a força cortante restauradora local atuante for superior a força cortante máxima implicará em uma rigidez correspondente àquela barra de valor nulo $\left(k_{i}=0\right)$, caso contrário, a rigidez tem o valor inicial. De posse desses dados, monta-se a matriz de rigidez da estrutura para cada passo.

Finalmente, deve-se fornecer ao programa a taxa de amortecimento dos dois primeiros modos de vibração da estrutura para a montagem da matriz de amortecimento. Considerando esses dados, a partir da matriz de massa e da matriz de rigidez elástica, determina-se a matriz de amortecimento da estrutura em questão.

Outra informação que deve estar na entrada de dados, já comentado anteriormente, é o vetor aceleração do solo obtido para cada passo de tempo $h$, portanto, seus valores podem ser determinados a partir da função aceleração do solo sugerida neste trabalho ou de valores obtidos por outros processos (por exemplo, medição de um terremoto real). 
Quando se utiliza a função de aceleração do solo, o coeficiente $R$ pode ser indicado na entrada de dados do programa, caso não precise ser utilizado, o valor adotado deve ser 1 (um).

As condições iniciais de deslocamento e velocidade também devem ser fornecidas ao usuário.

Para melhor entendimento da implementação executada, o fluxograma geral do programa é apresentado na Figura 5.1 com a seqüência dos cálculos realizada e a seguir o fluxograma mais detalhado na Figura 5.2 para descrever a implementação dos espectros de resposta de deslocamentos, velocidades e acelerações devidos ao comportamento elastoplástico.

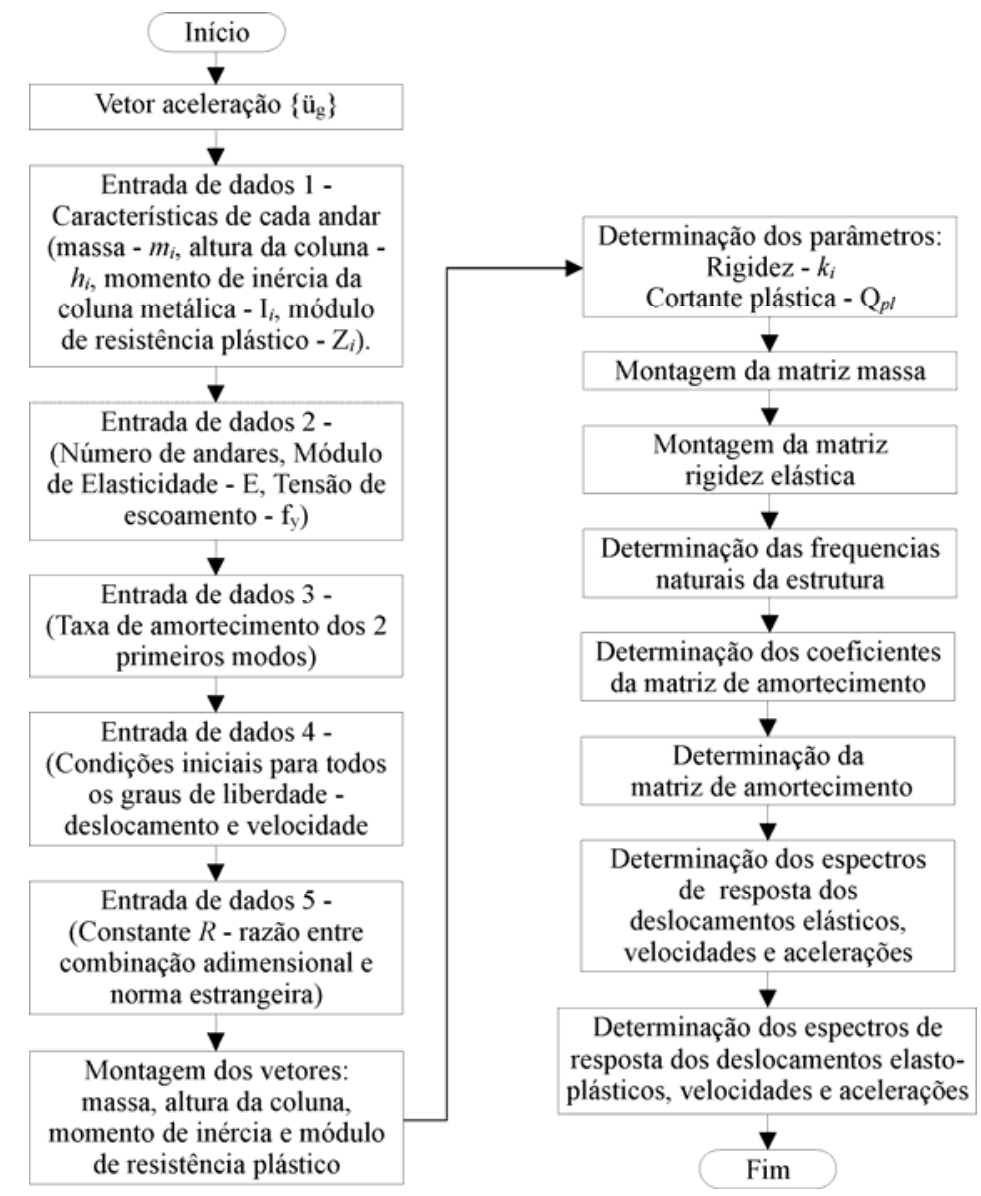

Figura 5.1 - Fluxograma geral do programa. 

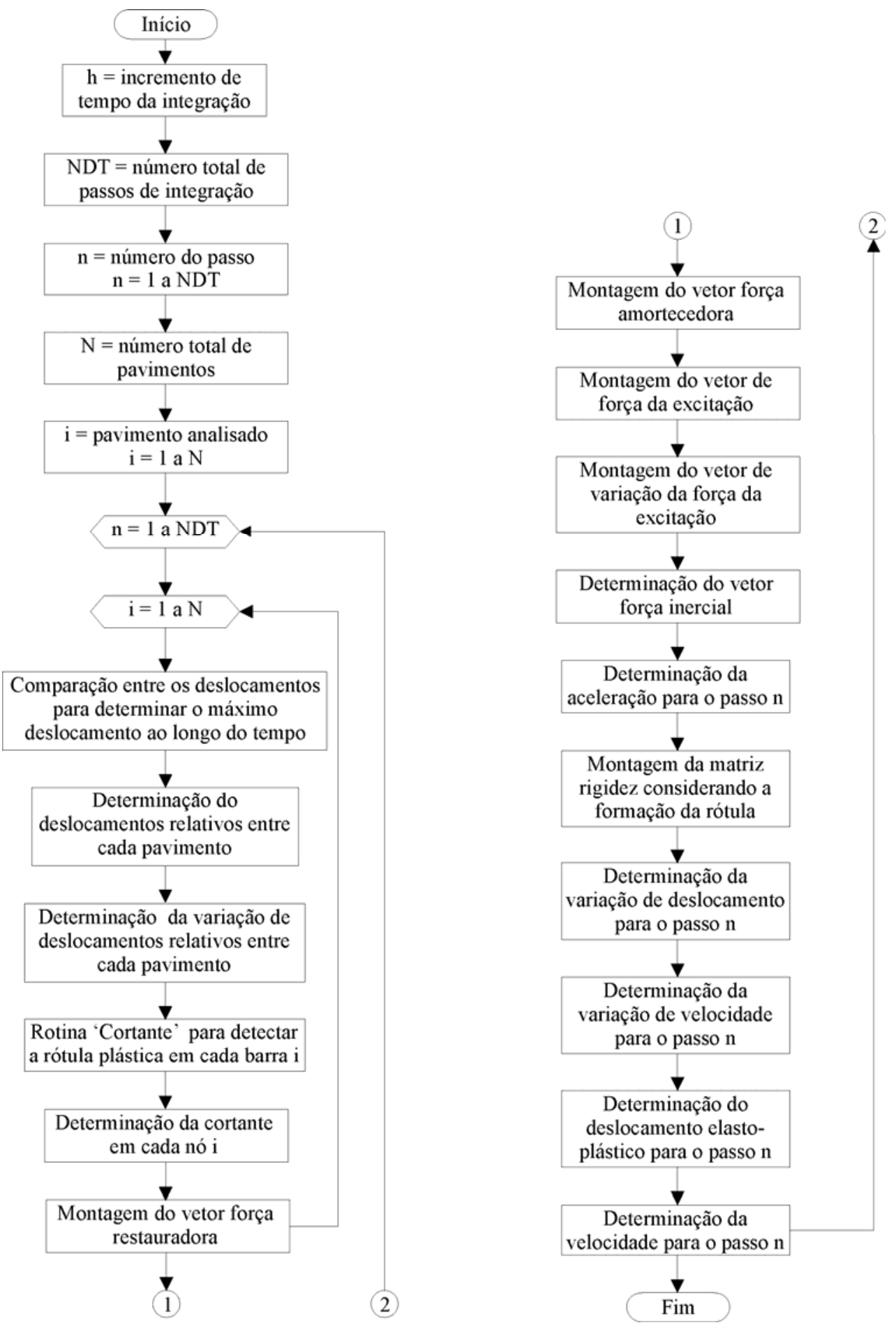

Figura 5.2 - Fluxograma de determinação dos espectros de respostas dos deslocamentos elasto-plásticos, das velocidades e das acelerações. 
Na determinação desses espectros foi utilizada uma rotina chamada 'Cortante', essa rotina determina o comportamento atuante na estrutura em cada passo, conforme descrito anteriormente, de maneira semelhante a descrita em Brasil e Bartolomucci (1997). O fluxograma de cálculo é indicado na Figura 5.3.

Os símbolos utilizados na Figura 5.3 são $Q_{f}$ para representar a força cortante definida inicialmente para o passo em questão e $Q$ define a força cortante do passo anterior. $Q_{p l}$, conforme descrito na eq. (5.4), é o parâmetro utilizado para determinar o comportamento do material. $D_{\text {elta }}$ representa a diferença entre a variação do deslocamento $\Delta u$ entre o pavimento $i$ e $i+1$, determinada no passo anterior.

A rigidez da coluna é representada pela constante $k_{c}$ que, inicialmente, assume valor da rigidez elástica daquela barra.

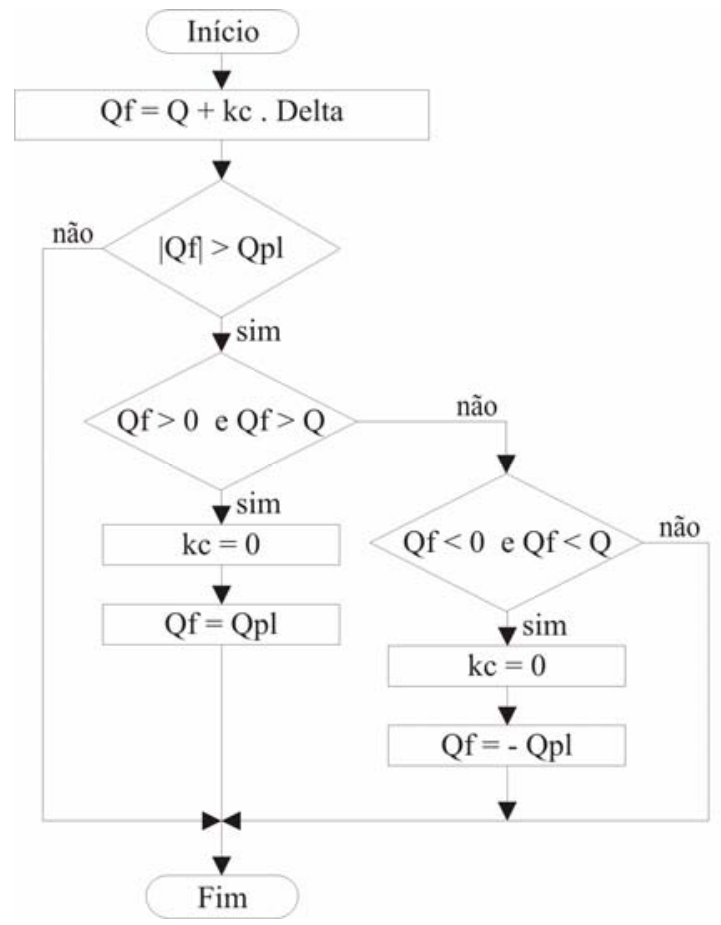

Figura 5.3 - Fluxograma da rotina 'Cortante'. 


\subsection{VALIDAÇÃO DO PROGRAMA}

Visando a verificação das respostas obtidas pelo programa, procurou-se na bibliografia algum exemplo compatível com a proposta apresentada neste trabalho. Encontrou-se um exemplo adequado em Chopra (1995) que utilizou uma estrutura com comportamento elasto-plástico ideal, entretanto, a resolução para esse sistema é obtida por um espectro de resposta plástico. Essa consideração não implicará em nenhuma alteração na resposta da estrutura, trata-se apenas de uma outra maneira de se resolver o problema.

Esse exemplo trata de uma edificação com 5 pavimentos em que o modelo utilizado para sua simulação é o de shear building e o amortecimento da estrutura é representado pela matriz de amortecimento de Rayleigh.

As características da estrutura são ilustradas na Figura 5.4. Conforme o exemplo utilizado, a massa em todos os pavimentos são iguais e valem 45.344 kg (100 kips/g) e a taxa de amortecimento nos dois primeiros modos de vibração é 5\%.

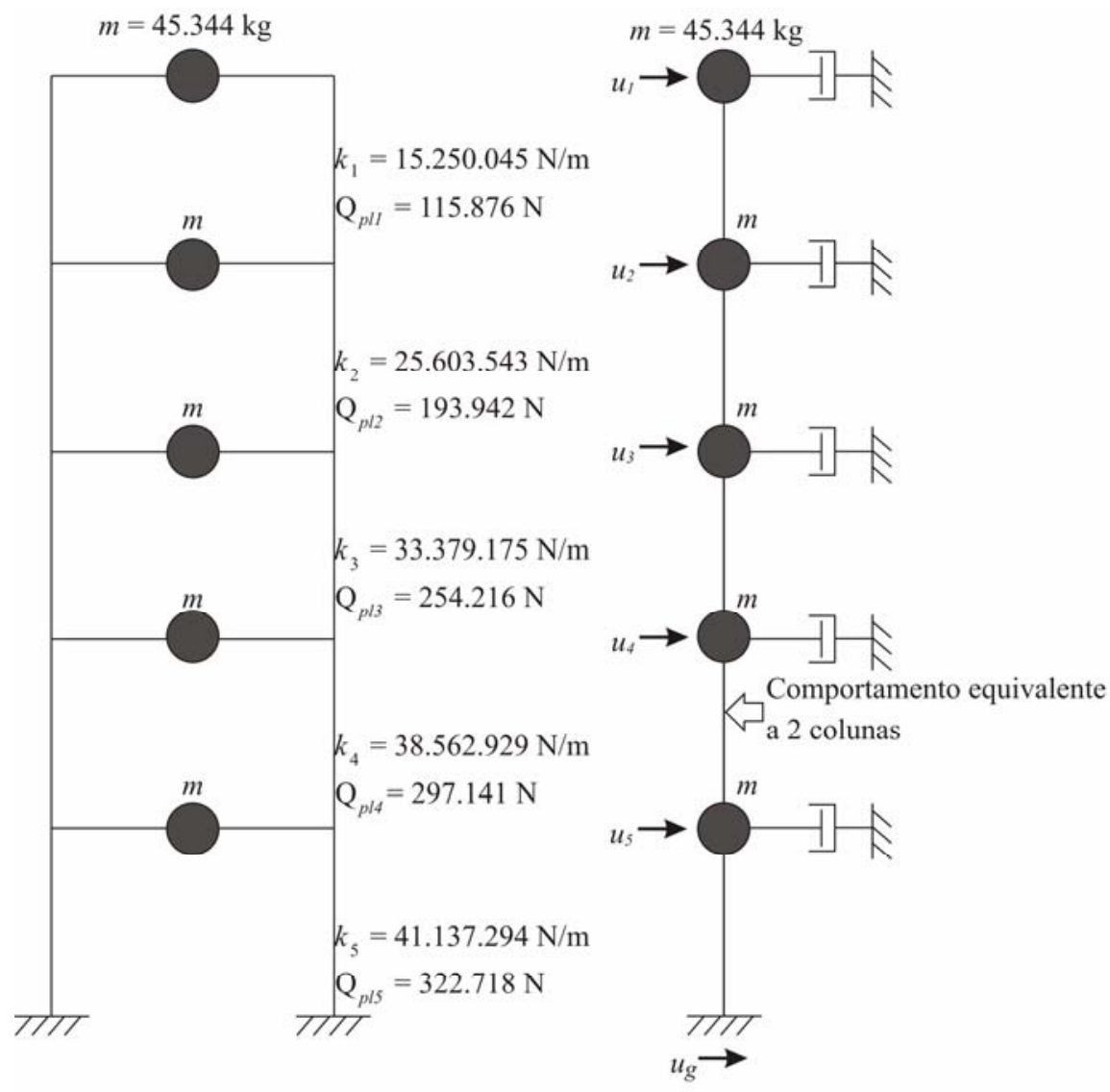

Figura 5.4 - Edifício com 5 pavimentos: características da estrutura 
Todavia, apresenta-se o valor final da rigidez e da força cortante máxima para cada barra e, para uma entrada de dados compatível com o programa desenvolvido, devem-se adaptar as características desse exemplo. Deste modo, foi adotado o módulo de elasticidade $E$ de $205000 \mathrm{MPa}$, a altura das colunas $\ell_{i}$ em todos os pavimentos é $3 \mathrm{~m}$ e tensão de escoamento $f_{y} 250 \mathrm{MPa}$ (aço A36). Consequentemente, é possível determinar o momento de inércia da coluna $I_{0 i}$ e o módulo de resistência plástico $Z_{i}$ para cada pavimento, como é indicado na Tabela 5.1.

Tabela 5.1 - Características das colunas em cada pavimento.

\begin{tabular}{|r|r|r|}
\hline \multicolumn{1}{|c|}{$i$} & $I_{0 i}\left(\mathrm{~cm}^{4}\right)$ & $Z_{i}\left(\mathrm{~cm}^{3}\right)$ \\
\hline \hline 1 & 8.369 & 695 \\
\hline 2 & 14.051 & 1.163 \\
\hline 3 & 18.318 & 1.525 \\
\hline 4 & 21.163 & 1.783 \\
\hline 5 & 22.575 & 1.936 \\
\hline
\end{tabular}

Em Chopra (1995), os valores da aceleração do solo são extraídos do acelerograma de El Centro (1940) para um incremento de tempo 0,02 s. O tempo total medido nesse terremoto é 31,20 segundos, assim, são realizados 1559 passos de integração. As condições inicias de deslocamento e velocidade são nulas.

A partir desses dados e utilizando o programa desenvolvido, determinou-se o histórico das respostas para todos os graus de liberdade. O histórico de resposta de deslocamento na direção $u_{1}$. é apresentado na Figura 5.5. 


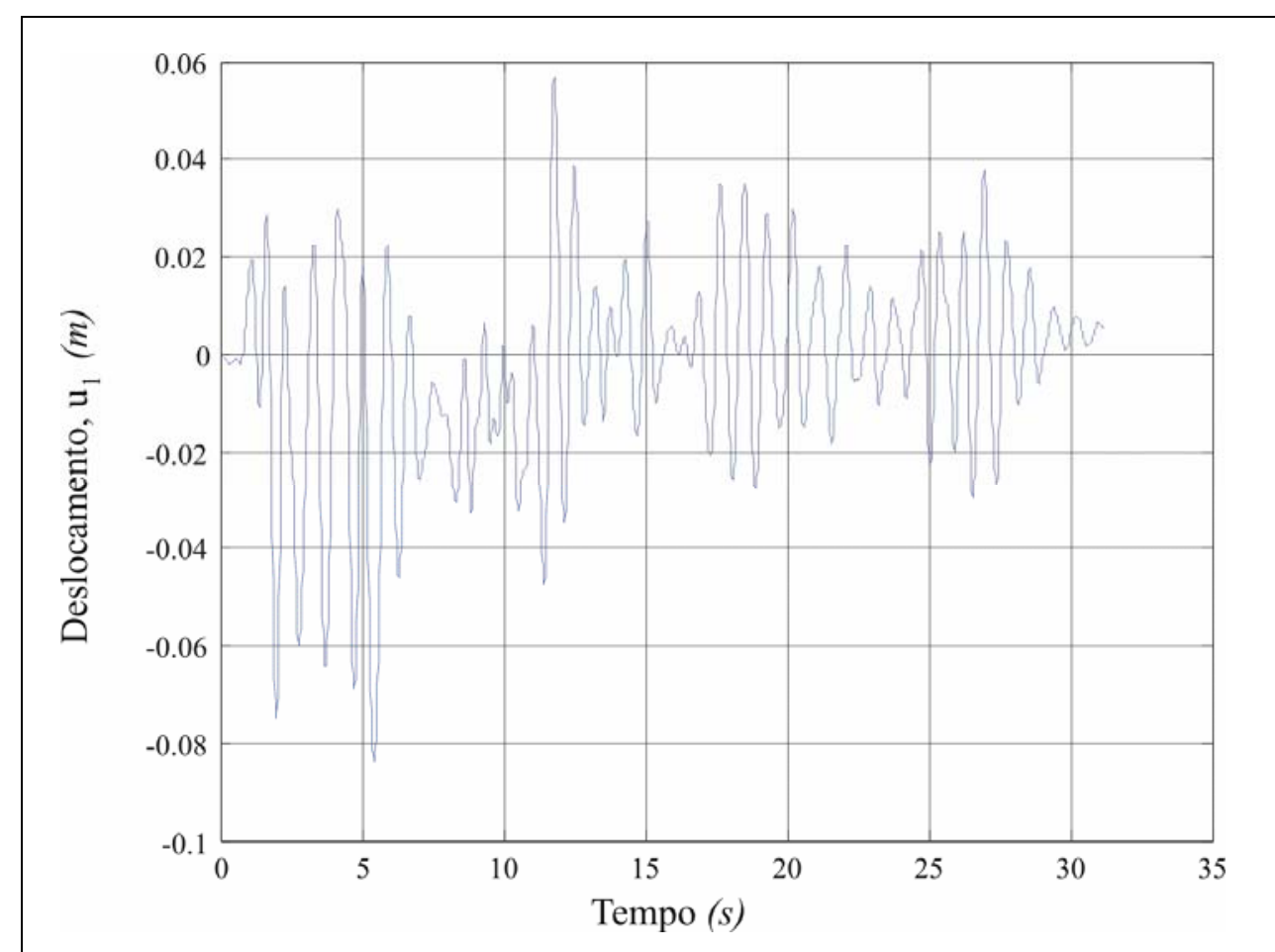

Figura 5.5 - Histórico de respostas dos deslocamentos na direção $u_{1}$, obtido no programa desenvolvido.

Como pode ser visualizada, a resposta máxima atingida por esse histórico é 0,083 m. Para essa mesma direção (direção de $u_{1}$ ), é apresentado o histórico de respostas dos deslocamentos em Chopra (1995) e o deslocamento máximo atingido é 0,081 m (3,203 in).

Esses valores, então, validam o programa desenvolvido neste trabalho. 


\section{EXEMPLOS NUMÉRICOS}

A metodologia desenvolvida neste trabalho foi primeiramente apresentada em Corbani e Brasil (2005) para o modelo shear building com 1 grau de liberdade, entretanto, a PSDF utilizada foi determinada a partir do acelerograma do terremoto de El Centro (1940), pois ainda não se tinha um modelo para a PSDF. Desta forma, foi possível realizar toda exemplificação do método.

Já em Brasil e Corbani (2006), apresentou-se o estudo do modelo de 1 grau de liberdade e, desta vez, aplicou o acelerograma proposto neste trabalho. Nessas condições, apresenta-se valores relacionados a uma estrutura com período de 0,4 segundo.

\subsection{GRAUS DE LIBERDADE}

Nesse exemplo para 5 graus de liberdade, utilizou-se a mesma estrutura apresentada para validar o programa (CHOPRA, 1995). Assim, as características já descritas no capítulo 5 são adotadas, exceto os valores de aceleração do solo, que por sua vez são determinados da maneira proposta no capítulo 4.

Com essa finalidade, numa primeira etapa, obtém-se as freqüências circulares naturais dos dois primeiros modos de vibração da estrutura e o incremento adequado para se determinar as funções harmônicas. Onde os valores das freqüências dos dois primeiros modos são 7,85 rad/s (isto é, o período é $0,8 \mathrm{~s}$ ) e 12,41 rad/s (período é 0,51 s) e o incremento deve ser inferior a 0,01 segundo.

Com o auxílio do programa EXCEL, formulou o PSDF reduzido com os valores assumidos 0,6 e $5 \pi \mathrm{rad} / \mathrm{s}$, respectivamente, para o fator não dimensional relacionado com o amortecimento do solo $H$ e a freqüência natural característica do solo $\omega_{g}$. Efetuando a integração do PSDF reduzido, determina-se as amplitudes das funções harmônicas para cada faixa de freqüência, como é apresentado na Tabela 6.1. Nesta tabela, relaciona-se a amplitude com cada freqüência circular correspondente.

No caso analisado, as funções harmônicas com freqüências ressonantes ao primeiro e ao segundo modo de vibração da estrutura são a sétima e a sexta, resultando um 
carregamento na faixa de freqüência mais desfavorável para essa estrutura. Para o intervalo gerado por essas freqüências, a fim de se ter faixas de freqüências iguais, determina-se as demais freqüências como submúltiplas ou múltiplas dessas freqüências.

Tabela 6.1 - Componentes harmônicos do terremoto

\begin{tabular}{|r|r|r|r|r|r|r|}
\hline $\mathrm{k}$ & $\mathrm{r}_{\mathrm{k}}$ & $\mathrm{T}_{\mathrm{k}}(\mathrm{s})$ & $\omega_{\mathrm{k}}(\mathrm{rad} / \mathrm{s})$ & $\mathrm{r}$ & \multicolumn{1}{c|}{$S_{\text {rüg }}$} & $\mathrm{C}_{\mathrm{k}}$ \\
\hline \hline 1 & 0,064 & 0,051 & 122,55 & 9,752 & 0,037 & 0,18 \\
\hline 2 & 0,101 & 0,081 & 77,52 & 6,169 & 0,059 & 0,23 \\
\hline 3 & 0,160 & 0,128 & 49,04 & 3,902 & 0,098 & 0,30 \\
\hline 4 & 0,253 & 0,203 & 31,02 & 2,469 & 0,171 & 0,40 \\
\hline 5 & 0,400 & 0,320 & 19,62 & 1,562 & 0,310 & 0,53 \\
\hline 6 & 0,633 & 0,506 & 12,41 & 0,988 & 0,416 & 0,62 \\
\hline 7 & 1,000 & 0,800 & 7,85 & 0,625 & 0,257 & 0,49 \\
\hline 8 & 1,581 & 1,265 & 4,97 & 0,395 & 0,127 & 0,34 \\
\hline 9 & 2,499 & 2,000 & 3,14 & 0,250 & 0,069 & 0,25 \\
\hline 10 & 3,951 & 3,161 & 1,99 & 0,158 & 0,041 & 0,19 \\
\hline 11 & 6,245 & 4,997 & 1,26 & 0,100 & 0,025 & 0,15 \\
\hline
\end{tabular}

A representação gráfica da amplitude $C_{k}$ para cada harmônico $k$ é feita na Figura 6.1 .

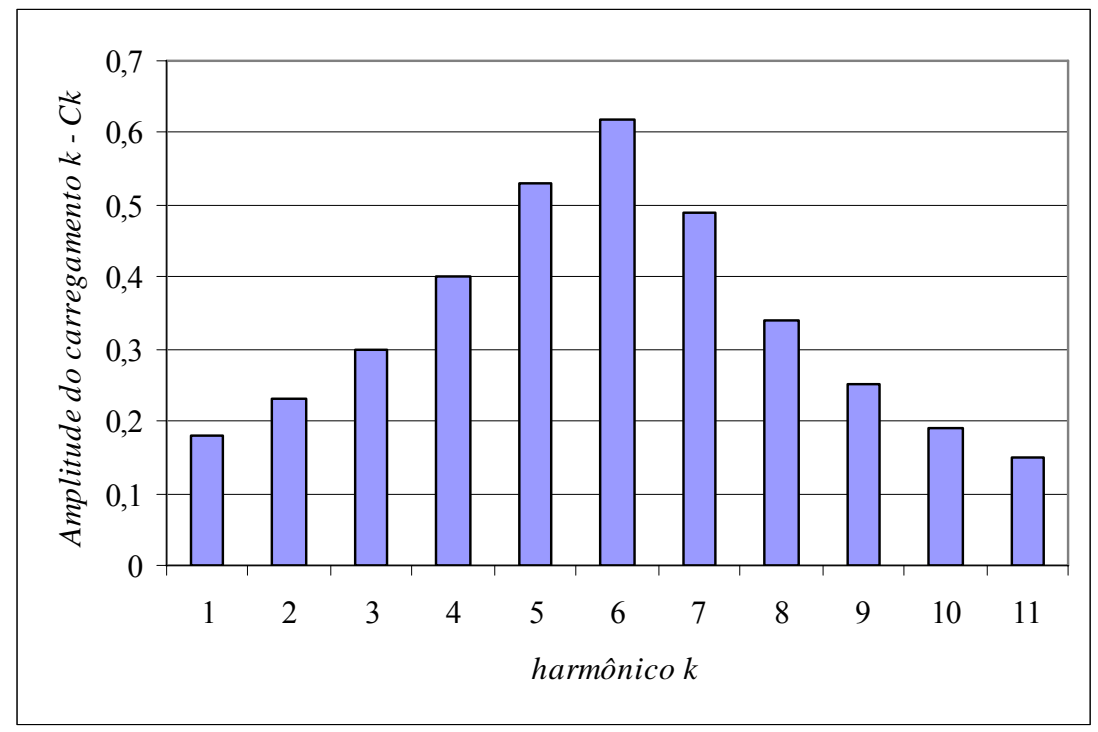

Figura 6.1 - Amplitudes dos harmônicos $k$.

Ainda utilizando o programa EXCEL, para o intervalo incremental de 0,0025 segundo que assegura a convergência do processo de integração numérica, calcula-se o valor 
da aceleração do solo. Desta forma, determinou-se a combinação adimensional de funções harmônicas para simular o acelerograma. Isto é, o coeficiente $R$ é unitário.

Essa combinação adimensional é apresentada na Figura 6.2 para o tempo total de 50 segundos.

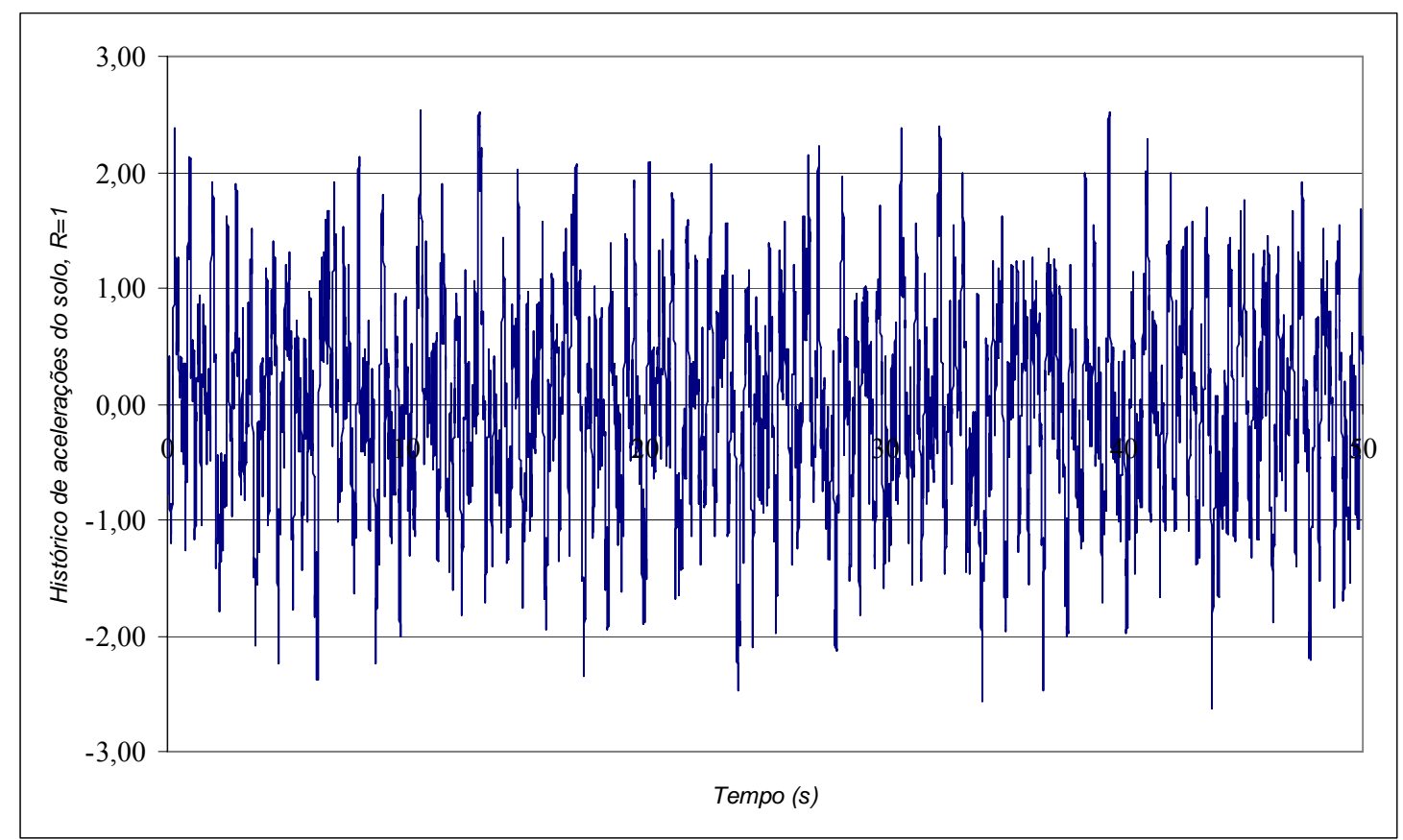

Figura 6.2 - Histórico de acelerações do solo, $R=1$.

Para essa combinação adimensional, determinou-se o histórico de resposta de aceleração da estrutura para um sistema massa-amortecedor-mola de um grau de liberdade, dado pela expressão:

$$
\ddot{u}(t)+2 \xi \bar{\omega} \dot{u}(t)+\bar{\omega}^{2} u(t)=-\ddot{u}_{g}(t)
$$

onde, $\ddot{u}_{g}(t)$ representa a combinação adimensional. $\mathrm{O}$ valor adotado para a taxa de amortecimento da estrutura $\xi$ é $5 \%$ e a freqüência natural da estrutura $\bar{\omega}$, dada por $\bar{\omega}=\frac{2 \pi}{\bar{T}}$, é obtida para o primeiro modo de vibração da estrutura, que nesse exemplo $\bar{T}$ é igual a 0,80 segundo. 
A partir desse histórico, determina-se a resposta máxima elástica da aceleração $\ddot{u}_{\text {máx }}$. As condições iniciais adotadas para o deslocamento e para a velocidade são nulas.

O próximo passo é determinar a aceleração máxima sugerida em norma, pois o coeficiente $R$ é obtido pela razão entre a aceleração sugerida em norma e a resposta máxima elástica da aceleração.

Visando determinar a aceleração máxima sugerida em norma, utilizou o espectro de projeto dado em COVENIN 1756 (2001). Assume-se o fator de redução como 1, ilustra-se esse espectro na Figura 6.3.

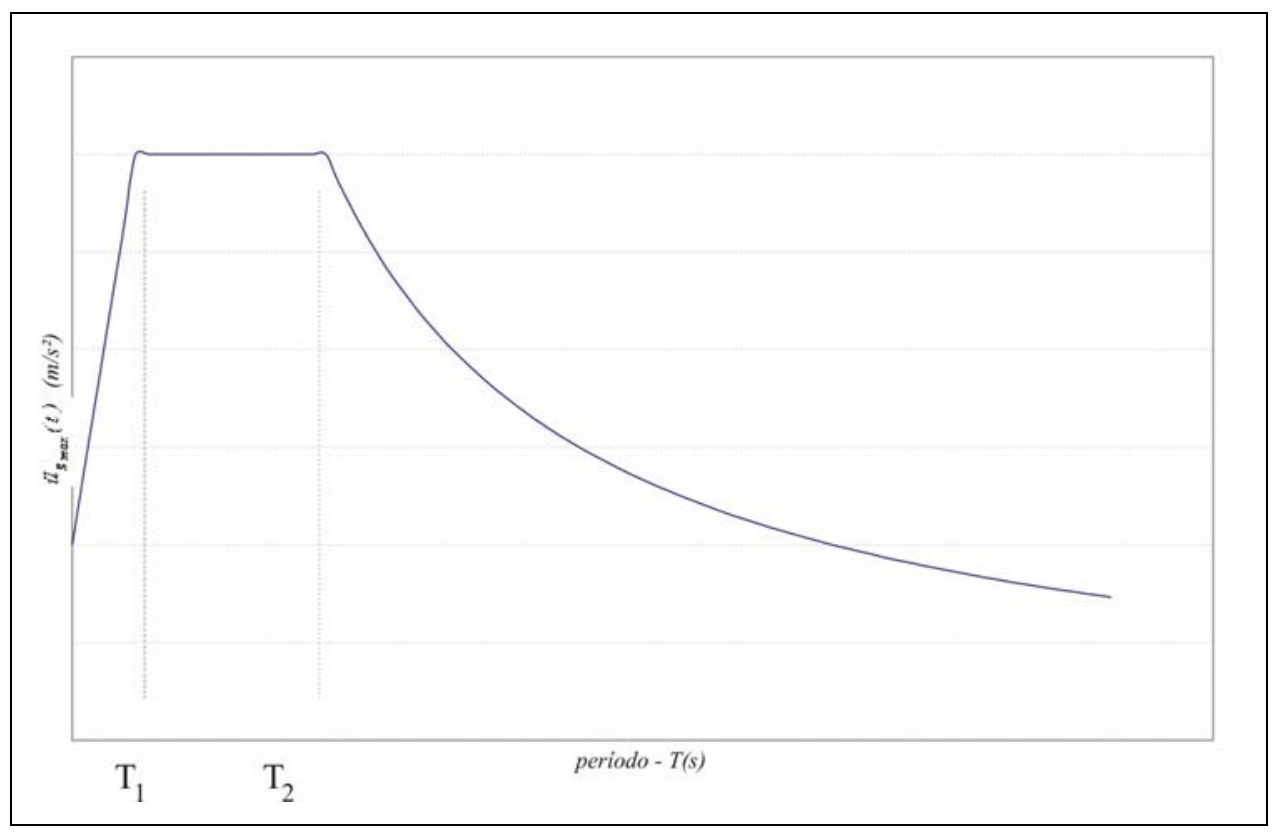

Figura 6.3 - Espectro de resposta elástico, fator de redução 1.

As ordenadas Ad para o fator de redução 1, são as seguintes:

$$
\begin{array}{lll}
\text { para } & \bar{T}<T_{0} & A d=\alpha \varphi \beta A_{0}\left[1+\frac{\bar{T}}{T_{0}}(\beta-1)\right] \\
\text { para } & T_{0} \leq \bar{T} \leq T^{*} & \text { Ad }=\alpha \varphi \beta A_{0} \\
\text { e } & \bar{T}>T^{*} & \text { Ad }=\alpha \varphi \beta A_{0}\left(\frac{T^{*}}{\bar{T}}\right)^{p} .
\end{array}
$$

Para esse exemplo, a zona sísmica adotada é 7 e o coeficiente coeficiente de aceleração horizontal $A_{0}$ de acordo com a zona sísmica é $0,4 \mathrm{~g}$. As constantes $T^{*}, \beta$ e p 
dependem da forma espectral determinada pelo perfil do solo, assim, foi adotado o perfil de solo S1. $\varphi$ é o fator de correção do coeficiente de aceleração e depende tanto do perfil do solo quanto da zona sísmica. Para esse caso, assumiu-se o valor 1,00

$\alpha$ é o fator de importância da construção e adotou-se 1,30 .

O período $T_{0}$ é proporcional a $T^{*}$, dado por $T_{0}=\frac{T^{*}}{4}$.

Nessas condições, para o período de vibração 0,8 segundo, é possível determinar a aceleração sugerida em COVENIN 1756 (2001). Consequentemente, a combinação harmônica das acelerações será dada pela expressão:

$$
\ddot{u}_{g}=\frac{1}{11} g \sum_{k=1}^{11} C_{k} \cos \left(\omega_{k} t-\theta_{k}\right) \text {. }
$$

Determinada a função aceleração do solo, foram gerados 33 carregamentos com ângulos de fase aleatórios. A característica estocástica do carregamento é ilustrada na Figura 6.4, onde são apresentadas 3 combinações de carregamento.

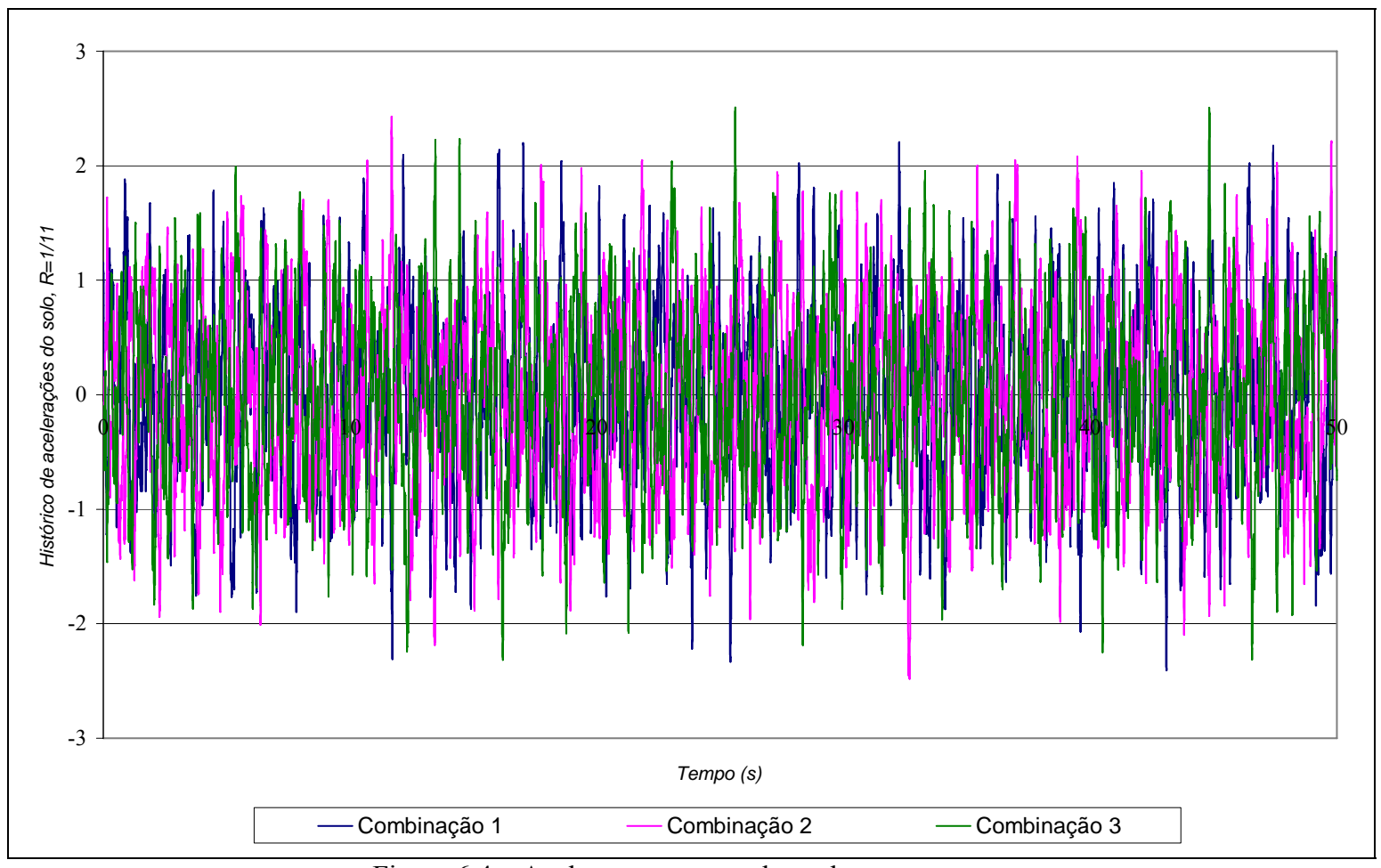

Figura 6.4 - Acelerogramas gerados pelo processo 
Utilizando o programa desenvolvido neste trabalho, consegue-se determinar o histórico de resposta dos deslocamentos para esses acelerogramas gerados. Na Figura 6.5 é ilustrado o histórico de resposta para os comportamentos elástico e elasto-plástico na direção $u_{1}$. Todavia, o comportamento elástico apenas é ilustrado hipoteticamente, pois as tensões obtidas nesse comportamento são superiores as tensões de escoamento.

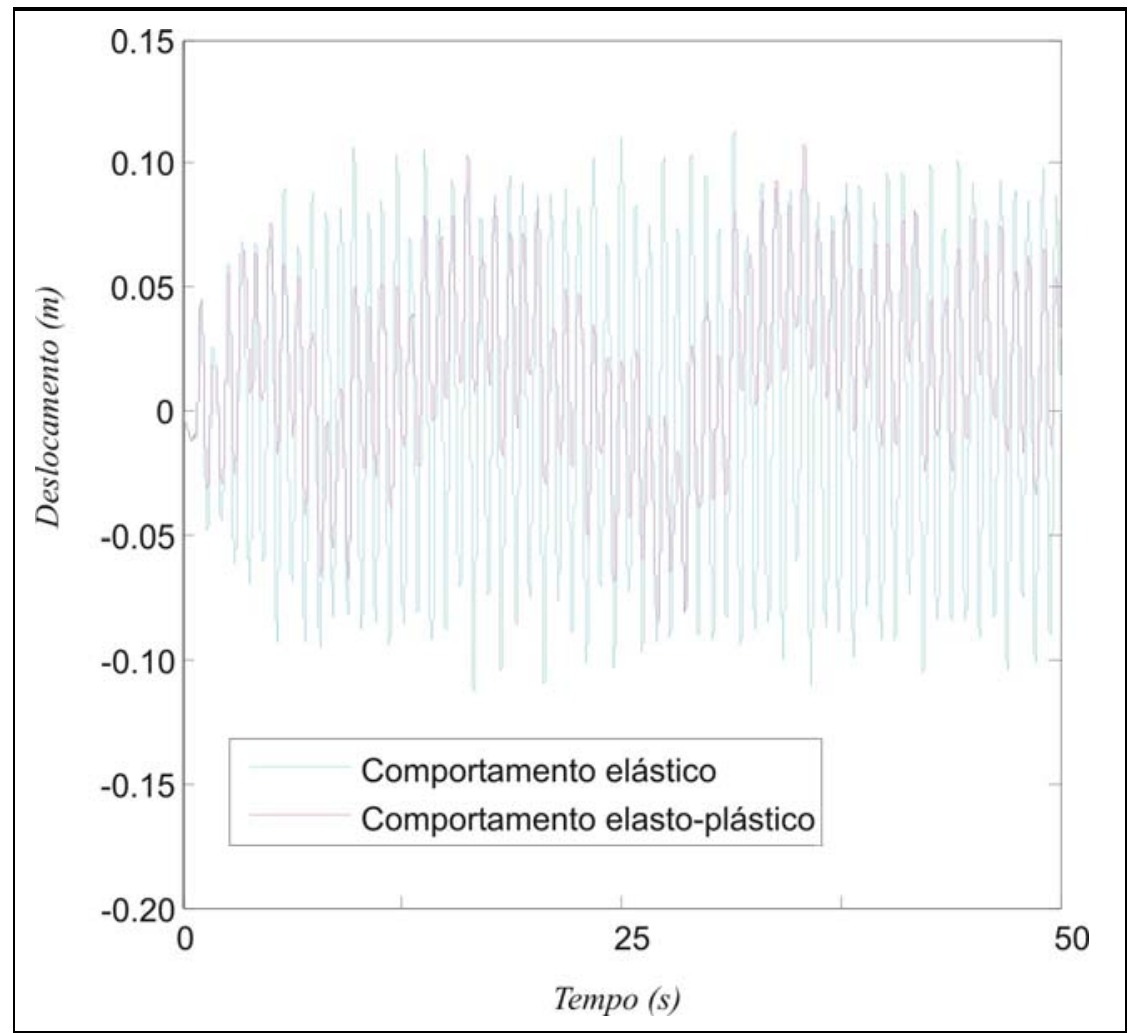

Figura 6.5 - Históricos de respostas para os comportamentos elástico e elasto-plástico, direção $u_{1}$.

Com base na Figura 6.5, observa-se que a amplitude da resposta é praticamente constante para o comportamento elástico, todavia, para o comportamento elasto-plástico, há um dano acumulado a cada formação da rótula plástica.

A direção $u_{1}$ está no topo da estrutura e atinge valores máximos de deslocamentos próximos a $0,12 \mathrm{~m}$.

$\mathrm{Na}$ direção mais próxima ao solo, indicada como direção $u_{5}$, visualiza-se mais claramente o acréscimo de danos cada vez que a rótula plástica é formada, conforme é apresentado na Figura 6.6. 


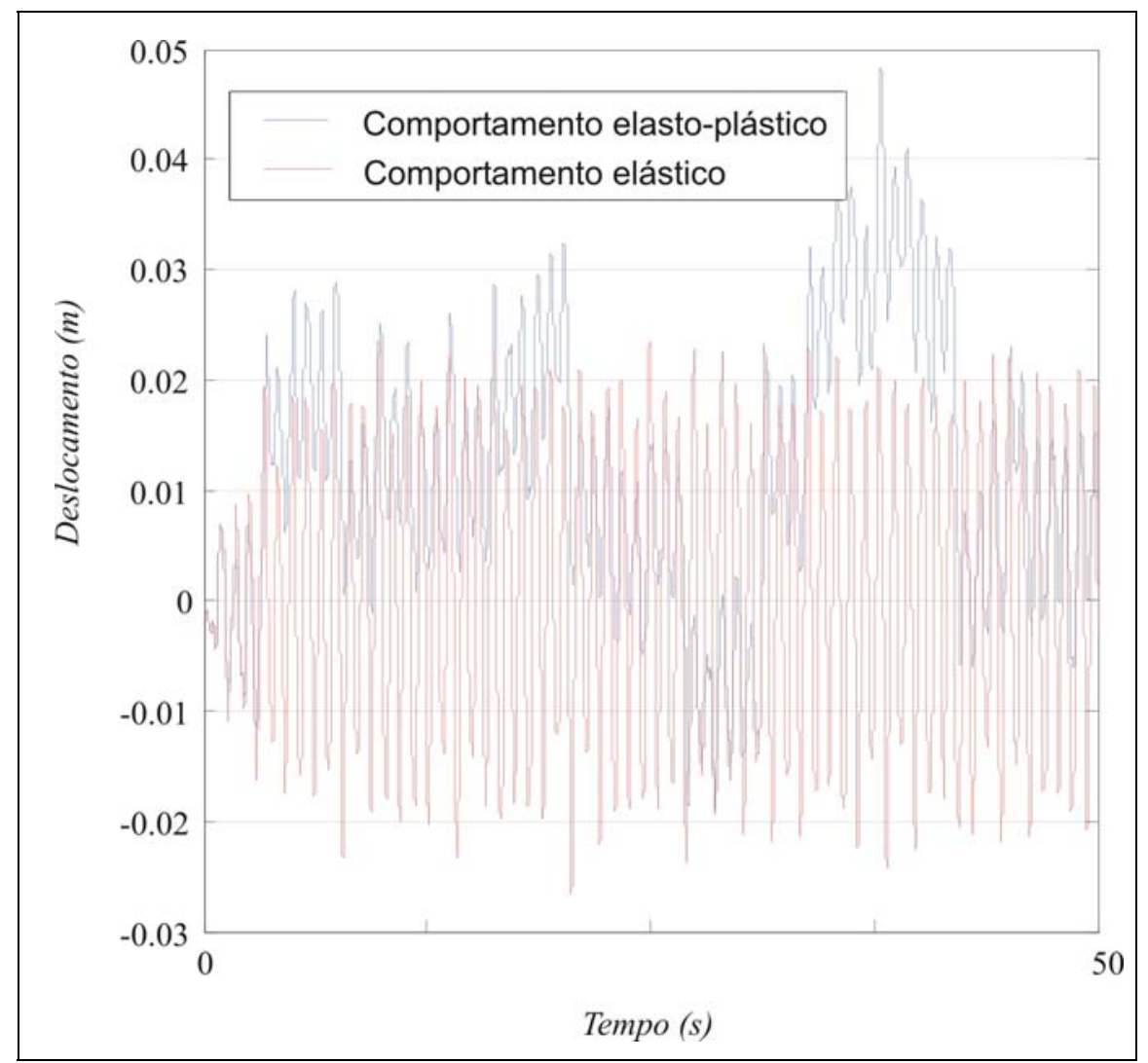

Figura 6.6 - Históricos de respostas para os comportamentos elástico e elasto-plástico, direção $u_{5}$.

Para a análise estatística das respostas, foi utilizado o histórico de resposta para a direção $u_{5}$. Dessa forma, para cada histórico de aceleração foi determinada a resposta máxima plástica e elasto-plástica ao longo de todo o tempo considerado, conforme é ilustrada na Figura 6.7. 


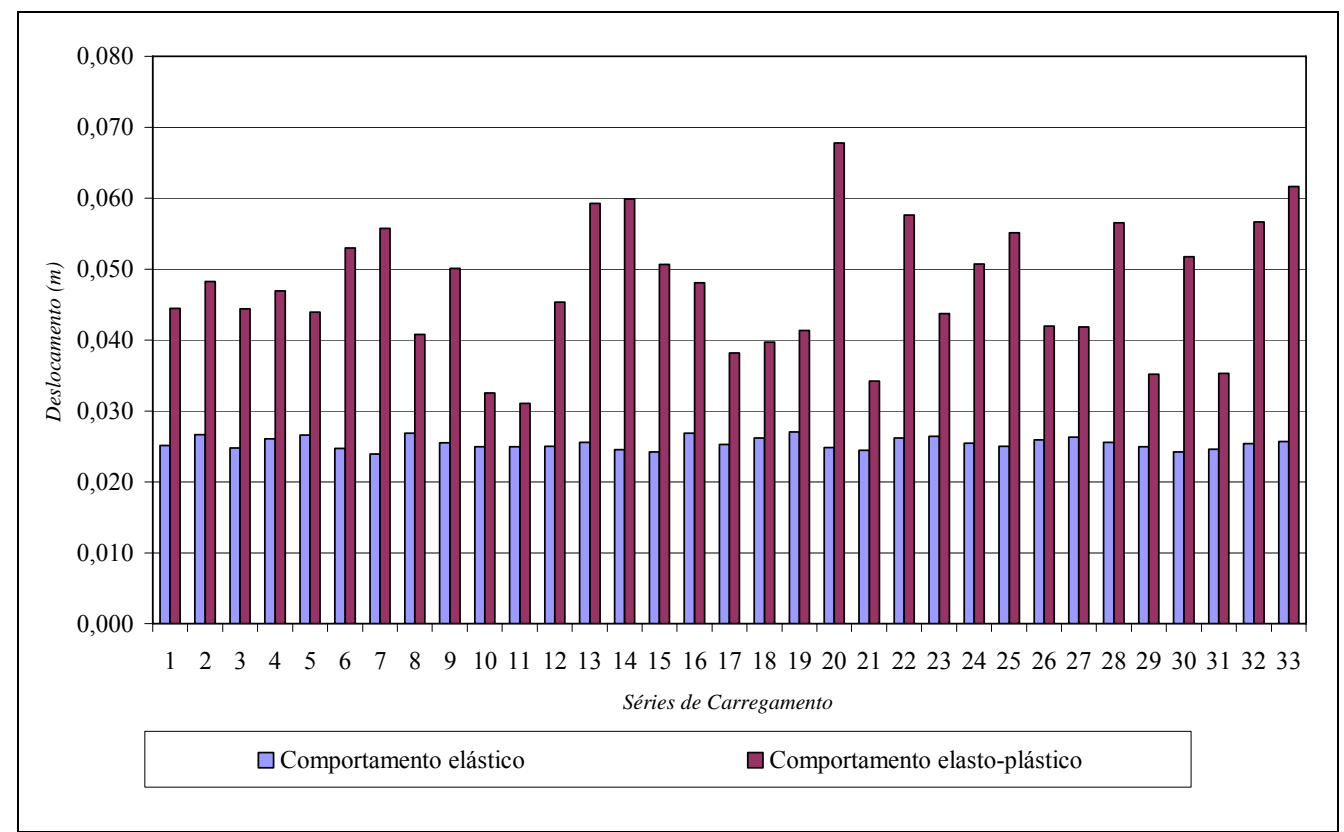

Figura 6.7 - Valores máximos dos deslocamentos de resposta da estrutura.

A seguir, admitindo uma distribuição normal, é feita uma análise estatística desses valores máximos. As propriedades estatísticas obtidas são apresentadas na Tabela 6.2.

Tabela 6.2 -Propriedades estatísticas

\begin{tabular}{lllr}
\hline \multicolumn{2}{c}{ Comportamento elástico } & \multicolumn{2}{c}{ Comportamento elasto-plástico } \\
\hline Média & 0,025 & Média & 0,047 \\
Desvio padrão & 0,001 & Desvio padrão & 0,009 \\
Valor característico & 0,027 & Valor característico & 0,062 \\
\hline
\end{tabular}

Determinado o valor característico, deve-se adotar como acelerograma crítico para dimensionar a estrutura aquele que a resposta máxima mais se aproxima, nesse caso é o acelerograma $j=33$. 


\section{CONCLUSÕES E PROPOSTAS}

Este capítulo traz as considerações finais do trabalho realizado, discutindo as conclusões obtidas e apresentando as sugestões para trabalhos futuros. Foi desenvolvida uma metodologia para gerar um acelerograma crítico de terremoto e análise de estruturas de barras com consideração de formação de rótulas plásticas.

A metodologia proposta foi inspirada no processo "Vento Sintético" (FRANCO, 1993). Para tanto, foi necessário realizar algumas adaptações do processo:

- solicitação de sismos não deve ser dividida em partes constante e flutuante;

- PSDF adequada para terremotos;

- faixa de freqüência importante para a solicitação de sismos;

- número de funções harmônicas para uma boa simulação de sismos;

- posicionamento da freqüência ressonante;

- duração no tempo da análise para analisar esse tipo de carregamento;

- número de combinações de funções harmônicas.

Nos parágrafos que se seguem são discutidas essas adaptações.

Em uma simulação de vento, é conveniente dividir o carregamento em duas parcelas: uma parcela constante (vento médio) e outra variável com o tempo (vento flutuante). Já para o caso de sismos, todo o carregamento é variável com o tempo.

Outro fator importante, é que as PSDF para as ações devidas ao vento são de fácil obtenção na literatura técnica, enquanto o mesmo não acontece com terremotos. Assim, um grande desafio deste trabalho foi determinar uma PSDF de acelerações de solo coerente com os modelos propostos em Normas (nacional e estrangeiras), onde só se encontram Espectros de Resposta Elástica. A solução adotada foi determina-se uma combinação adimensional de funções harmônicas com amplitudes extraídas de PSDF reduzido (adimensional) e calibrar-se essa combinação por comparação das respostas com as obtidas com um espectro de resposta elástica apresentado em Normas internacionais.

O modelo reduzido utilizado para a PSDF é o modelo de Kanai-Tajimi e, para o caso do exemplo apresentado, assumiu-se um valor de aceleração máxima conforme sugerido em COVENIN 1756 (2001).

Outra adaptação necessária foi à determinação da faixa de freqüência interessante, já que em uma análise dinâmica de vento ela se situa entre 0,10 rad/s (1ciclo/min) e 
freqüências mais altas, enquanto o valor correspondente para terremotos é na faixa entre 6,28 e 31,42 rad/s (1 Hz e $5 \mathrm{~Hz})$.

Essas características refletem-se na resposta dinâmica da estrutura. Por exemplo, a faixa de freqüência importante em ventos faz com que seja indicada a análise dinâmica em estruturas flexíveis. Já os terremotos apresentam as freqüências dominantes na PSDF coincidindo com a freqüência natural de muitos tipos de estruturas usuais (Figura 4.5).

Considerando essa faixa de freqüência em um terremoto, foi estudada a quantidade de funções harmônicas indicadas para bem representar essa ação utilizando o espectro reduzido. Resultou em um número mínimo de onze funções harmônicas, coincidindo com o número utilizado no "Vento Sintético". O termo ressonante para as freqüências naturais da estrutura são, para estrutura com freqüência natural entre 1 e $2 \mathrm{~Hz}$, o sétimo, e o sexto, para freqüências iguais ou superiores a $2 \mathrm{~Hz}$.

Ainda adaptando o processo, deve-se analisar o fenômeno em uma duração de 50 segundos, conforme sugerida em Gould e Abu-Sitta (1980).

O número de combinações harmônicas utilizado no exemplo é 33, esse número é superior a 25 como o sugerido em Hoel; Port e Stone (1978). Fechando, assim, todas as considerações para simular a ação sísmica coerentemente.

O modelo estrutural adotado em nossa aplicação foi o de shear building, muitas vezes utilizado para representar o comportamento de prédios com múltiplos andares.

Para essas condições, conseguiu-se analisar a estrutura para o comportamento elasto-plástico ideal e realizar o tratamento estatístico das respostas máximas para todas as combinações de funções harmônicas.

A partir desse tratamento, percebe-se claramente o quanto o ângulo de fase influencia na resposta da estrutura no comportamento elasto-plástico, que é o oposto para o comportamento elástico, como se pode observar na Tabela 6.2 onde o desvio padrão para o comportamento elasto-plástico é consideravelmente maior que o obtido para o comportamento elástico.

Isso se deve à excitação imposta pelo acelerograma ao longo do tempo, uma vez que a maneira que ele varia influencia na ocorrência das rótulas plásticas. Elas, por sua vez, devido aos deslocamentos residuais ocasionados, fazem com que os futuros deslocamentos após sua primeira ocorrência transmitam essa característica.

Um comentário importante é que a resposta máxima do deslocamento obtida no exemplo numérico do método na direção de $u_{1}$ é $0,12 \mathrm{~m}$ para o carregamento crítico, portanto, é superior a resposta máxima obtida pelo terremoto El Centro para essa mesma 
direção $(0,08 \mathrm{~m})$. Todavia, com um único exemplo é difícil afirmar se o processo está ou não a favor da segurança.

A seguir, apresentam-se algumas sugestões e propostas para continuidade da pesquisa apresentada.

Quanto ao programa, podem-se implementar as funções harmônicas e sortear automaticamente todos os ângulos de fase no MATLAB. Desta forma, a entrada de dados seria o número total de combinações de carregamentos, a aceleração máxima do espectro de resposta elástico para a freqüência do primeiro modo da estrutura estudada extraída de qualquer espectro de resposta sugerido em Normas e os valores adotados de $H$ e $\omega_{g}$. Esse procedimento exige um computador de grande capacidade, pois o tempo de processamento é maior do que o programa inicial.

O projeto mais ambicioso de continuidade é a implementação de análises similares para estruturas mais complexas, iniciando-se com pórticos planos mais complexos que os shear buildings, passando para pórticos espaciais e depois para elementos finitos em geral para estruturas de folhas e maciças, permitindo análise sísmica de barragens e centrais nucleares. 


\section{REFERÊNCIAS}

ASOCIACIÓN COLOMBIANA DE INGENIERÍA SÍSMICA - AIS. Normas Colombianas de Diseño y Construcción Sismo Resistente - NSR-98. Bogotá D. C., 1997

ASSOCIAÇÃO BRASILEIRA DE NORMAS TÉCNICAS. NBR 8800: Projeto e execução de estruturas de aço de edificações. Rio de Janeiro, 1988. 80 p.

BAKER, J.; HEYMAN, J. Plastic design of frames. Great Britain: Cambridge University, 1969. v. 1.

BALENDRA, T. Vibration of buildings to wind and earthquakes loads. London; New York: Springer-Verlag, 1993. 149 p.

BLESSMANN, J. Introdução ao estudo das ações dinâmicas do vento. Porto Alegre: Editora da UFRGS, 1998. 282 p.

BRASIL, R. M. L. R. F. Programas de microcomputador para a análise dinâmica de estruturas nos domínios do tempo e da freqüência: parte 1: um grau de liberdade. São Paulo: Epusp, 1991. 31 p. Boletim Técnico do Departamento de Engenharia de Estruturas e Fundações, 9106.

; BARTOLOMUCCI, A. F. Integração explícita aplicada à análise dinâmica de treliças espaciais de comportamento elasto-plástico. São Paulo: EPUSP, 1997. 10 p. Boletim Técnico da Escola Politécnica da USP. Departamento de Engenharia de Estruturas e Fundações, BT/PEF/9701.

; CORBANI, S. Inelastic behavior of shear-buildings under random seismic excitation. In: IBERIAN LATIN AMERICAN CONGRESS ON COMPUTATIONAL METHODS IN ENGINEERING, 27., 2006, Belém. Anais...Belém: Editora da UFPA, 2006. 12 p. 1 CDROM.

BUCHHOLDT, H. A. An introduction to cable roof structures. $2^{\text {nd }}$ ed. London: Thomas Telford, 1999. 285 p.

CARRIL JÚNIOR, C. F. Análise numérica e experimental do efeito dinâmico do vento em torres metálicas treliçadas para telecomunicações. 2000. 143 f. Tese (Doutorado) - Escola Politécnica, Universidade de São Paulo, São Paulo, 2000. 
CHAPMAN, S. J. Programação em MATLAB para engenheiros. São Paulo: Pioneira Thomson Learning, 2003. 477 p.

CHEN, W. F., SOHAL, I. Plastic design and secord-order analysis of steel frames. United States of America: Springer-Verlag, 1995. 509 p.

CHOPRA, A. K. Dynamics of structures: theory and applications to earthquake engineering. Upper Saddle River: Prentice Hall, 1995. 729 p.

CLOUGH, R., PENZIEN, J. Dynamics of structures. New York: McGraw-Hill, [1975]. 634 p.

COMISIÓN FEDERAL DE ELECTRICIDAD (CFE). Manual de diseño de obras civiles: Estructuras: criterios de diseño: C.1.3. Diseño por sismo. México, DF, 1993. 36 p.

COMISIÓN DE NORMAS DE ESTRUCTURAS PARA EDIFICACIONES DEL MINISTERIO DE DESARROLLO URBANO Y COMISIÓN VENEZOLANA DE NORMAS INDUSTRIALES. COVENIN 1756:2001-1: Edificaciones sismorresistentes, Parte 1: Requisito. Caracas, 2001. 124 p.

CORBANI, S.; BRASIL, R. M. L. R. F. Monte carlo type simulation of the inelastic behavior of steel structures under random seismic excitation. In: IBERIAN LATIN AMERICAN CONGRESS ON COMPUTATIONAL METHODS IN ENGINEERING, 26., 2005, Guarapari. Proceedings... Guarapari: s.n., 2005. 10 p. 1 CD-ROM.

FARINHA, J. S. B.; FARINHA, M. B.; FARINHA, J. P.; REIS, A. C. Tabelas técnicas. Portugal: Edições Técnicas E.T.L., 2003. 696 p.

FRANCO, M. Direct along-wind dynamic analysis of tall structures. São Paulo: Epusp, 1993. 22 p. Boletim Técnico da Escola Politécnica da Usp. Departamento de Engenharia de Estruturas e Fundações, BT/PEF/9303.

O "Vento sintético" e a análise dinâmica das estruturas de grande altura no domínio do tempo. São Paulo: Epusp, 2003. 21 p. Boletim Técnico da Escola Politécnica da Usp. Departamento de Engenharia de Estruturas e Fundações, BT/PEF/0302.

.; ISYUMOV, N. Overview of procedures for evaluating the effect of wind on tall buildings. São Paulo: Epusp, 1997. 10 p. Boletim Técnico da Escola Politécnica da USP. Departamento de Engenharia de Estruturas e Fundações, BT/PEF/9720. 
GOULD, P. L.; ABU-SITTA, S. H. Dynamic response of structures to wind and earthquakes loading. London: Pentech Press, 1980. 175 p.

HOEL, P.G.; PORT, S.C.; STONE, C.J. Introdução à teoria da probabilidade. Tradução de Fernando Yassou Chiyoshi. Rio de Janeiro: Interciência, 1978. 269 p.

INTERNATIONAL COUNCIL OF BUILDING OFFICIALS. Uniform building code. Whittier: IBCO, 1988.

JOINT COMMITTEE ON STRUCTURAL SAFETY. The JCSS probabilistic model code. 2001. Disponível em:

<http://www.jcss.ethz.ch/JCSSPublications/PMC/LOADS/Earthquake1b.pdf>. Acesso em: 15 set. 2006.

KANAI, K. Semi-empirical formula for the seismic characteristics of the ground. Bulletin of the Earthquake Research Institute, Tokyo, v. 35, p.309-325, mar. 1957.

LAZANHA, E. C. Análise dinâmica elasto-plástica de estruturas metálicas sob excitação aleatória de vento.2003. 142 f. Dissertação (Mestrado) - Escola Politécnica, Universidade de São Paulo, São Paulo, 2003.

LEITE, W. C. Análise dinâmica estocástica de estruturas de cabos de comportamento não linear sob vibrações aleatórias devidas ao vento. 1998. 115 f. Tese (Doutorado) Escola Politécnica, Universidade de São Paulo, São Paulo, 1999.

LEVY, S.; WILKINSON, J. P. D. Generation of artificial time histories, rich in all frequencies, from given response spectra. In: INTERNATIONAL CONFERENCE ON STRUCTURAL MECHANICS IN REACTOR TECHNOLOGY, 3., 1975. London. Transactions of the 3rd International Conference on Structural Mechanics in Reactor Technology. London; New York: American Elsevier, 1975. Paper F2/5.

McGUIRE, W.; WINTER, G. Steel structures. Englewood Cliffs: Prentice-Hall, 1968. 1112 p.

NEAL, B. G. The plastic methods of structural analysis. London: Chapman \& Hall, 1956.

NEWLAND, D. E. An introduction to random vibrations and spectral analysis. $2^{\text {nd }}$ ed. New York: Wiley, 1975. 377 p. 
ROFOOEI, F. R.; MOBARAKE, A.; AHMADI, G. Generation of artificial earthquake records with a nonstationary Kanai-Tajimi model. Engineering Structures, Guildford, v. 23, n.7, p. 827-837, jul. 2001.

SANTOS, S. H. C.; LIMA, S. S. Subsídios para uma futura normalização brasileira para resistência anti-sísmica das estruturas de concreto dos edifícios. Revista IBRACON, São Paulo, v. 1, n. 1, p. 55-62, 2005.

SILVEIRA, E. País tem risco de terremoto, mostra pesquisa. O Estado de São Paulo, 29 nov. 2002, p. A13.

TAJIMI, H. A statistical method of determining the maximum response of a building structure during an earthquake. In: WORLD CONFERENCE ON EARTHQUAKE ENGINEERING, 2., 1960, Japan. Proceedings... Japan: WCEE, 1960. v.2, p. 781-797. 